\title{
HYDRATION AND SHRINKAGE OF GEOSYNTHETIC CLAY LINERS UNDER SIMULATED LANDFILL CONDITIONS
}

\author{
A thesis submitted to \\ the Faculty of Graduate and Postdoctoral Affairs \\ in Partial Fulfillment of the requirements for the degree \\ Master of Applied Science
}

by

Hamid Sarabadani

Department of Civil and Environmental Engineering

Carleton University

Ottawa-Carleton Institute of Civil and Environmental Engineering

November 2012

C2012 Hamid Sarabadani 
Library and Archives

Canada

Published Heritage

Branch

395 Wellington Street

Ottawa ON K1A ON4

Canada
Bibliothèque et

Archives Canada

Direction du

Patrimoine de l'édition

395 , rue Wellington

Ottawa ON K1A ON4

Canada
Your file Votre référence

ISBN: 978-0-494-94272-7

Our file Notre référence

ISBN: 978-0-494-94272-7
NOTICE:

The author has granted a nonexclusive license allowing Library and Archives Canada to reproduce, publish, archive, preserve, conserve, communicate to the public by telecommunication or on the Internet, loan, distrbute and sell theses worldwide, for commercial or noncommercial purposes, in microform, paper, electronic and/or any other formats.

The author retains copyright ownership and moral rights in this thesis. Neither the thesis nor substantial extracts from it may be printed or otherwise reproduced without the author's permission.
AVIS:

L'auteur a accordé une licence non exclusive permettant à la Bibliothèque et Archives Canada de reproduire, publier, archiver, sauvegarder, conserver, transmettre au public par télécommunication ou par l'Internet, prêter, distribuer et vendre des thèses partout dans le monde, à des fins commerciales ou autres, sur support microforme, papier, électronique et/ou autres formats.

L'auteur conserve la propriété du droit d'auteur et des droits moraux qui protege cette thèse. $\mathrm{Ni}$ la thèse ni des extraits substantiels de celle-ci ne doivent être imprimés ou autrement reproduits sans son autorisation.
In compliance with the Canadian Privacy Act some supporting forms may have been removed from this thesis.

While these forms may be included in the document page count, their removal does not represent any loss of content from the thesis.
Conformément à la loi canadienne sur la protection de la vie privée, quelques formulaires secondaires ont été enlevés de cette thèse.

Bien que ces formulaires aient inclus dans la pagination, il n'y aura aucun contenu manquant. 


\section{Abstract}

Geosynthetic Clay Liners (GCLs) are used as part of composite liner systems in municipal solid waste landfills to prevent the escape of contaminants into the surrounding environment. The performance of the GCL is primarily dependent on the degree of the hydration from the underlying subsoil. The level of the normal stress applied to the GCL by the overlying layers affects the rate of hydration as well as the equilibrium moisture content of the GCL. In order to investigate this phenomenon, the hydration behavior of two GCL products from different subsoil conditions while subjected to various normal stresses $(0-8 \mathrm{kPa})$ was investigated. The normal stress of 2 to $5 \mathrm{kPa}$, which could be easily provided by a typical Leachate Collection System (LCS), was shown to induce the maximum equilibrium moisture content and an adequately high rate of hydration.

In addition, previous studies have shown that the GCL panels are prone to significant shrinkage (up to $30 \%$ ) and separation while the geomembrane is exposed to solar radiation. Hence, extensive experimental models were initiated to evaluate the effect of daily thermal cycles on shrinkage of different GCL products subjected to simulated landfill conditions. The manufacturing techniques, the initial moisture content and the aspect ratio of the GCL as well as the subsoil grain size distribution were found to considerably affect the maximum shrinkage of GCLs. The derived results of this study highlight the importance of employing cover soil or construction of LCS shortly after the liner installation. 
Dedicated to my lovely parents 


\section{Acknowledgements}

My first and foremost sincere thanks go to my supervisor, Dr. Mohammad T. Rayhani for his help and support to complete this research. I am also grateful for the valuable comments of my thesis examination committee, Dr. Paul. H. Simms and Dr. Mamadou Fall.

This research has been founded by Natural Science and Engineering Research Council of Canada (NSERC), and also our industrial partner Terrafix Geosynthetics Inc. which provided us with GCL specimens and technical supports. Their supports are gratefully acknowledged. Also, I am very grateful for all the efforts and help of the staff of Civil Engineering Laboratory during the research.

Moreover, I would like to thank my friends for their understanding and support, also my lab-mate, Abdulghader Aldaeef who helped me in this research.

Finally, I want to dedicate my thesis to my parents who have taught me how to love without expectation. I want them to know that their love and support will always help me to move forward in the University of Life. 


\section{Table of Contents}

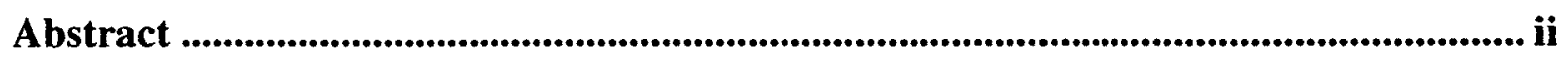

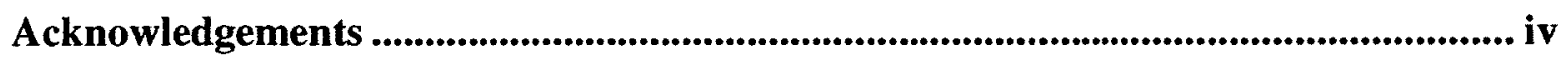

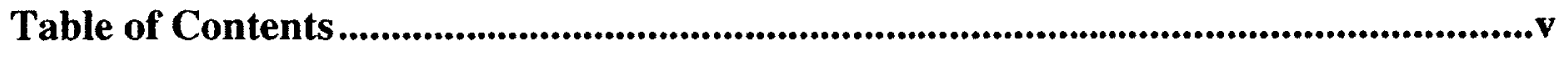

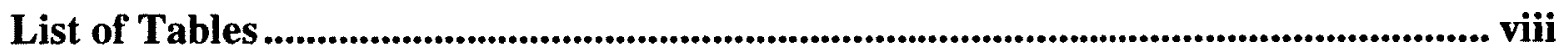

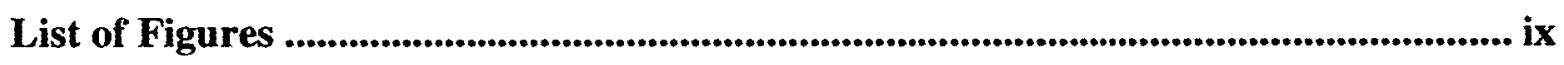

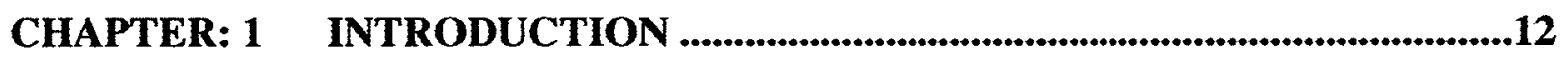

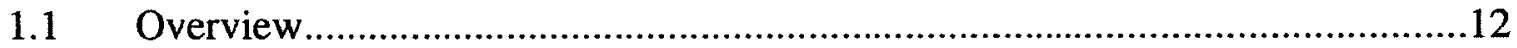

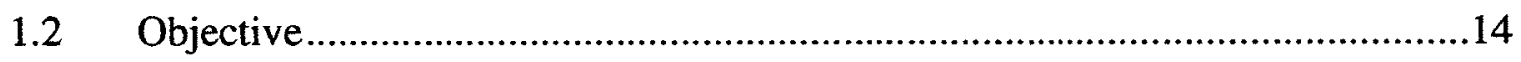

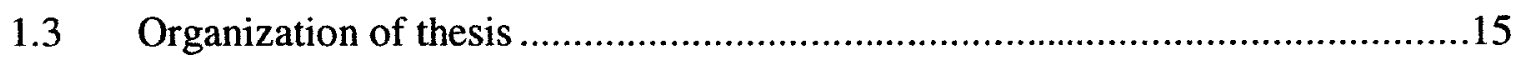

CHAPTER: $2 \quad$ LITERATURE REVIEW .......................................................16

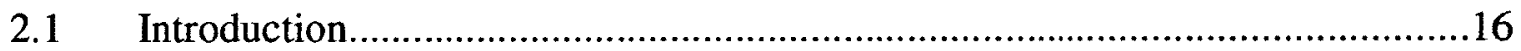

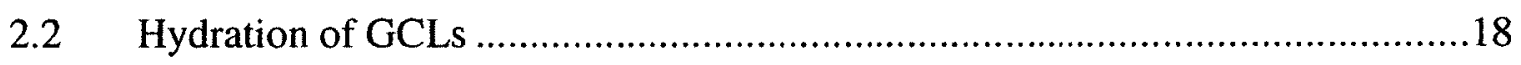

2.2.1 GCL manufacturing techniques .................................................. 18

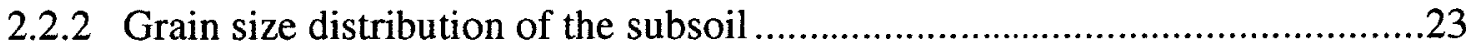

2.2.3 Initial moisture content of the subsoil ...................................................25

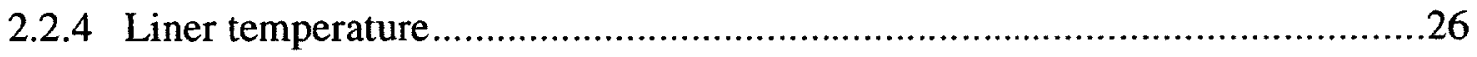

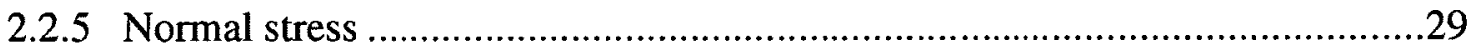

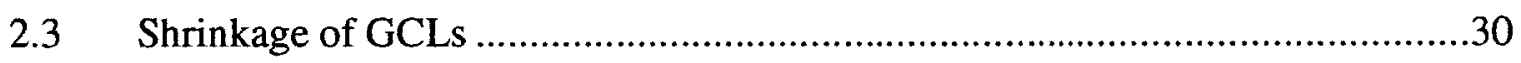

2.3.1 Boundary conditions, size, and aspect ratio of the GCL specimen ...............32

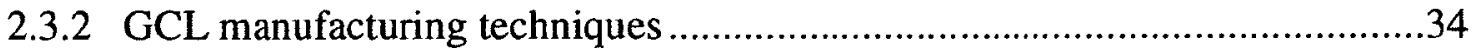

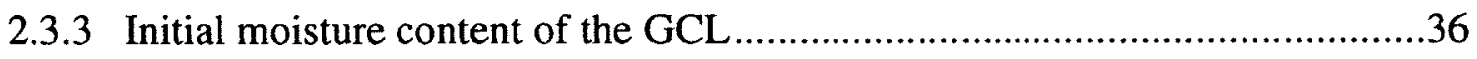

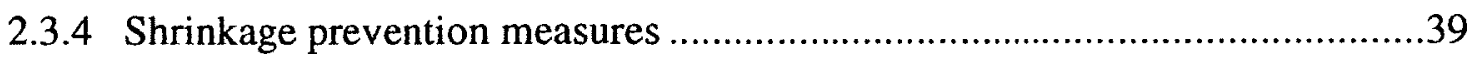

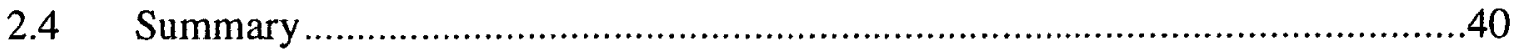

\section{CHAPTER: 3 INFLUENCE OF NORMAL STRESS ON}

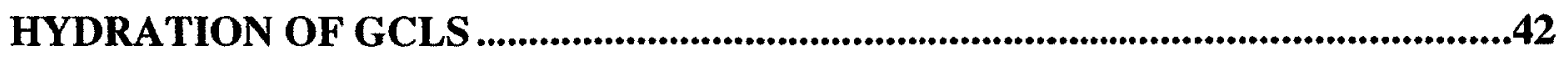

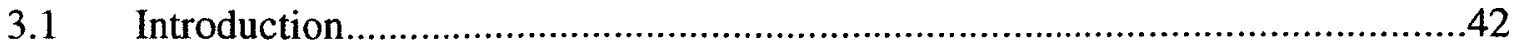




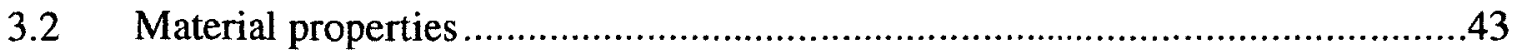

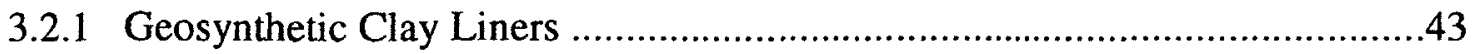

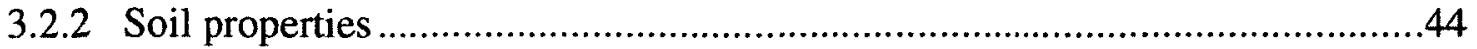

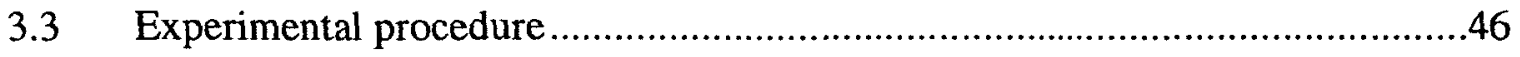

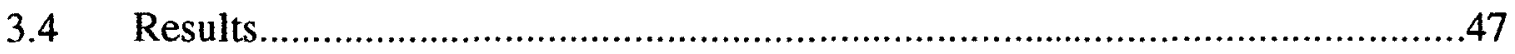

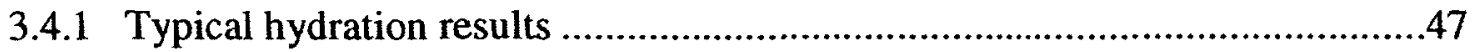

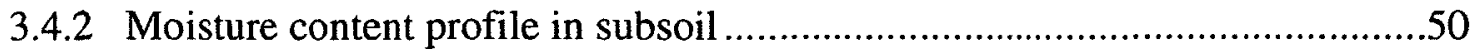

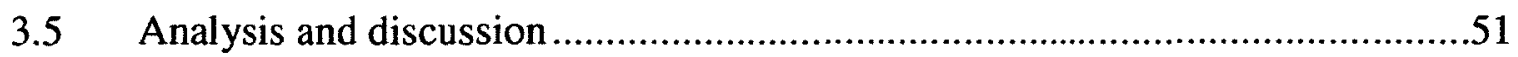

3.5.1 Effect of normal stress on GCL hydration................................................51

3.5.2 Effect of normal stress on GCL swelling (thickness) .................................55

3.5.3 Effect of GCL manufacturing techniques on hydration .................................56

3.5.4 Effect of subsoil grain size distribution on GCL hydration ...........................59

3.5.5 Comparison with results of previous studies ...............................................60

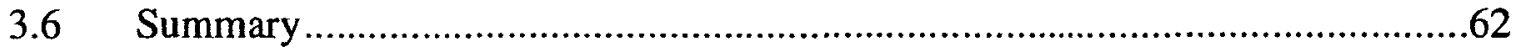

\section{CHAPTER: 4 SHRINKAGE OF THE GCL UNDER SIMULATED THERMAL}

CYCLES ...............................................................................................................................................64

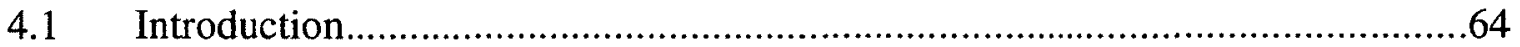

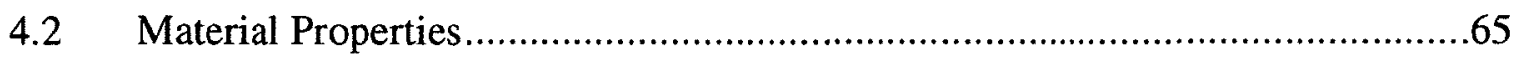

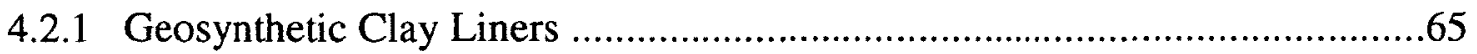

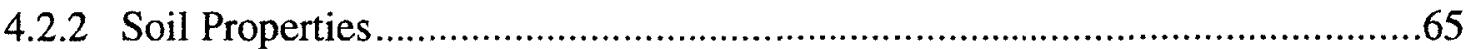

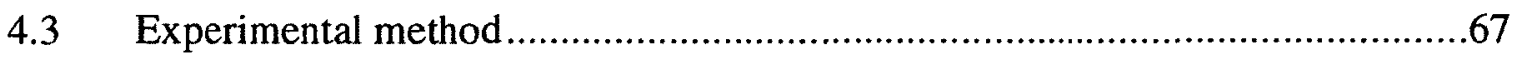

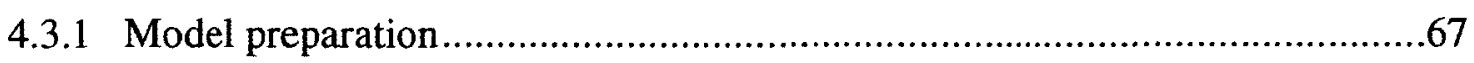

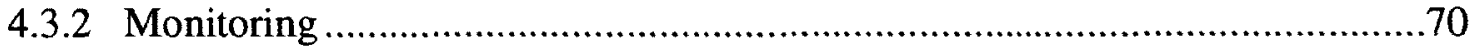

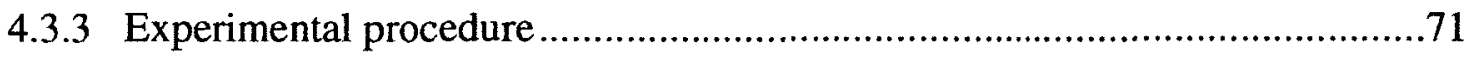

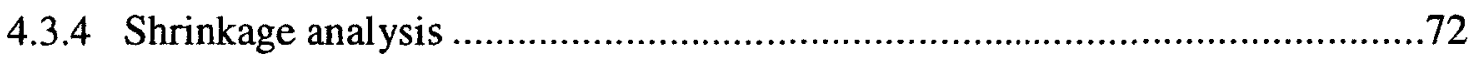

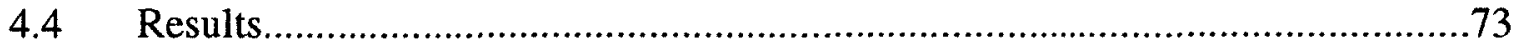

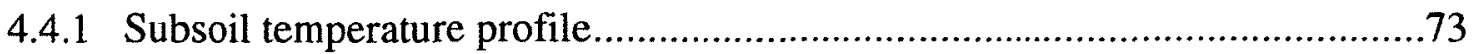

4.4.2 Subsoil gravimetric moisture content profile …........................................

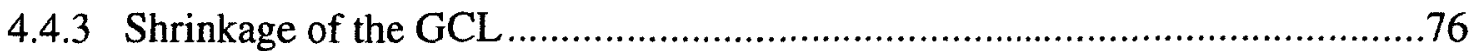

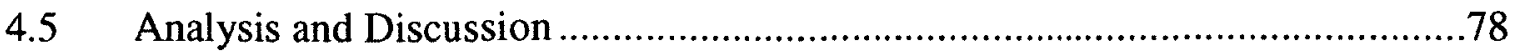

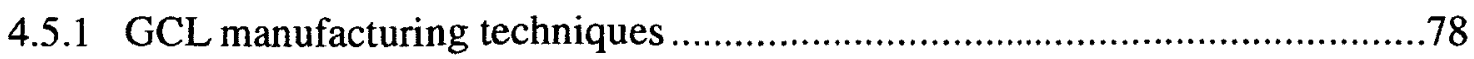




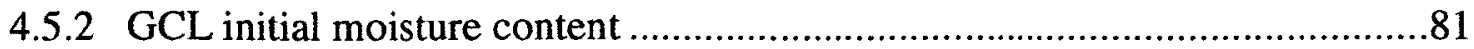

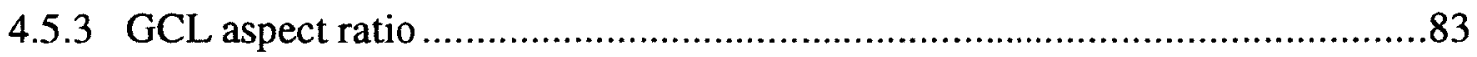

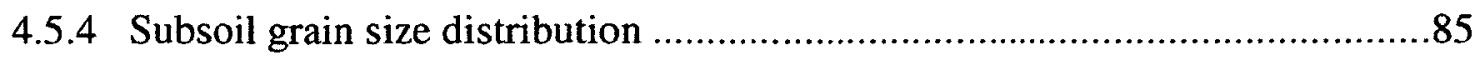

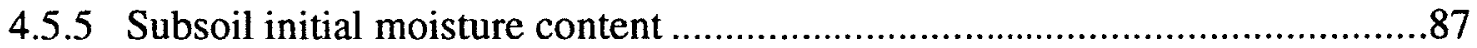

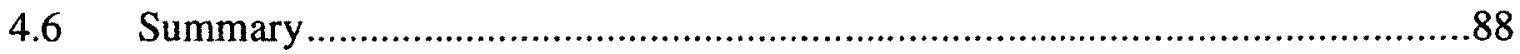

CHAPTER: 5 CONCLUSIONS AND RECOMMENDATIONS........................91

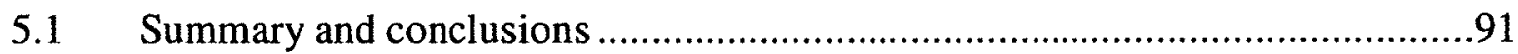

$5.2 \quad$ Recommendation for Future Studies ...................................................94

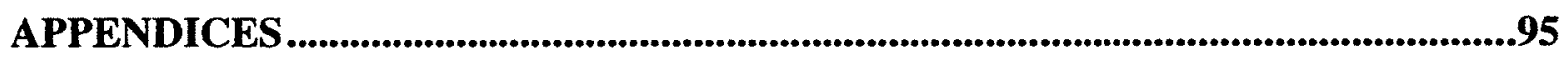

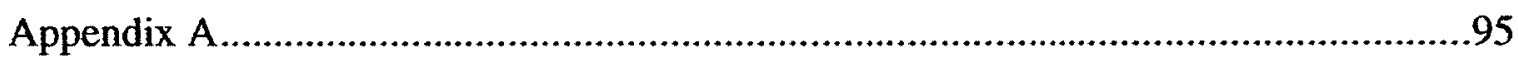

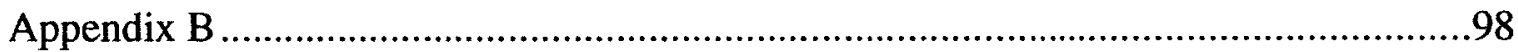

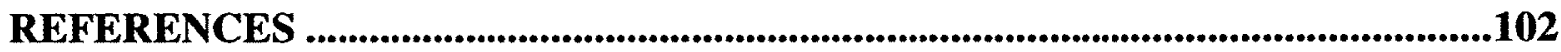




\section{List of Tables}

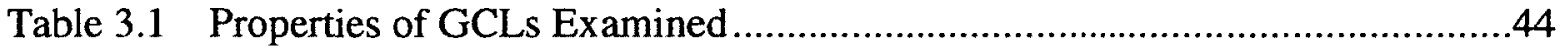

Table 3.2 Details of experiments conducted under isothermal condition ......................49

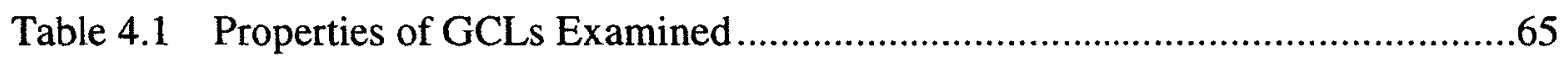

Table 4.2 Location of the TM probes embedded within the subsoil .............................71

Table 4.3 Details of experiments conducted for shrinkage analysis of GCLs under

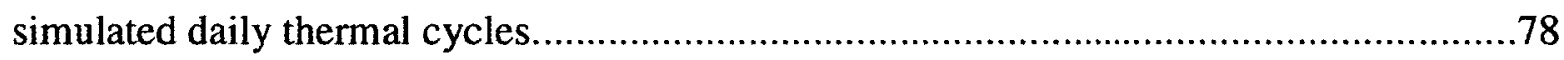




\section{List of Figures}

Figure 2.1 Nonwoven scrim-reinforced/nonwoven carrier/cover sodium bentonite GCL with thermally treated connection layer

Figure 2.2 Comparison between the WRCs of geotextile and low-plasticity clay, (Bouazza et al., 2006; Beddoe et al., 2010)

Figure 2.3 Comparison of the GCL and bentonite water retention curves reported by Beddoe et al. (2011), Southen and Rowe (2007) (GCL-SR) Marcial et al. (2002) (BENM), Japan Nuclear Cycle Development Institute (JNC) (2000) (BEN-JNC), and Villar and Lloret (2004) (BEN-VL)

Figure 2.4 Hydration of the scrim reinforced, thermally treated GCL from different subsoils with an initial gravimetric moisture content of $10 \%$ (Clay (CL), clayey sand (SC), silty sand (SM), and poorly graded sand (SP)) (Sarabian et al., 2012; Anderson et al., 2012; Rayhani et al., 2011). .24

Figure 2.5 Hydration of the scrim reinforced, thermally treated GCL from sand (SP) and silty sand (SM) subsoils with an initial gravimetric moisture content of $10 \%$ while subjected to simulated daily thermal cycles (Rowe et al., $2011 \mathrm{~b}$ ). .24

Figure 2.6 Relation between the GCL gravimetric moisture content and the initial gravimetric moisture content of silty sand (SM) subsoil (Azad et al., 2011) .28

Figure 2.7 The equilibrium gravimetric moisture content of the GCL versus the level of normal stress (top), swelling of the bentonite versus time (bottom) (Chevrier et al., 2012)

Figure 2.8 Shrinkage of the scrim reinforced, thermally treated GCL under simulated daily thermal cycles (Thiel et al., 2006).

Figure 2.9 Influence of GCL specimen aspect ratio on shrinkage (Bostwick et al. 2007) .34

Figure 2.10 Influence of bentonite grain size distribution on shrinkage (Rowe et al. 2011b) .36

Figure 2.11 Influence of the initial gravimetric moisture content of the GCL on shrinkage (Bostwick, 2009) 
Figure 3.1 Grain size distributions for the subsoils examined .45

Figure 3.2 Water Retention Curves (WRCs) for the subsoils examined .45

Figure 3.3 Geometry of the apparatus used for evaluation of hydration under isothermal condition

Figure 3.4 profile of the gravimetric moisture content in the subsoil before and after the test

Figure 3.5 Hydration of GCL 1 from sand (SP) subsoil while subjected to different normal stresses.

Figure 3.6 Effect of normal stress on the equilibrium moisture content of GCLs

Figure 3.7 Effect of normal stress on maximum moisture content, immersed in water $\left(w_{\text {ref }}\right)$

Figure 3.8 Effect of normal stress on the final thickness of GCLs. .56

Figure 3.9 Effect of GCL type on rate of hydration from clay subsoil .58 Figure 3.10 Effect of GCL type on the normalized equilibrium moisture content for different normal stresses 58

Figure 3.11 Effect of subsoil grain size distribution on the equilibrium moisture content of GCL2 for different normal stresses .60

Figure 3.12 Effect of subsoil grain size distribution on GCL hydration .60

Figure 3.13 Comparison with results of previous studies .61

Figure 4.1 Grain size distributions for the subsoils examined .66

Figure 4.2 Water Retention Curves (WRCs) for the subsoils examined .67

Figure 4.3 Geometry of the experimental model utilized for the evaluation of GCL shrinkage; $a: A R=2.3, b: A R=5$.

Figure 4.4 Schematic of the containers used for evaluation of shrinkage under simulated daily thermal cycles .71

Figure 4.5 Profile of the temperature in sand (SP) subsoil $\left({ }^{\circ} \mathrm{C}\right)$ .73

Figure 4.6 Applied temperature and temperature profile in sand (SP) subsoil during a thermal cycle

Figure 4.7 Profile of the gravimetric moisture content in subsoil before and after the daily thermal cycle. 
Figure 4.8 Profile of the gravimetric moisture content in clay (CL) subsoil during a

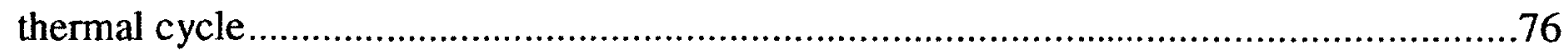

Figure 4.9 Shrinkage of $\mathrm{GCLl}\left(\mathrm{w} / \mathrm{w}_{\mathrm{re}}=25 \%, \mathrm{AR}=5\right)$ under simulated thermal cycles,

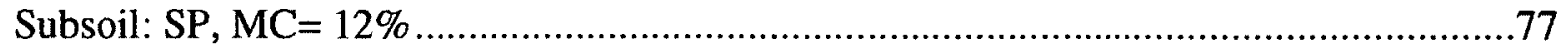

Figure 4.10 Effect of the manufacturing techniques of GCLs on maximum shrinkage ..80 Figure 4.11 Effect of the initial normalized moisture content $\left(w / w_{\text {ref }}\right)$ of GCLs on

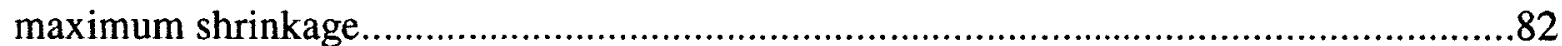

Figure 4.12 Effect of the aspect ratio of GCLs on maximum shrinkage …...................84

Figure 4.13 Effect of the grain size distribution of subsoil on maximum shrinkage.......86

Figure 4.14 Effect of the initial moisture content of the subsoil on maximum shrinkage .88 


\section{CHAPTER: 1 INTRODUCTION}

\subsection{Overview}

Composite liners are utilized at the bottom of solid waste landfills as a barrier system to prevent the escape of contaminants into the ground water. Case histories along with the laboratory and field investigations have shown that the application of either the Compacted Clay Liner (CCL) or Geosynthetic Clay Liner (GCL) while underlain by a Geomembrane could effectively prevent the advection or diffusion of the contaminants into the surrounding environment (e.g., Rowe, 2011; Bostwick, 2009). Nevertheless, the application of the CCL is reliant upon the availability of a considerable volume of the clay which may not be plausible either practically or economically in field applications. Hence the GCL/geomembrane composite liner has gathered momentum among many industries and professions since they have shown to provide the sufficient hydraulic conductivity as a liner. The GCL is mainly composed of a layer of bentonite which is encapsulated between two layers of geotextiles by a connection layer. The performance of the GCL primarily depends on the absorption of moisture from the underlying subsoil. The bulk void ratio of the GCL (bentonite) decreases as its gravimetric moisture content increases due to the high swelling capacity of the bentonite and also the anchorage which is provided by the connection layer. The GCL should have a sufficient rate of hydration, i.e. moisture uptake, to be adequately saturated prior to being exposed to the leachate. The manufacturing techniques of the GCL, the type of subsoil, and also the initial moisture content of the subsoil are the three significant factors which affect the hydration of the GCL. In addition, the field exposure conditions such as daily thermal cycles, 
before waste placement, as well as the elevated temperatures at the base of landfills after depositing the waste, due to the biodegradation of the organic waste, have shown to cause significant loss of moisture and limit the hydration of the GCL. Also, the normal stress subjected to the liner by the overlying Leachate Collection System (LCS) and waste may influence both the rate of hydration and maximum equilibrium moisture content of the GCL. The normal stress could increase the contact intimacy between the subsoil and the GCL which induces higher rate of hydration (Rayhani et al., 2011). However, increasing the normal stress applied to a GCL specimen from 7 to $28.2 \mathrm{kPa}$ decreased the final moisture content of the GCL (Chevrier et al., 2012). Hence, there is a paucity of data pertaining to the effect of the normal stress on the rate of hydration and the equilibrium (final) moisture content of the GCL.

The GCL panels may be exposed to the weather for a period of time which could last up to years before they are covered by the LCS and waste. This in turn could cause significant variation of the moisture content in the GCL panels and, hence, their shrinkage due to the extreme temperature variation of the overlying geomembrane during the daylight and night-time, particularly in the summer. The shrinkage and separation of GCL panels due to daily thermal cycles has been known as one of the main concerns pertaining to the GCL as documented in the literature. Six incidences of GCL panel shrinkage (GCL panel separation up to $120 \mathrm{~cm}$ ) were reported in 2005 , in which leachate could have leaked into the environment through any holes in the geomembrane (Thiel and Richardson, 2005; Koerner and Koerner 2005a, b). The phenomenon of the shrinkage of GCL panels has been evaluated by many researchers, indicating that the GCL manufacturing techniques, initial moisture content of the GCL at the beginning of each 
thermal cycle, and length to the width ratio (aspect ratio) of the GCL could considerably affect the shrinkage of the GCL (e.g., Thiel et al., 2006; Bostwick 2009; Rowe et al., 2011a; Beddoe et al., 2010, 2011). GCL specimens placed over aluminum baking pans were watered by a garden sprayer to the gravimetric moisture content of $60-65 \%$ for hydration, and were subsequently placed in an oven with the average temperature of $60^{\circ} \mathrm{C}$ to simulate daily thermal cycles (Rowe et al., 2011a). The results derived demonstrated the potential influence of the aforementioned factors properly; however, may not be a good approach to estimate accurately the shrinkage behavior of GCLs since the specimens were not in a closed system while placed on subsoil similar to field conditions. Without a full understanding of mechanisms involved in hydraulic performance of the GCL under realistic field conditions, there is an uncertainty for all GCL designers, manufacturers and users about the performance of GCLs used in a wide range of applications.

\subsection{Objective}

The purpose of this research is to complement the work of other researchers pertaining to the hydration and shrinkage of the GCL in order to quantify the controlling factors on hydraulic performance of the GCL and provide recommendations for the careful design of the composite liners. The main objectives of this study are:

- To investigate the hydration of the GCL from the subsoil while it is subjected to different normal stresses, and find the optimum normal stress which induces the highest rate of hydration as well as the maximum equilibrium moisture content. 
Also, the effect of the GCL manufacturing techniques and subsoil under different normal stresses on the equilibrium moisture content of the GCL is investigated.

- To study the shrinkage of the GCL under simulated field conditions, i.e. the GCL is in a closed system and absorbs moisture from the underlying subsoil. Also, the effects of GCL properties such as the initial hydration moisture content; aspect ratio, and the GCL manufacturing techniques along with the role of the subsoil and its initial moisture content on shrinkage of the GCL are scrutinized.

\subsection{Organization of thesis}

This thesis contains 5 chapters. Chapter 1 presents an introduction regarding the hydration and shrinkage of the GCLs along with the need for further investigation. Also, the objectives of the study along with the organization of the thesis are illustrated. Chapter 2 provides a comprehensive literature review pertaining to the factors which affect the hydration and shrinkage of the GCL. Chapter 3 illustrates the results for the experimental testing utilized to evaluate the hydration of the GCL under different normal stresses. In Chapter 4, the experimental model for analyzing the shrinkage of the GCL under simulated daily thermal cycles is presented, and also the results of the experiments are thoroughly discussed. Finally, the conclusions of the research and the recommendations for future studies are summarized in Chapter 5. 


\section{CHAPTER: 2 LITERATURE REVIEW}

\subsection{Introduction}

Geosynthetic Clay Liners (GCLs) are typically employed in modern solid waste landfills as part of composite liner systems to prevent the leakage of contaminated waste water into the ground water. GCLs typically consist of three components including a central layer of bentonite, upper geotextile, and lower geotextile which have been needlepunched together (Figure 2.1). The cover geotextile is typically Non-Woven (NW) while the carrier geotextile could be Non-Woven, Woven (W) or Scrim Reinforced Non-Woven (SRNW). The connection between the geotextile layers could be Needle-Punched (NP), stitched, or Needle-Punched and Thermally Treated (NPTT). Bentonite is basically originated from the chemical alteration of volcanic ash, and contains a clay mineral known as montmorillonite. Montmorillonite is composed of permanently charged crystallite layers which are neutralized by exchange cations (e.g. $\mathrm{Na}^{+}$and $\mathrm{Ca}^{2+}$ ) of the interlayer space (Gates et al., 2009). Montmorillonite may experience a considerable swelling due to separation of the crystallite layers upon absorption of water (up to 10 times its initial volume) (Egloffstein 1995; Gates, 2009). The combination of tortuous flow paths within the swollen layers and sufficient confining stress provided by needlepunching makes GCLs an effective barrier (Gates et al., 2009).

GCLs are typically used as part of a composite liner system in which the GCL is underlain by a geomembrane. This composite liner has shown to have one to two orders of magnitude lower leakage in comparison to geomembrane/Compacted Clay Liners (CCL) (Rowe, 2011). This is due to the fact that there is a lower possibility of holes in the 
geomembrane underlain by a GCL in comparison to the geomembrane underlain by the CCL which could contain stones, and the GCL hinders the escape of contaminants through potential holes (e.g. Rowe, 2011 and Rowe et al., 2004). The hydration of the GCL could also fill potential small gaps at the interface of geomembrane and the GCL, and prevent the lateral movement of leachate to other points. This is considered to be another reason for better performance of the GCL due to lower possibility of interaction with leachate in comparison to CCLs (Row 2011).

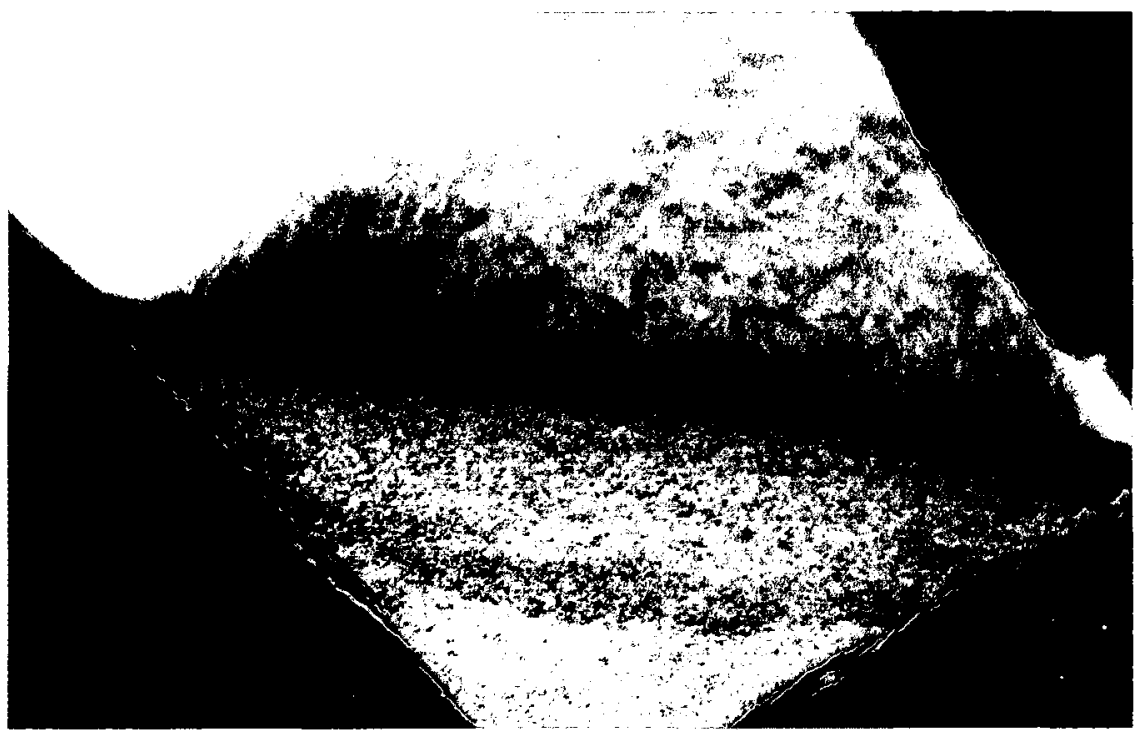

Figure 2.1 Nonwoven scrim-reinforced/nonwoven carrier/cover sodium bentonite GCL with thermally treated connection layer

GCLs have shown sufficiently low hydraulic conductivity provided that they are adequately hydrated (Petrov and Rowe 1997, Rowe et al., 2011b), and the overlap between the panels is maintained (Bostwick et al., 2010 and Rowe, 2005). To date many studies have been conducted to evaluate the factors which affect the hydration as well as the shrinkage of GCLs. The main objective of this chapter is to provide a brief summary of the studies in the literature, and illuminate the areas of research which have not been 
documented in previous studies.

\subsection{Hydration of GCLs}

GCLs are typically placed directly on the underlying subsoil, where the GCL absorbs water from the subsoil's pore voids. Once sufficiently hydrated, the GCL is able to effectively prevent the flow of leachate from the landfill. The hydraulic performance of the GCL depends on both the rate and degree of hydration from the underlying subsoil. The bulk void ratio of the GCL decreases as the moisture content of the GCL increases due to hydration. This in turn causes higher degree of saturation $(S)$ and lower hydraulic conductivity of the GCL.

There are many factors, reported in literature, affecting the hydration of GCLs including the GCL manufacturing techniques, grain size distribution and initial moisture content of the subsoil, ambient ground temperature, and normal stress provided by the leachate collection system and waste. The aforementioned factors are discussed in the following sections.

\subsubsection{GCL manufacturing techniques}

GCL manufacturing process has shown to affect the hydration behavior of the GCL while placed on the subsoil (Anderson et al., 2012; Sarabian et al., 2012; Beddoe et al., 2010, 2011; Rayhani et al., 2011 ; Rowe at al. 2011b). As the GCL absorbs pore water from the subsoil, its moisture content increases until it levels off at a specific value. The type of cover and carrier geotextiles, connection layer, and bentonite properties are the three major factors which could affect the hydration behavior of different GCL products. A 
better anchorage between the carrier and cover geotextiles could prevent the excessive swelling of the bentonite during hydration. This in turn induces lower final bulk void ratio, higher final degree of saturation and, hence, lower hydraulic conductivity for the GCL. The NW/SRNW GCL with needle-punched and thermally treated connection layer was reported to provide much lower swelling and final bulk void ratio after immersion in water, compared to other needle-punched GCLs (Rayhani et al., 2011; Anderson at al., 2012). This low swelling was related to an improved anchorage of the aforementioned GCL product. The scrim-reinforced thermally treated GCL has also led to higher rate of hydration compared to NW/NW GCL with simply needle-punched (NP) connection layer (Rayhani et al., 2011). Therefore, it could be concluded that better anchorage induces higher rate of hydration and in turn less time required to attain the sufficient hydraulic conductivity (Sarabian et al. 2012). This is crucial since GCLs must become sufficiently hydrated before they are exposed to waste and subsequently the leachate. The NW/W needle-punched GCL with thermally treated connection layer has also shown to supply lower anchorage and in turn lower final degree of saturation in comparison to the GCL with thermally treated scrim-reinforced carrier geotextile (Anderson et al. 2012).

The Water Retention Curve (WRC) of the GCL and subsoil play a major role in hydration behavior of the GCL. WRC is described as the moisture storage capacity of a material as its moisture content changes when subjected to different levels of suction (Vanapalli et al., 2002). The change in the total suction is due to the movement of water in the liquid and vapor phase which are known as matric suction $\left(\mathrm{u}_{\mathrm{a}}-\mathrm{u}_{\mathrm{w}}\right)$ and osmotic suction ( $\pi$ ), respectively (Vanapalli et al., 2002). It is of paramount importance to obtain the WRC of the GCLs to estimate their ultimate moisture content, rate of moisture uptake 
from different subsoils, and potential shrinkage due to thermal cycles (Beddoe et al., 2010). In terms of shrinkage under thermal cycles, both wetting and drying paths of the WRC for GCLs are required to investigate their hydration behavior and loss of moisture, respectively (Beddoe et al., 2011). Nevertheless, obtaining the WRCs for different types of GCLs is complicated due to various reasons which could be summarized as follows (Beddoe et al., 2010, 2011):

- As shown by Bouazza et al., (2006) (Figure 2.2), there is a significant difference between the WRCs of the geotextiles and clays. To elaborate, geotextiles hold significant amount of water while saturated but they lose all of their water content under a meager suction of approximately $1 \mathrm{kPa}$. Clays, however, demonstrate absolutely an opposite behavior.

- The confinement induced by the needle-punching affects the behavior of bentonite due to the change in bulk void ratio during swelling (Lake and Rowe, 2000).

- There is a wide range of suction values for the GCLs required to study which varies from $1 \mathrm{kPa}$ in saturated condition to $120 \mathrm{MPa}$ at a typical off-the-roll moisture content. 


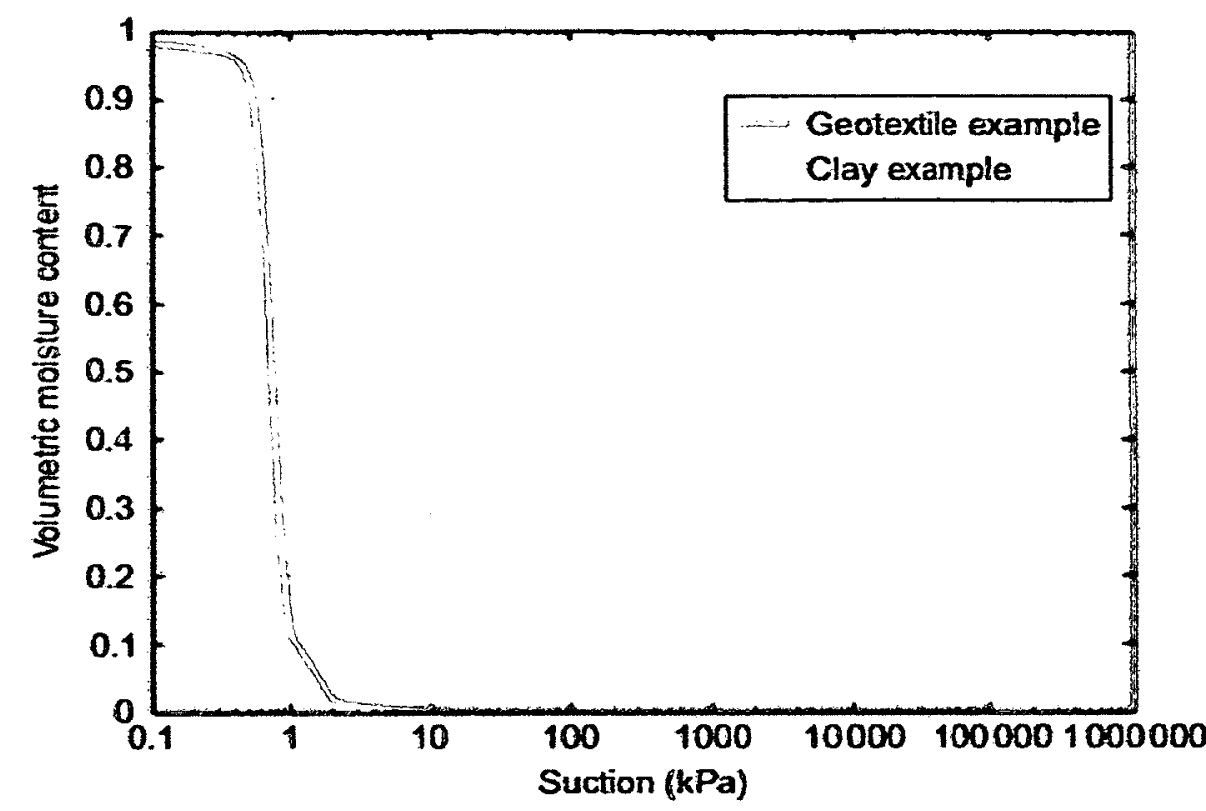

Figure 2.2 Comparison between the WRCs of geotextile and low-plasticity clay, (Bouazza et al., 2006; Beddoe et al., 2010)

Beddoe et al. (2010) obtained the WRC of GCLs utilizing a combination of the High Capacity Tensiometer (HCT) which covered lower suction values up to $1500 \mathrm{kPa}$ with the capacitive relative humidity sensor for relatively high suction values. Figure 2.3 demonstrates the WRCs for four different GCL products investigated by Beddoe et al. (2011) while comparing them with other types of GCLs and also pure bentonite reported in the literature. The GCL suction was found to be mostly affected by the bentonite component rather than the GCL properties (i.e. the type of GCL connection layer) in high ranges of suction. This is associated to the fact that no significant difference was observed among the WRCs of different GCLs and pure bentonite in suction values of more than $10 \mathrm{MPa}$. Comparatively, the type of GCL and the amount of the normal stress applied to them affected the WRC of GCLs significantly in low ranges of suctions. This is due to the role of the connection layer of GCLs in deterring the swelling of the bentonite which is generated due to high values of the moisture content in the lower 
suction region (Beddoe et al., 2011). They also reported that the thermally treated, scrimreinforced GCL underwent the minimum hysteresis between the gravimetric wetting and drying curves. This could also be attributed to the sufficient anchorage against the significant swelling which occurs in high values of moisture contents. As shown in Figure 2.3, the thermally treated, scrim reinforced GCL (GCL2) has the lowest variation of moisture content with the range of 0 to approximately $118 \%$ within the whole suction range due to a greater anchorage between the carrier and cover geotextiles. Hence, it is expected that this type of GCL undergoes the lowest variation of moisture content under thermal cycles. This is in accordance to the results reported by Rowe et al. (2011b), indicating that the scrim reinforced, thermally treated GCL placed in contact with silty sand subsoil experienced a meager $2 \%$ daily variation in gravimetric moisture content under simulated daily thermal cycles.

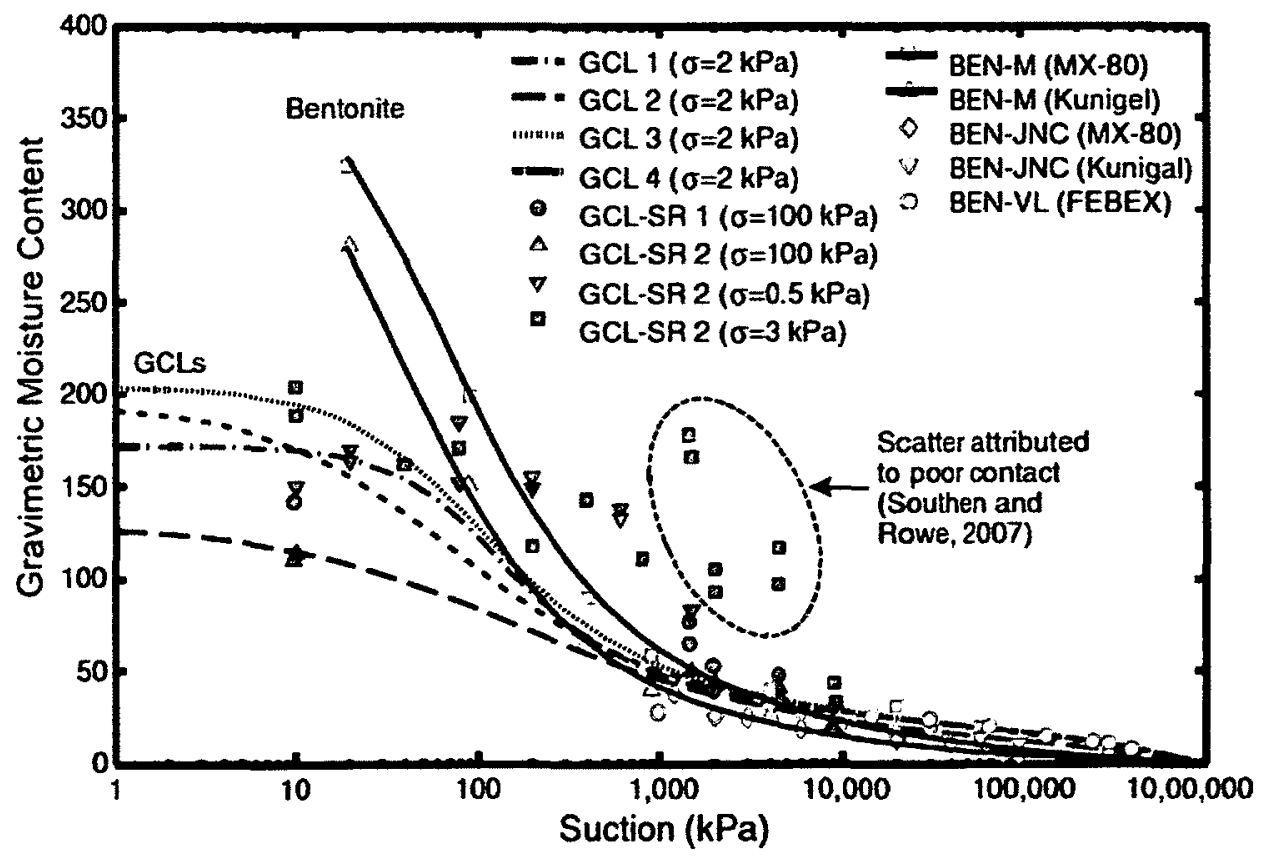

Figure 2.3 Comparison of the GCL and bentonite water retention curves reported by Beddoe et al. (2011), Southen and Rowe (2007) (GCL-SR) Marcial et al. (2002) (BEN-M), Japan Nuclear Cycle Development Institute (JNC) (2000) (BEN-JNC), and Villar and Lloret (2004) (BEN-VL) 


\subsubsection{Grain size distribution of the subsoil}

GCLs are placed over different subsoils depending on the availability of the type of the soil where a solid waste landfill is constructed. The hydration behavior of the GCL depends on the water retention curves of both subsoil and the GCL (Beddoe et al., 2010, 2011). Therefore, the subsoil grain size distribution is expected to affect the rate of hydration as well as the equilibrium moisture content for the GCL. The rate of moisture uptake from the subsoil is dependent on the difference in suction between the GCL and the subsoil. The higher difference in suction at the interface of the GCL and the subsoil causes better hydration of the GCL (Rayhani et al., 2011; Chevrier, et al., 2012; Rowe et al., 2011 b; Anderson et al., 2012; Sarabaian et al., 2012). Chevrier, et al. (2012) reported that both the rate of hydration and the equilibrium moisture content for the GCL specimens placed over sand subsoil were higher than those on clay subsoil. Similarly, the GCL specimen placed in contact with poorly graded sand subsoil (SP) was shown to have higher rate of hydration compared to those on silty sand (SM) (Rayhani et al., 2011). This difference in rate of hydration was attributed to a higher unsaturated hydraulic conductivity of sand subsoil compared to that of silty sand subsoil.

The GCL placed in contact with sand (SP) subsoil was also shown to have the highest equilibrium moisture content $(\mathrm{MC}=88 \%)$ in comparison to those with silty sand (SM) $(\mathrm{MC}=85 \%)$, clayey sand $(\mathrm{SC})(\mathrm{MC}=80 \%)$, and clay $(\mathrm{CL})(\mathrm{MC}=48 \%)$ subsoils

(Figure 2.4) (Rayhani et al., 2011; Anderson et al., 2012; Sarabaian et al., 2012). This could be attributed to the fact that the difference between the suction of the GCL and the subsoil decreased as the portion of fine particles within the subsoil increased which in turn induced lower moisture uptake for the GCL (Anderson et al., 2012). Similar results 
were derived by Rowe et al. (2011b) under simulated daily thermal cycles, indicating that the initial suction (at moisture content of 10\%) in sand (SP) subsoil is lower in comparison to that of silty sand which in turn resulted in higher equilibrium moisture content (Figure 2.5).

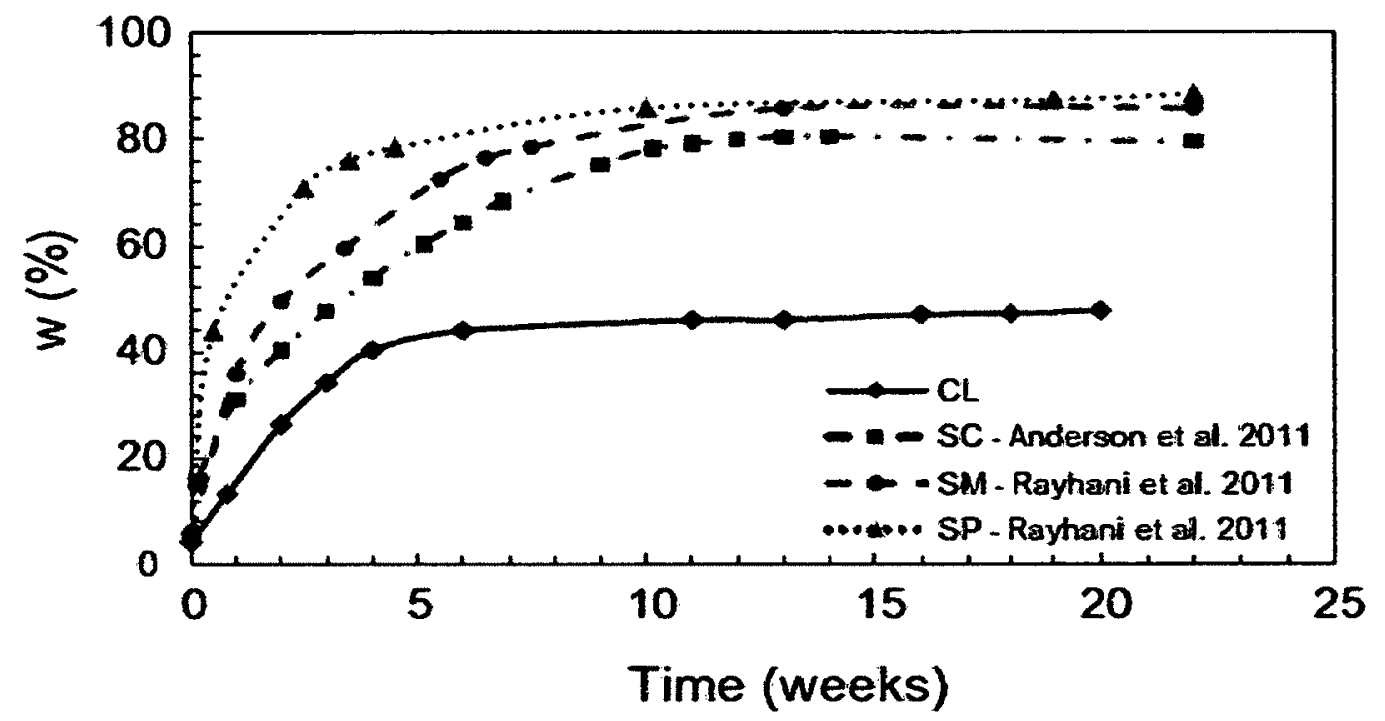

Figure 2.4 Hydration of the scrim reinforced, thermally treated GCL from different subsoils with an initial gravimetric moisture content of $10 \%$ (Clay (CL), clayey sand (SC), silty sand (SM), and poorly graded sand (SP)) (Sarabian et al., 2012; Anderson et al., 2012; Rayhani et al., 2011)

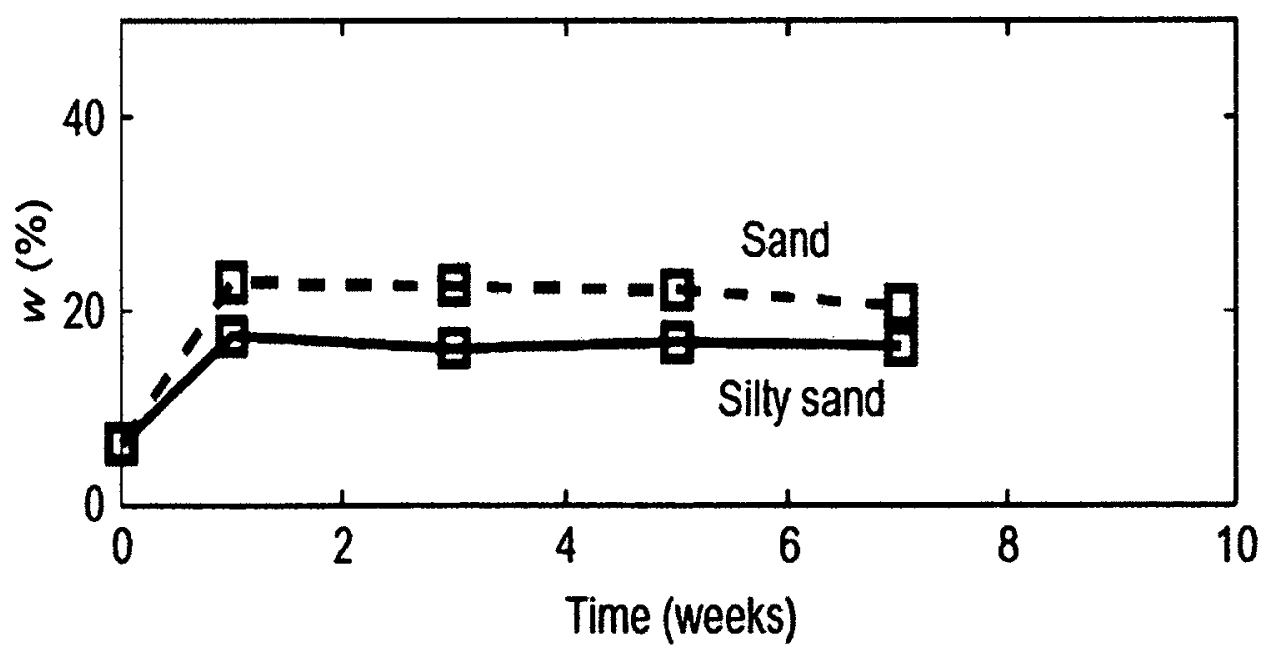

Figure 2.5 Hydration of the scrim reinforced, thermally treated GCL from sand (SP) and silty sand (SM) subsoils with an initial gravimetric moisture content of $10 \%$ while subjected to simulated daily thermal cycles (Rowe et al., 2011 b) 


\subsubsection{Initial moisture content of the subsoil}

The initial moisture content of the subsoil varies from place to place which is contingent upon the topography, the annual precipitation, the type of subsoil, etc. Therefore, considerable investigations have been conducted to evaluate the effect of the initial moisture content of the subsoil on the rate of hydration as well as the final degree of saturation of GCLs (Chevrier et al., 2012; Rayhani et al., 2011; Anderson et al., 2012; Rowe et al., 2011b; Azad et al., 2011). Considering the typical water retention curve for the soils, the higher initial moisture content of the subsoil leads to a lower suction in the subsoil during the hydration. This induces higher suction difference at the interface of the GCL and the subsoil and in turn higher rate of moisture uptake from the underlying subsoil (Rowe et al., 2011b). For instance, Chevrier et al. (2012) reported that the average hydration rate (i.e. increase of the gravimetric moisture content) of a Non-woven/woven needle-punched GCL increased from $0.27 \%$ per day to over $0.50 \%$ per day as the initial moisture content of its clay subsoil increased from 15 to $25 \%$.

Similarly, the higher initial moisture content of the subsoil can induce higher moisture uptake. GCL specimens examined by Rayhani et al. (2011) irrespective of their manufacturing properties hydrated as though they were immersed in water when placed in contact with silty sand subsoil at an initial moisture content of $21 \%$ (close to field capacity). Field capacity is defined as the maximum gravimetric moisture content which a soil could contain against the gravity. A similar trend was demonstrated by Anderson et al. (2012) indicating that the GCL specimens placed over clayey sand subsoil at initial gravimetric moisture contents of 5 and $20 \%$ stabilized at the maximum degrees of saturation of $12-18 \%$ and $90-92 \%$, respectively. 


\subsubsection{Liner temperature}

Composite liners in landfill applications might be left exposed to daily thermal cycles due to solar radiation for a period of time prior to waste placement. Thermal cycles or relatively high temperatures $\left(60^{\circ} \mathrm{C}\right.$ or more in the geomembrane) could significantly decrease the hydration rate of GCLs, particularly while the initial moisture content of the subsoil is significantly below the field capacity (Rowe et al., 2011b; Anderson et al., 2012; Sarabian et al., 2012). Rowe et al. (2011b) reported that the daily thermal cycles of $22-60{ }^{\circ} \mathrm{C}$ significantly suppressed the rate of hydration of GCLs placed on silty sand subsoil at initial gravimetric moisture contents of 5,10, and 16\% (i.e. moisture contents corresponding to suctions greater than the air entry values). Nevertheless, the maximum degree of saturation of GCLs in contact with subsoil at an initial gravimetric moisture content of $21 \%$ (i.e. close to saturated moisture content) proliferated as high as $81-100 \%$. Similarly, the maximum moisture content of GCL specimens subjected to simulated daily thermal cycles was found to be lower than $30 \%$ of those studied under isothermal condition (Anderson et al., 2012). This shows that the GCL may undergo significant loss of moisture content while subjected to daily thermal cycles. Furthermore, Sarabian et al. (2012) reported that seasonal cooling periods followed by daily thermal cycles, which could normally occur during winter, may not guarantee the sustainable hydration of the $\mathrm{GCL}$, as the moisture uptake will drop to its initial level as the thermal cycles resume.

Also, constant thermal gradients applied to the GCLs placed over subsoil could induce loss of moisture and, hence, desiccation and cracking of the GCLs. The temperature at the base of bioreactor landfills and also the Municipal Solid Waste (MSW) landfills where the Leachate Collection System (LCS) has failed could increase up to 40- 
$60^{\circ} \mathrm{C}$ or more after placing the waste (Azad et al., 2011). This is mainly considered to be due to biodegradation of organic waste during the life of MSW landfills (Collins, 1993). The elevated temperature desaturates the GCL-subsoil interface which causes the transition of the GCL hydration from the liquid phase to vapor phase and, therefore, lower equilibrium moisture content (Barclay et al., 2012). Furthermore, the temperature within the aquifer is significantly lower which in turn causes temperature gradients. This induces downward flux of vapor (diffusion) from the GCL to the subsoil which causes the moisture loss of GCLs and the desiccation cracking of the GCLs (e.g. Barclay et al., 2012; Azad et al., 2011; Southen and Rowe, 2005). Azad et al. (2011) conducted a series of tests on a simulated Double Composite Liner System (DCLS) in laboratory to investigate the effect of the initial water content of the subsoil and thermal gradients on the hydration and desiccation cracking of the GCLs. They reported that there was a positive correlation between the initial moisture content of silty sand subsoil and the moisture content of the Secondary Geosynthetic Clay Liner (SGCL) after 88 days of hydration before subjecting the model to thermal gradients (Figure 2.6). The same trend was observed for the final SGCL moisture content after being subjected to thermal gradients. To elaborate, it was shown that the $10-11 \%$ initial gravimetric moisture content for the silty sand subsoil was sufficient to prevent the SGCL from desiccation while the surface temperature of the DCLS was $29-45^{\circ} \mathrm{C}$ (thermal gradients of $20-67^{\circ} \mathrm{C} / \mathrm{m}$ ). However, considerable loss of moisture and cracking occurred for the specimen with silty sand subsoil at the initial gravimetric moisture content of $5 \%$ (at the thermal gradient of $59^{\circ} \mathrm{C} / \mathrm{m}$ ). The results reported by Rowe et al. (2011b) and Azad et al. (2011) demonstrate the role of sufficiently high gravimetric moisture content of the subsoil in hindering 
significant loss of moisture in the GCLs exposed to relatively high thermal gradients. This could be attributed to the upward flux of liquid water due to the capillary force from the subsoil to the GCL which relatively compensates for the downward vapor flux.

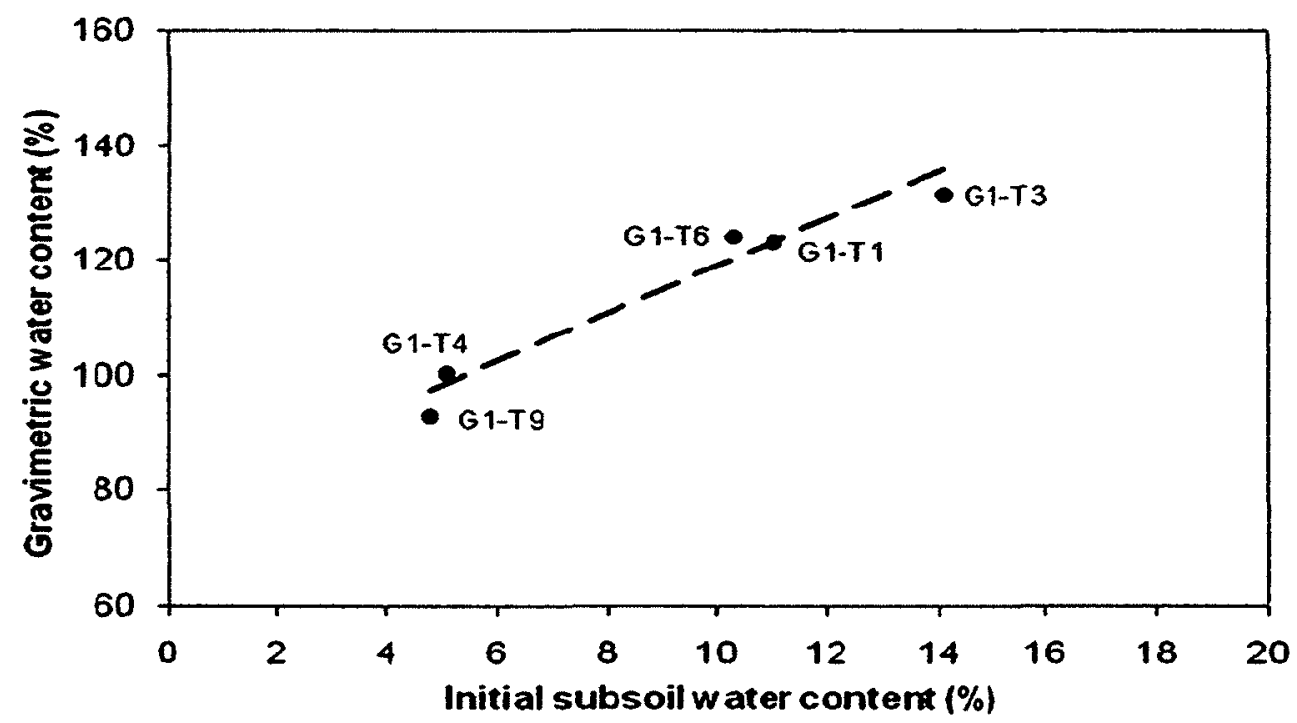

Figure 2.6 Relation between the GCL gravimetric moisture content and the initial gravimetric moisture content of silty sand (SM) subsoil (Azad et al., 2011)

The results reported in the literature magnify the need for the application of a method to decrease the temperature at the bottom of landfills. For instance, heat exchanger technology could be utilized to decrease the temperature at the base of landfills and, consequently, prevent the loss of moisture and desiccation cracking in the GCLs. Horizontal pipes arrays could be used so that the heat is absorbed by the coolant, and subsequently transferred outside the landfill. After extracting the heat by facilities outside the landfill, the coolant could be recirculated back to the landfill (Rowe et al., 2007; Rowe, 2011). 


\subsubsection{Normal stress}

It may take months or even years after the installation of the GCL liner system to construct the Leachate Collection System (LCS) and deposit the waste into the solid waste landfills. The normal stress applied to the GCL during hydration could affect the swelling characteristics along with the rate and the final moisture content of the GCL. This normal stress can increase the contact intimacy at the interface of the GCL and the underlying subsoil which could cause higher rate of hydration. This was substantiated by Rayhani et al., (2011), demonstrating that a GCL specimen subjected to $2 \mathrm{kPa}$ normal stress underwent higher rate of hydration than an unconfined GCL specimen under similar conditions. Similarly, Chevrier et al. (2012) demonstrated that the GCL specimen placed over clay subsoil while subjected to $4 \mathrm{kPa}$ normal stresses stabilized 30 days earlier than the similar specimen without normal stress.

The magnitude of the normal stress subjected to the GCL could also affect the maximum moisture content of the GCL attained at the completion of hydration from the subsoil. This could be attributed to both the better contact intimacy at the GCL-subsoil interface and the potential obstruction of bentonite swelling due to the normal stress. The former does enhance the convenience of moisture uptake; however, the latter might decrease the maximum moisture content of the GCL through limiting the swelling of the bentonite. Chevrier et al. (2012) reported that the equilibrium moisture content decreased by approximately $12.5 \%$ as the confining stress increased from $7 \mathrm{kPa}$ to $28.2 \mathrm{kPa}$. A similar trend was demonstrated between the swelling $(\mathrm{mm})$ of the bentonite and normal stress (Figure 2.7). On the other hand, Petrov et al. (1997) showed that an increase in the normal stress prior to hydration contributed to lower final bulk void ratios, less time 
required for complete hydration, and a reduction in GCL hydraulic conductivity from $3.7 \times 10^{-11}$ to $6.4 \times 10^{-11} \mathrm{~m} / \mathrm{s}$ for low normal stresses $(\sigma=3-4 \mathrm{kPa})$, to $7.1 \times 10^{-12}$ to $7.9 \times 10^{-12}$ $\mathrm{m} / \mathrm{s}$ for high normal stresses $(\sigma=109-117 \mathrm{kPa})$.
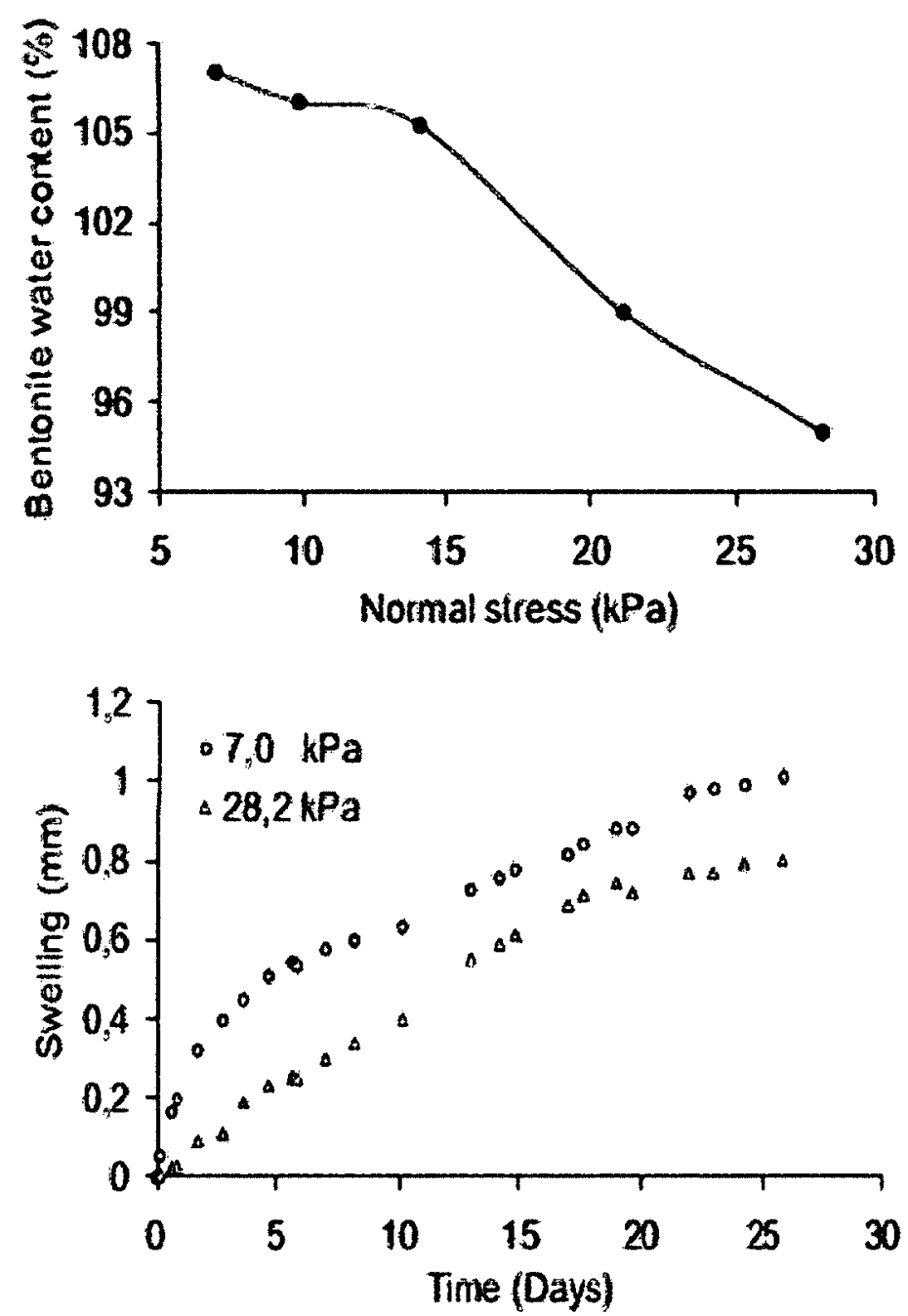

Figure 2.7 The equilibrium gravimetric moisture content of the GCL versus the level of normal stress (top), swelling of the bentonite versus time (bottom) (Chevrier et al., 2012)

\subsection{Shrinkage of GCLs}

The combination of GCLs and geomembrane is employed in composite liners to limit leakage and diffusion. This is attainable provided that the GCL panels continuously cover the subsoil (Rowe et al., 2004; Rowe, 2005). GCL liners could be exposed to weather, i.e. 
daily or seasonal thermal cycles, for a period of time before being covered by the waste or the leachate collection system. Due to solar radiation during the day light, the temperature of the geomembrane may increase up to $70^{\circ} \mathrm{C}$ (Pelte et al., 1994; Koerner and Koerner, 1995) which in turn could induce drying of the GCL panels. Drying the $\mathrm{GCL}$ alone was shown to induce the maximum shrinkage of $2 \%$ at the midpoint of the GCLs which is negligible compared to values observed in the field (3.3-30\%) (Thiel et al., 2006). However, repeated drying and cooling cycles in field conditions could cause significant amounts of accumulated shrinkage. The moisture of the GCL is lost due to drying, and subsequently is either absorbed by the subsoil or accumulated beneath the wrinkles existing between the geomembrane and GCL. GCL moisture, at a particular location, may also flow down slope if the GCL is located on a steep slope (Bostwick et al., 2007). As shown in Figure 2.8, a fraction of the shrinkage after the drying portion is recovered due to the absorption of some of the lost moisture during the cooling portion, i.e. during the night, which in turn induces a residual shrinkage (Thiel et al. 2006).

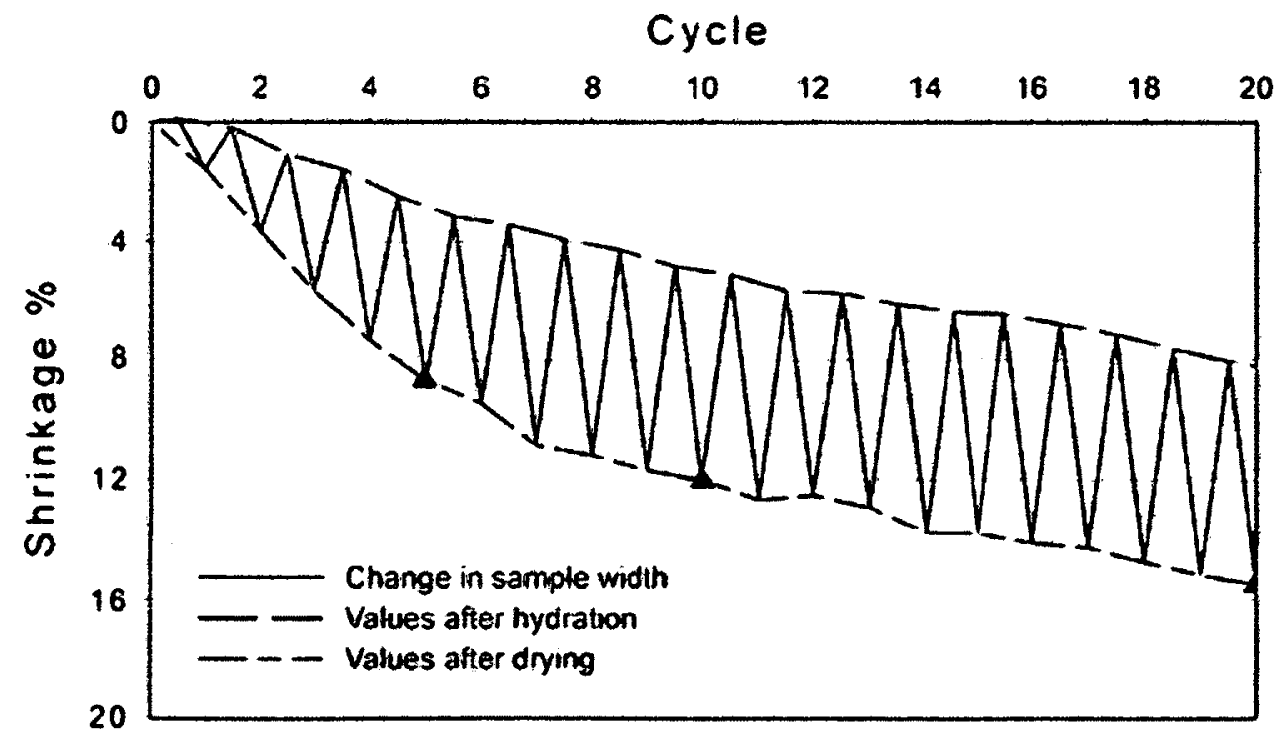

Figure 2.8 Shrinkage of the scrim reinforced, thermally treated GCL under simulated daily thermal cycles (Thiel et al., 2006) 
A field study in Wyoming conducted on GCL panels placed over silty clay subsoil with the initial moisture content of $5 \%$ revealed that although the temperature of geomembrane increased as high as $60^{\circ} \mathrm{C}$, the GCLs had only a moisture variation between 11 and $40 \%$, and experienced 0.6 to $0.9 \%$ shrinkage during a 10 month period (CETCO, 2006; Thiel and Rowe, 2010). A $300 \mathrm{~mm}$ overlap of GCL panels at a site located in Melbourne Australia was also found to be satisfactory to prevent the separation of GCL panels (Gassner, 2009). However, drying and wetting cycles were shown to induce lateral gaps of 150 to $1350 \mathrm{~mm}$ between GCL panels which originally had 150 mm overlaps, i.e. the shrinkage of 3.3 to $30 \%$ for a typical 4.5 wide GCL panel (Thiel and Richardson, 2005; Koerner and Koerner, 2005a,b; Thiel et al., 2006). The effect of thermal cycles has been evaluated in the literature by application of wet-dry cycles in laboratory tests (Bostwick et al., 2007, 2010; Bostwick 2009; Rowe et al. 2011a; Thiel et al. 2006; Thiel and Rowe 2010). Many factors were shown to affect the magnitude of shrinkage in GCL panels exposed to drying and wetting cycles including GCL ratio of length to width (aspect ratio), size, boundary conditions, GCL manufacturing rechniques, etc. Thus, a brief summary is provided here to describe the previous studies which have been reported in the literature and to illuminate the uncertainties that still exist regarding the shrinkage of GCLs in field applications.

\subsubsection{Boundary conditions, size, and aspect ratio of the GCL specimen}

The GCL panels may be stretched in the bottom of solid waste landfills with different sizes and ratios of length to the width, i.e. Aspect Ratios (ARs), which might affect the shrinkage behavior of GCLs. Also, whether the GCL panels are restrained at either end 
along the width could influence the maximum shrinkage of GCLs under thermal cycles. In order to investigate the effect of daily thermal cycles on GCL shrinkage, Bostwick et al. (2007, 2010) watered GCL specimens placed over aluminum baking pans for hydration to the initial moisture content of $65 \%$. The specimens were then put in an oven with the temperature of $60{ }^{\circ} \mathrm{C}$ to simulate the wet-dry cycles. Based on the results derived, there was no significant difference in the magnitude of shrinkage between longitudinal and transverse direction in unrestrained samples, particularly for the scrim reinforced, thermally treated GCLs. Also, the GCL specimens having more variation in bentonite distribution were shown to undergo larger shrinkage strains. Bostwick et al. (2007) and (2010) reported that there was a positive correlation between the aspect ratio and the maximum shrinkage of the restrained GCL specimens up to the aspect ratio of 5 (Figure 2.9). The positive correlation between the aspect ratio and the maximum shrinkage observed in the midpoint of the specimens was attributed to the lower effect of the restraints at either end in hindering the movement and, hence, the maximum shrinkage. It should be noted that the increase of the aspect ratio after a specific value (i.e. $A R=5$ ) did not make any significant difference due to lower effect of the restraints. The maximum shrinkage of the specimen with the aspect ratio of 10 was found to be approximately $25 \%$ more than that of the case with the aspect ratio of 1.6 . Comparatively, the size was reported to have a negligible effect on GCL shrinkage. In addition, it was noted that generally the maximum shrinkage of restrained specimens was only 1.1 times that of unrestrained specimens. This meager increase could be associated with the Poisson effect due to the restraints at either end (Bostwick et al., 2010). 


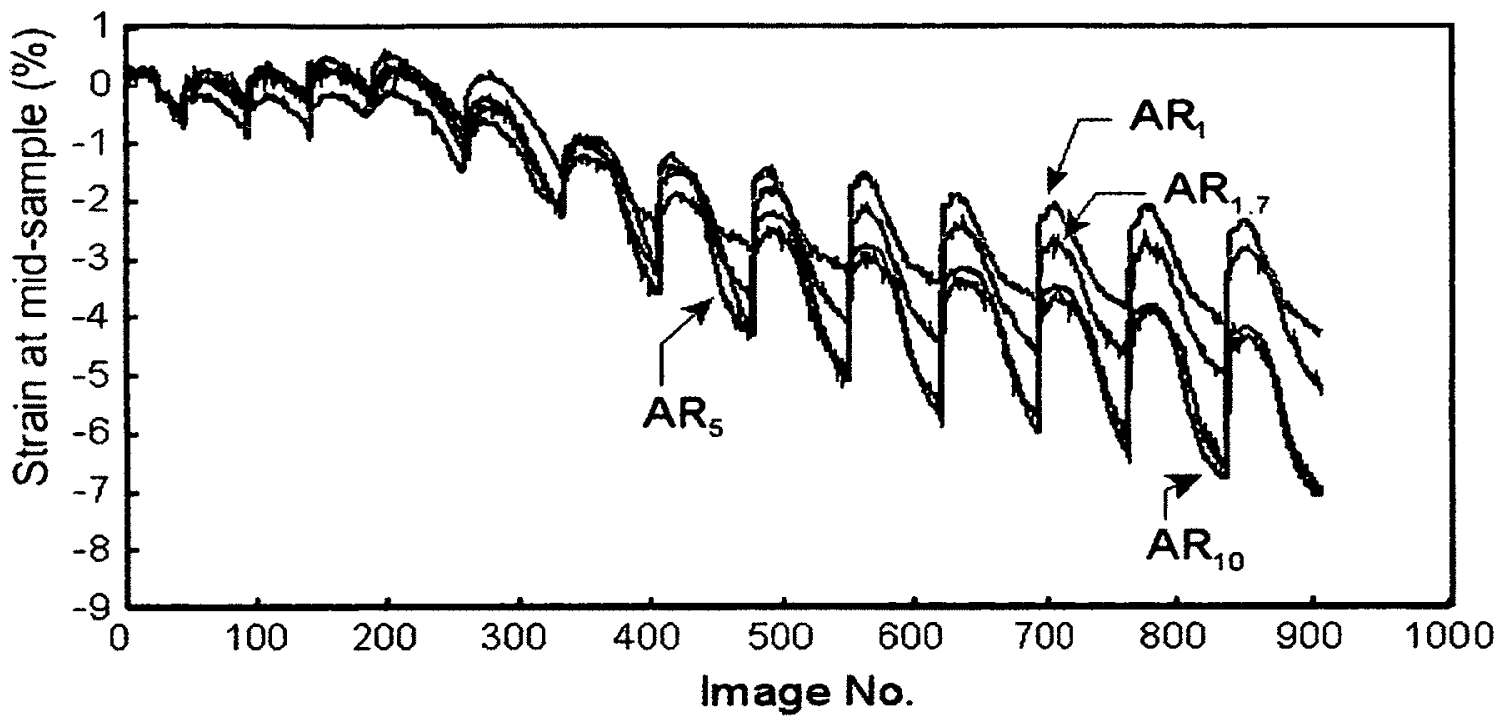

Figure 2.9 Influence of GCL specimen aspect ratio on shrinkage (Bostwick et al. 2007)

\subsubsection{GCL manufacturing techniques}

Shrinkage of the GCLs occurs due to hydration and loss of moisture during the cooling and drying portions of thermal cycles, respectively. The hydration behavior of the GCL is significantly dependent on the manufacturing techniques of the GCL (e.g. Anderson et al., 2012; Beddoe et al., 2011; Rayhani et al., 2011; Rowe at al. 2011b). Particularly, the water retention curve of the GCL which is affected by the manufacturing techniques specifies the hydration and shrinkage behavior of the GCL (Beddoe et al., 2010). Hence, GCL properties which include the type of cover and carrier geotextiles, bentonite, and connection layer affect the maximum shrinkage of the GCL under daily thermal cycles. For instance, Thiel et al. (2006) reported that geotextiles alone did not contribute significantly to the overall shrinkage of GCLs. However, the maximum shrinkage of GCLs observed in the laboratory and field conditions were shown to be significantly high. Rowe et al. (2011a) reported that the scrim-reinforced thermally treated GCL $(A R=1.6)$ and the simply needle-punched $G C L$ with nonwoven carrier geotextile 
$(A R=1.6)$ experienced a maximum shrinkage of $10.8 \%$ and $13.5 \%$, respectively, under simulated daily thermal cycles. Also, a high intensity of needle punching and lower initial moisture content at the beginning of each wet-dry cycle were shown to lessen the potential and rate of shrinkage (Thiel et al., 2006). The shrinkage of the GCL under daily thermal cycles relies on the variation of the moisture content in each thermal cycle (Rowe et al., 2011b). Hence, the better anchorage provided by thermal treatment and scrim reinforcement of the carrier geotextile, or higher intensity of needle-punching in the GCL causes lower variation of moisture content in each thermal cycle and, therefore, lower accumulated shrinkage.

The water retention curve and in turn the shrinkage behavior of the GCL is also dependent on bentonite type and granularity, particularly in higher levels of suction values (Beddoe et al. 2010, 2011). Sodium-activated bentonite GCLs demonstrated more shrinkage in comparison to GCLs with natural Wyoming bentonite (Bostwick et al. 2010). Also, the GCL specimens with powdered bentonite were found to have up to 20 percentages more shrinkage than the GCL specimens with granular bentonite in pan-tests; however, they have experienced similar values of shrinkage up to the $5-10^{\text {th }}$ cycle (Figure 2.10). Nonetheless, the grain size distribution of the bentonite could not affect the shrinkage of the GCL in the field where the number and severity of thermal cycles may not be as significant as the pan-tests (Rowe et al., 2011a; Bostwick, 2009). For instance, Thiel et al. (2006) noted that the maximum shrinkage of a NW/W GCL panel detected in two filed observations was found to be approximately half the values derived in simulated pan-tests in the laboratory. The shrinkage observed in the field corresponded to 4-5 wetting-drying cycles of the laboratory tests. This could be attributed to the fact that 
GCLs in field conditions absorb pore water from the underlying subsoil rather than being watered directly in the laboratory, and also the temperature of the subsoil is implicitly lower than that of the pans placed in the oven. These factors could be considered as the main reasons for less moisture content variation in each thermal cycle and, consequently, less shrinkage in the field. Also, the frictional force at the interface of GCL panels and the subsoil could obstruct the movement and shrinkage of the GCL.

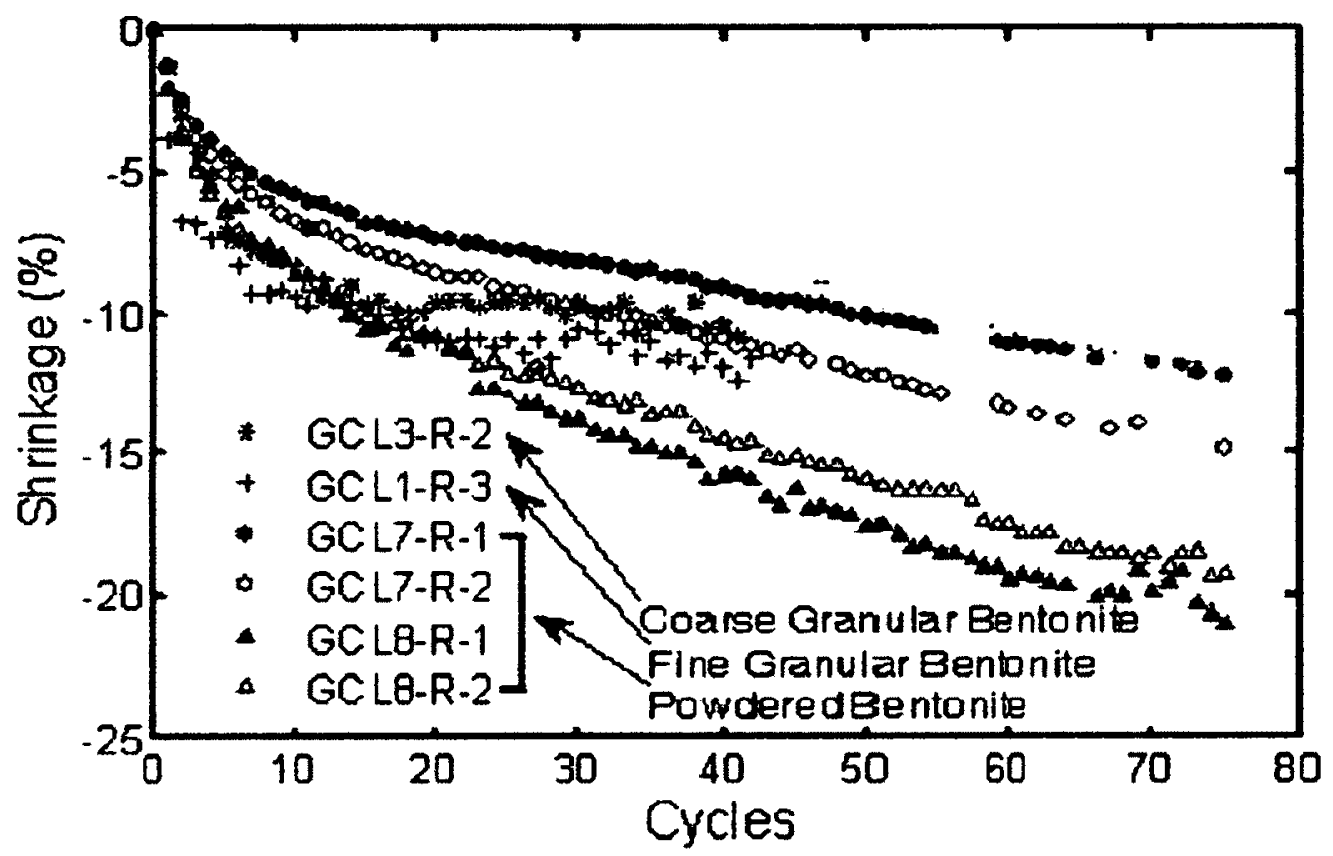

Figure 2.10 Influence of bentonite grain size distribution on shrinkage (Rowe et al. 2011b)

\subsubsection{Initial moisture content of the GCL}

GCL rolls typically contain the initial gravimetric moisture content of 5-30\% (Bostwick 2009); however, they absorb pore water from the subsoil, or might be watered directly, and hydrated to different gravimetric moisture contents after they are placed over the subsoil. The GCL panels in the composite liners could be considered to be in a closed system which is surrounded by the geomembrane from the top and the subsoil from the 
bottom. This would be particularly accurate in flat slopes where the moisture of the GCL is absorbed by the subsoil and subsequently is driven back to the GCL during the heating and cooling portions of each thermal cycle, respectively. Therefore, high values of initial moisture content for the GCL could contribute to significant moisture variation in each thermal cycle and, hence, more shrinkage. To estimate the effect of initial moisture content of the GCL on shrinkage, Rowe et al. (2011a) subjected four unrestrained GCL specimens with the initial moisture content of $5,19,64$, and $72 \%$ to wet-dry cycles. They demonstrated that the initial moisture content of the GCL did not affect significantly the final shrinkage (Figure 2.11). It should be noted that the shrinkage of the specimens with low initial moisture contents after five cycles was found to be $3.2-3.8 \%$ which was approximately half that of the specimens with higher initial moisture contents. The results reported for the $5^{\text {th }}$ cycle are more accurately representative of the effect of the initial moisture content in field conditions since the GCL specimens were not in a closed system during the drying portion in the oven and were watered with the same volume of water in the subsequent cycles. This negated the effect of the initial moisture content (Rowe et al., 2011a). 


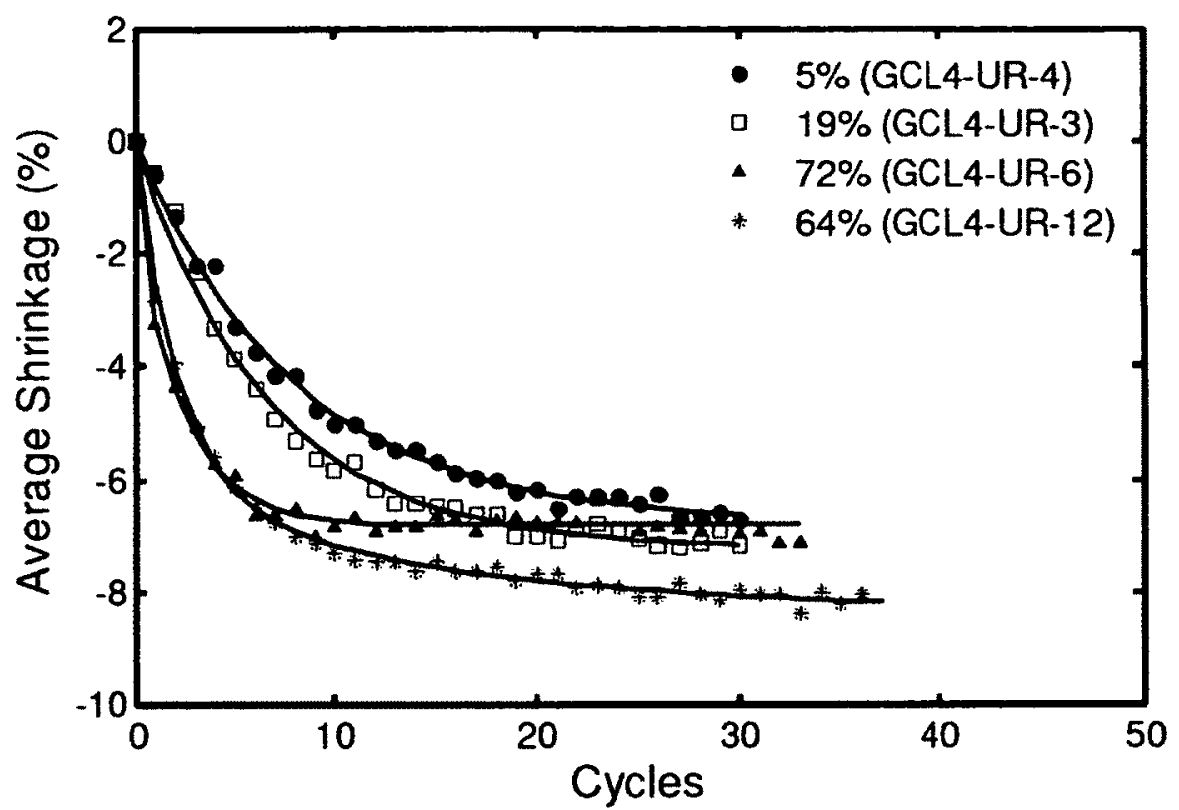

Figure 2.11 Influence of the initial gravimetric moisture content of the GCL on shrinkage (Bostwick, 2009)

Thiel et al. (2006) compared the shrinkage of two identical NW/SRNW specimens and reported that increasing the volume of water addition in each cooling cycle from 300 to $500 \mathrm{~mL}$ increased both the rate of shrinkage and the final shrinkage from 14.4 to $19.2 \%$. However, Rowe et al. (2011a) demonstrated that increasing the volume of water added to the NW/SRNW specimen at the beginning of each thermal cycle from 500 to $1000 \mathrm{~mL}$ did not significantly affect the maximum shrinkage. They noted that the lower shrinkage for the specimens with added water of $300 \mathrm{~mm}$ could be associated to the probable uneven hydration due to lack of water. This is similar to the results reported by Bostwick (2009), indicating that the GCL specimens which are wetted unevenly have less potential to shrink in comparison to those wetted evenly under similar conditions. 


\subsubsection{Shrinkage prevention measures}

There are many methods reported in the literature to decrease the risk of GCL panel separation. Rowe et al. (2010) and Rowe (2012) recommended overlapping the panels of GCLs by $300 \mathrm{~mm}$ and placing leachate collection system or cover soil on the geomembrane within less than 30 days to prevent the separation of GCL panels. Also, Thiel and Rowe (2010) suggested supplying the GCL material with lower initial moisture content in manufacturing, utilizing thermally-locked scrim reinforcement or woven fabric, and application of heat-tacked GCL seams. However, the aforementioned approaches could be impractical or costly in some field applications, and may not guarantee prevention of panel separation under severe conditions (Rowe et al., 2010; Rowe, 2012).

The field experience of Carlota Copper Mine in Miami substantiated the potential benefits of heat-tacked seams in preventing the separation of GCL panels (Thiel and Thiel, 2009). To elaborate, GCL panels were installed with $150 \mathrm{~mm}$ seam overlap along the length, and subsequently were heat-tacked continuously by a flame torch along the overlaps. Some samples were derived from the GCL seams after 60-90 days of the composite liner exposure to weather. All the GCL seams were found to be intact, and no separation of GCL panels was observed (Thiel and Thiel, 2009). Furthermore, to evaluate the tensional strength of the heat-tacked specimens, they were subjected to simulated daily thermal cycles in a study by Rowe et al. (2010). After the end of the daily thermal cycles ( 40 cycles), the tensional strength of the heat-tacked specimens was measured (ASTM D4595). They reported that the seamed samples withstood stresses as high as the 
GCL itself before failure through the heat-tacked seams. This shows that the application of heat-tacked GCL seams along the length of GCL panels could be a good approach to prevent the shrinkage of GCLs laterally.

\subsection{Summary}

Geosynthetic Clay Liners are utilized as part of composite liner systems in municipal solid waste landfills for their low hydraulic conductivity. The performance of the GCL primarily depends on the hydration of the GCL which occurs due to moisture uptake from the underlying subsoil. The hydration behavior of the GCL is fundamentally dependent on the water retention curves of both the GCL and the subsoil. Reviewing the extensive studies reported in the literature, illuminates the effect of the manufacturing techniques of the GCL, grain size distribution, and the initial moisture content of the subsoil on the level of suction at the interface of the GCL and subsoil. This is of paramount importance since the difference in suction between the GCL and subsoil positively affects the rate of hydration as well as the maximum moisture content of the GCL. However, it should be noted that the GCL hydration may also be significantly suppressed due to daily thermal cycles prior to the construction of the leachate collection system and also elevated isothermal temperatures at the base of landfills after the deposition of the waste. Even more notably, the normal stress applied to the liner by either the cover soil, leachate collection system, or the waste could affect the hydration of the GCL. The normal stress was shown to enhance the contact between the GCL and the subsoil and in turn augment the hydration rate; however, relatively high levels of the normal stress were shown to decrease the final moisture content of the GCL due to hindering the swelling and 
moisture uptake of the bentonite. There are still continued uncertainties regarding the optimum normal stress which contributes to the highest final moisture content and rate of hydration for the GCL. Thus, one of the objectives of this research is to investigate the rate of hydration of two different GCL products while placed over different subsoils under a wide range of normal stresses, and to find the optimum normal stress which results in the highest final moisture uptake and rate of hydration.

In addition, the GCL panels may be subjected to solar radiation and in turn daily thermal cycles for a period of time prior to being covered by the leachate collection system and the waste. Many case histories and laboratory investigations have reported the shrinkage and separation of the GCL panels due to thermal cycles, although the GCL panels are typically stretched at the base of landfills with $150 \mathrm{~mm}$ overlap. The aspect ratio, manufacturing techniques, and also the moisture content of the GCL were shown to affect the shrinkage of GCL. However, the shrinkage data derived in previous studies provide information as to the expected effect of different factors on the shrinkage of GCLs in severe thermal cycles. The experiments did not represent field conditions properly since GCL samples were not placed over subsoil and they were watered directly during the cooling cycle. During hydration, GCLs absorb moisture from the subsoil and the condensed vapor beneath the geomembrane (Rowe et al. 2011b). Considering this phenomenon, another objective of the current study is to investigate the shrinkage of the GCL under simulated field conditions where the hydration of the GCLs is influenced by the Water Retention Curve (WRC) of both subsoil and the GCL, the initial moisture content of the subsoil, and also initial moisture content and the aspect ratio of the GCL. 


\section{CHAPTER: 3 INFLUENCE OF NORMAL STRESS ON}

\section{HYDRATION OF GCLS}

\subsection{Introduction}

Previous studies have shown that the rate of hydration of a GCL is influenced by the GCL manufacturing techniques (e.g. Beddoe et al., 2011; Rayhani et al., 2011). A thermally treated scrim-reinforced GCL was shown to have a higher rate of hydration when placed in contact with sand subsoil (Rayhani et al., 2011), and lower susceptibility to shrinkage under simulated daily thermal cycles between 20 and $60^{\circ} \mathrm{C}$ (Rowe et. al., 2011b). The initial moisture content and the type (grain size distribution) of subsoil were also shown to affect the rate of hydration of the GCL (Chevrier et al., 2010; Rayhani et al., 2011; Rowe et al. 2011b). Composite liners in landfill applications might be left exposed to daily thermal cycles for a period of time prior to being covered by the waste. Rowe et al. (2011b) reported that the thermal cycles significantly suppressed the rate of hydration of GCLs placed on silty sand subsoil at initial moisture contents of $5 \%, 10 \%$ and $16 \%$.

The moisture uptake data noted above provides information as to the likely hydrated moisture content for the GCLs under small normal stresses (mostly under 2 $\mathrm{kPa}$ ). However, there is limited data in the literature assessing the effect of normal stress on the rate of hydration of GCLs. Rayhani et al. (2011) evaluated the rate of hydration for two GCL samples under unconfined conditions and a normal stress of $2 \mathrm{kPa}$. The confined GCL showed a higher rate of hydration due to better contact intimacy with the subsoil. Chevrier et al. (2010) demonstrated a reduction of approximately $12.5 \%$ in the 
equilibrium moisture content of a needle-punched GCL placed over sand subsoil as the initial normal stress of $7 \mathrm{KPa}$ was increased to $28.2 \mathrm{KPa}$. However, there are still continued uncertainties regarding the effect of normal stress in other ranges. Furthermore, the optimum normal stress which contributes to the highest final equilibrium moisture uptake as well as the rate of hydration of GCLs has not been documented in the literature. Thus, this chapter presents an experimental program to investigate the rate of hydration of two different GCL products using different subsoils under a wide range of normal stresses $(0-8 \mathrm{kPa})$, and to find the optimum normal stress which results in the highest equilibrium moisture uptake and rate of hydration. In addition, the effects of the GCL manufacturing techniques and the grain size distribution of the subsoil on the GCL hydration behavior are investigated.

\subsection{Material properties}

\subsubsection{Geosynthetic Clay Liners}

Two different types of GCLs (GCL1 and GCL2) were examined in this study for hydration analysis. The index properties of the GCLs, including carrier and cover geotextiles, layer connection, and average peel strength are given in Table 3.1. Both GCLs contained granular sodium bentonite with similar smectite contents of 50 to $58 \%$. GCL1 and GCL2 had swell indexes of 24 and $23 \mathrm{ml} / 2 \mathrm{~g}$ min., respectively. The former GCL contained fine grained bentonite with $D_{50}$ of about $0.35 \mathrm{~mm}$, while the latter contained coarse granular bentonite with $\mathrm{D}_{50}$ of approximately $1.0 \mathrm{~mm}$. The plasticity index of bentonite was measured at approximately $216 \%$ for GCL1 and $262 \%$ for GCL2 
(ASTM D 4318). The cation exchange capacities of the bentonite were 78 and 103 meq $/ 100 \mathrm{~g}$ for GCLs 1 and 2 , respectively.

Table 3.1 Properties of GCLs Examined

\begin{tabular}{|c|c|c|c|c|c|c|c|}
\hline \multirow[b]{2}{*}{ GCL } & \multirow{2}{*}{$\begin{array}{c}\text { Total dry } \\
\text { mass/area } \\
\left(\mathrm{g} / \mathrm{m}^{2}\right)\end{array}$} & \multicolumn{2}{|c|}{ Carrier GT } & \multicolumn{2}{|c|}{ Cover GT } & \multirow[b]{2}{*}{$\begin{array}{c}\text { Connection } \\
\text { Layer }\end{array}$} & \multirow{2}{*}{$\begin{array}{c}\text { Average } \\
\text { peel } \\
\text { strength } \\
(\mathbf{N})^{*}\end{array}$} \\
\hline & & Type & $\begin{array}{l}\text { Mass } \\
\left(\mathrm{g} / \mathrm{m}^{2}\right)\end{array}$ & Type & $\begin{array}{c}\text { Mass } \\
\left(\mathrm{g} / \mathrm{m}^{2}\right)\end{array}$ & & \\
\hline 1 & $3312-4006$ & SRNW & $230-253$ & NW & $200-224$ & NPTT & $260 \pm 17$ \\
\hline 2 & $4499-5295$ & W & $120-130$ & NW & $260-280$ & NP & $204 \pm 35$ \\
\hline
\end{tabular}

W = Woven, $\mathbf{N W}=$ Nonwoven, SRNW $=$ Scrim reinforced nonwoven, $\mathbf{N P}=$ Needle punched, $\mathbf{N P T T}=$ Needle punched \& thermally treated; *Tests performed by $M$. Hosney, Queen's University

\subsubsection{Soil properties}

Hydration rates for the two GCL specimens were examined using two different subsoils: ordinary construction sand (SP in USCS classification system, ASTM D2487), and Ontario Leda clay (CL) from the Navan landfill near Ottawa, Ontario, Canada. Leda clay has been originally formed from the deposition of grounded sediments in sea water after deglaciation. It is has a significant porous and sensitive structure due to leaching of the salt minerals which primarily bonded the powdery particles (Rankka et al., 2004). The particle size distributions of both soils are shown in Figure 3.1 (ASTM D 422). The sand (SP) contained approximately $5 \%$ fines passing through the $0.075 \mathrm{~mm}$ sieve. The fines were non-plastic. The plasticity index of the clay (CL) was found to be $21.6 \%$ (ASTM D4318). The Standard Procter compaction tests (ASTM D 698) indicated maximum dry densities of 1.68 and $1.43 \mathrm{Mg} / \mathrm{m}^{3}$ at optimum gravimetric moisture contents of $10 \%$ and $28.3 \%$ for the sand (SP) and clay (CL), respectively. GeoStudio (2007) was implemented to estimate the WRC of the sand, based on the grain size distribution and the saturated 
moisture content of the soil. Also, Van Genuchten (1980) model was used to derive the water retention curve of the clay (CL) based on the experimental data points reported by Taha (2010).The initial suction in the clay is much higher than that of the sand subsoil.

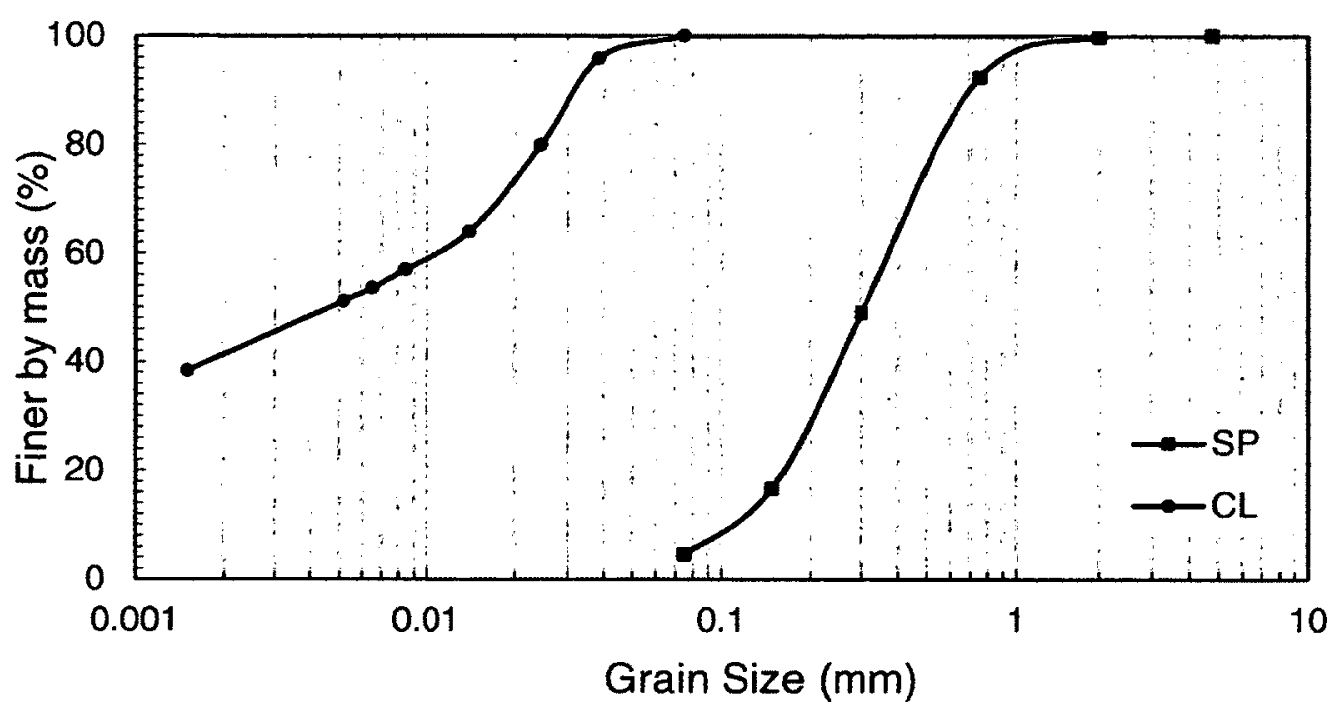

Figure 3.1 Grain size distributions for the subsoils examined

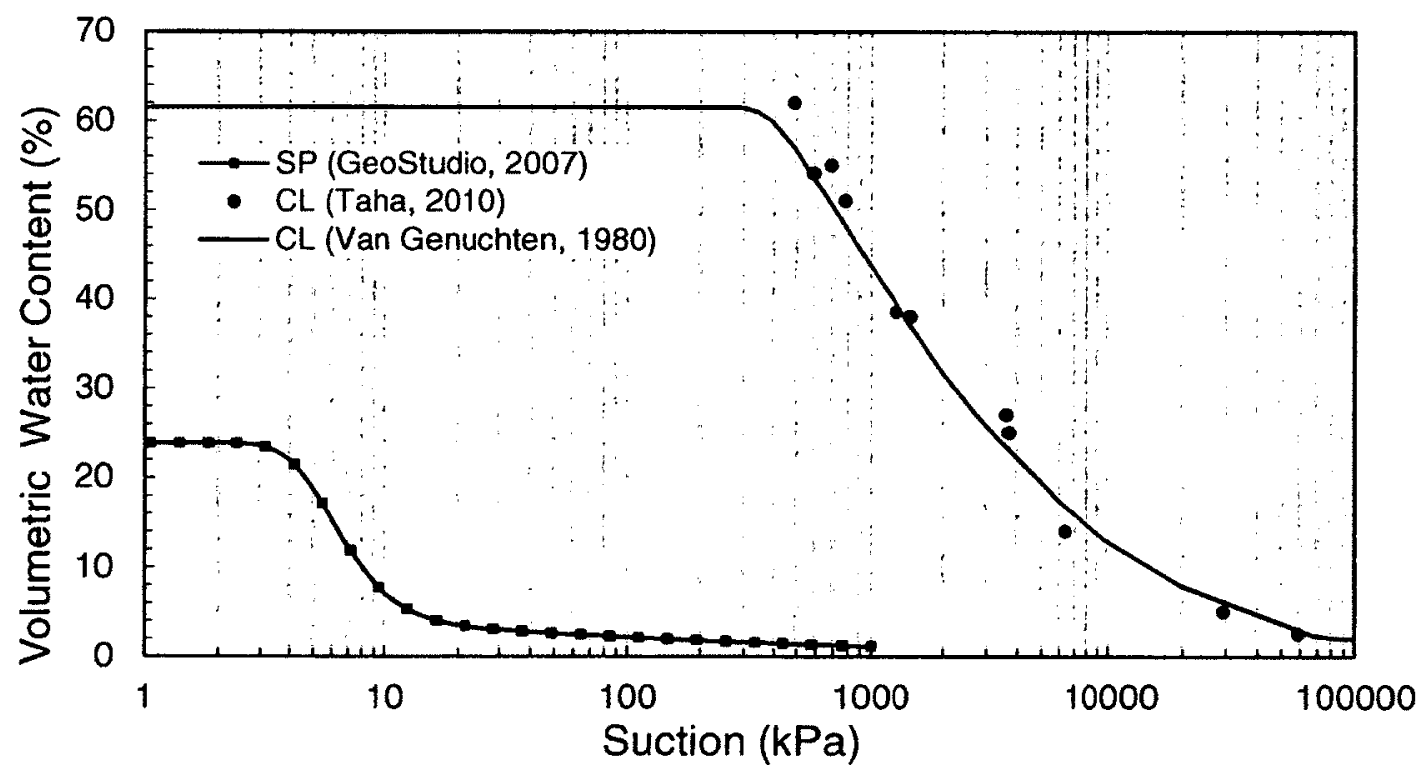

Figure 3.2 Water Retention Curves (WRCs) for the subsoils examined 


\subsection{Experimental procedure}

This paper investigates the effect of normal stress on the hydration behavior of GCLs from the underlying subsoil. Typical composite liner profiles were made in Polyvinyl Chloride (PVC) cells having a diameter of $150 \mathrm{~mm}$ and a height of up to $500 \mathrm{~mm}$. The experimental testing consisted of 24 cells, with tests performed at ambient room temperature $\left(22^{\circ} \mathrm{C}\right)$. Each cell consisted of $250 \mathrm{~mm}$ of subsoil, a GCL, a geomembrane, and a steel seating block with a known weight to provide specific normal stresses on the GCL (Figure 3.3).

Bulk samples of dry sand (SP) were mixed with tap water having an average calcium concentration of $40 \mathrm{mg} / \mathrm{L}$ in order to bring its moisture content to $12 \%$, i.e. a moisture content which is $2 \%$ higher than the Standard Proctor optimum moisture content $\left(w_{\text {opt }}+2 \%\right)$, to represent the moisture content used in the construction of barrier systems in most modern solid waste landfills. The sand was then compacted into the PVC cylinders (12 cells) in three layers with a final height of $250 \mathrm{~mm}$, and a dry density of $1.51 \mathrm{Mg} / \mathrm{m}^{3}$, corresponding to approximately $90 \%$ of the maximum dry density $\left(\rho_{d(\max )}\right)$. Similarly, 12 cells were filled with clay (CL) subsoil at a moisture content of $30 \%$ and compacted to a dry density of $1.29 \mathrm{Mg} / \mathrm{m}^{3}$. Each cell was closed, sealed, and left for 24 hours to cure before the GCL sample was placed on top of the soil. GCL samples with a diameter of $150 \mathrm{~mm}$ were cut from the roll, placed over the subsoil, and overlain by a geomembrane. Afterwards, a steel seating block was placed on the geomembrane to apply normal stress over the GCL, except for the samples which were not to be subjected to normal stress. Details of the initial moisture content of the GCLs as well as the normal stresses applied to the GCLs are outlined in Table 3.2. 
The hydration process of the GCLs was monitored by measuring the gravimetric moisture content of the GCLs for up to 40 weeks in order to evaluate the hydration of GCLs under different normal stresses. The test cells were opened at specific times (weekly) in order to measure the mass and the average thickness of the GCL, before returning it to the cell. The cells were closed and sealed again to prevent any loss of moisture. A schematic of a typical test cell is demonstrated in Figure 3.3.

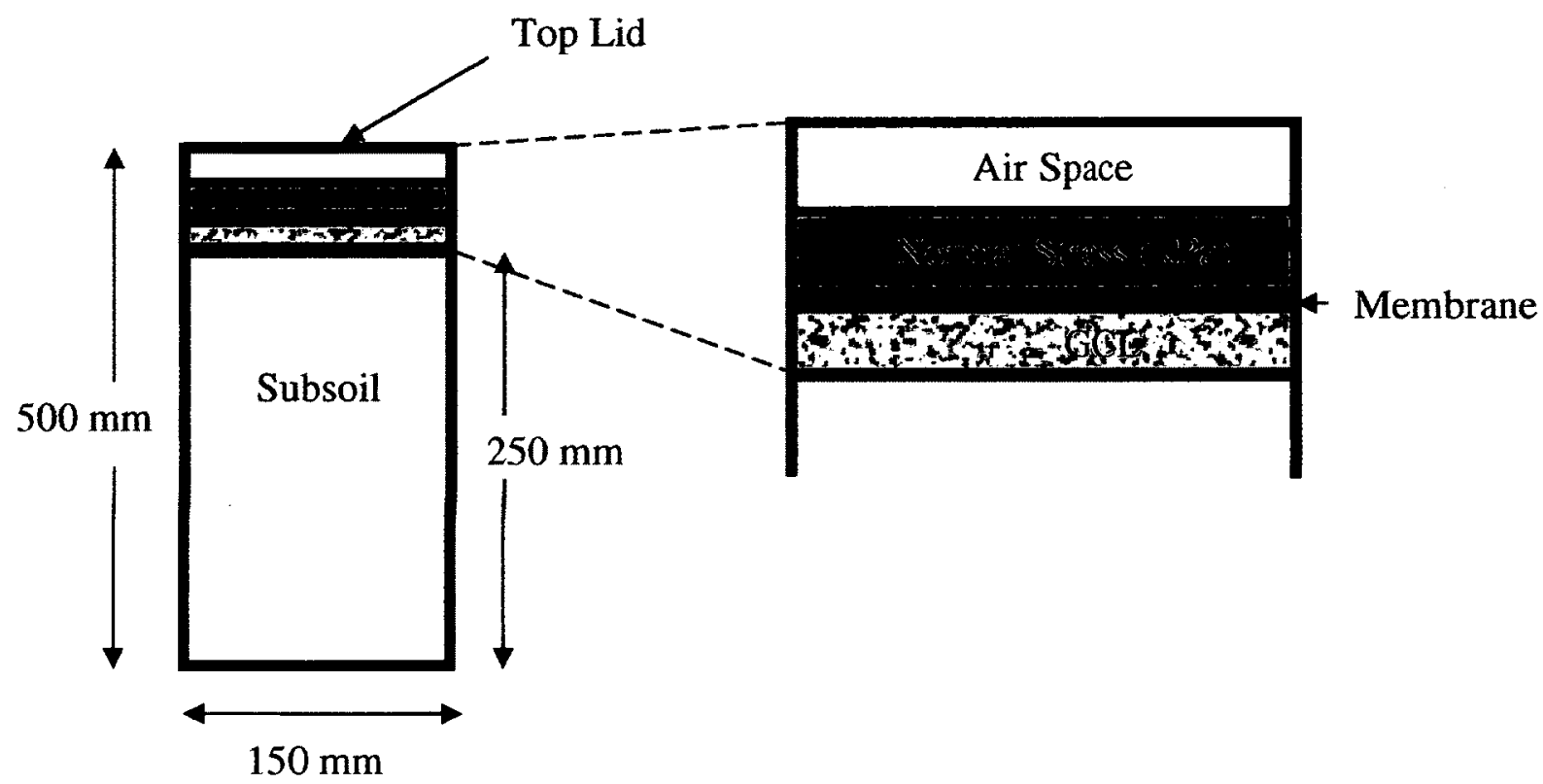

Figure 3.3 Geometry of the apparatus used for evaluation of hydration under isothermal condition

\subsection{Results}

\subsubsection{Typical hydration results}

In general, the gravimetric moisture content of the GCL increases until the GCL attains equilibrium with the subsoil. The rate of hydration was significantly higher during the first 10 weeks, but it gradually decreased, and the gravimetric moisture content of the GCLs finally leveled out and reached a steady-state value. The corresponding gravimetric moisture content is reported as the equilibrium moisture content. Also, the normalized 
moisture content $\left(\mathrm{w} / \mathrm{w}_{\mathrm{ref}}\right)$ of GCLs has been calculated so that it would be possible to compare the rate of hydration of GCLs which are different in manufacturing techniques. The normalized moisture content was defined as the ratio of moisture content of the GCL to the hydration potential $\left(w_{\text {ref }}\right)$, i.e. the maximum moisture content of the GCL when there is no limitation on the moisture content available. To obtain the $\mathrm{w}_{\mathrm{ref}}$, the GCL specimens were immersed in water while applying the same normal stresses to which the GCLs were subjected during the hydration from subsoil experiments. Geotextiles were placed between the GCL samples and the seating block in order to provide sufficient space for water to reach the GCL.

The equilibrium moisture content, normalized moisture content, and also the time required to reach equilibrium for GCL1 and GCL2 while placed over sand (SP) and clay (CL) subsoils are reported in Table 3.2. The time required to reach equilibrium moisture for GCL1 placed over sand (SP) subsoil was typically lower than that of clay (CL) subsoil. Also, it took a longer time for GCL2 to attain the equilibrium moisture content in comparison to GCL1 at the same normal stresses in contact with the same subsoil. Moreover, the results for initial thickness and final thickness of the GCL samples are indicated in Table 3.2. The thickness of the GCLs was measured at three specific points using a caliper, and finally averaged to obtain a value which represents the mean thickness of the GCL. Based on the derived data, the effect of the normal stress on GCL swelling was also evaluated and will be further described. In the remainder of this chapter, the factors which influence the hydration of GCLs, including normal stress, the GCL manufacturing techniques, and subsoil grain size distribution are analyzed and discussed in detail. Meanwhile, the results of this research are compared with those of previous investigations. 
Table 3.2 Details of experiments conducted under isothermal condition

\begin{tabular}{|c|c|c|c|c|c|c|c|c|c|c|c|}
\hline \multirow[t]{2}{*}{ GCL } & \multirow[t]{2}{*}{$\begin{array}{l}\text { Sub } \\
\text { soil }\end{array}$} & \multirow{2}{*}{$\begin{array}{l}\text { Conf. } \\
\text { Stress } \\
\text { (KPa) }\end{array}$} & \multirow{2}{*}{$\begin{array}{c}\text { Dry } \\
\text { mass/ } \\
\text { area } \\
\left(\mathrm{g} / \mathrm{m}^{2}\right)\end{array}$} & \multirow{2}{*}{$\begin{array}{l}\text { Initial } \\
\text { Thick. } \\
\text { (mm) }\end{array}$} & \multirow{2}{*}{$\begin{array}{l}\text { Final } \\
\text { Thick. } \\
\text { (mm) }\end{array}$} & \multicolumn{3}{|c|}{$\begin{array}{c}\text { Moisture } \\
\text { Content, w (\%) }\end{array}$} & \multicolumn{2}{|c|}{$\begin{array}{c}\text { Normalized } \\
\text { MC. } \\
\left(w^{*}{ }^{*} \mathbf{w}_{\text {ref }}\right)(\%)\end{array}$} & \multirow{2}{*}{$\begin{array}{c}\text { Time } \\
\text { to } \\
\text { Reach } \\
\text { Eq. } \\
\text { (week) }\end{array}$} \\
\hline & & & & & & Initial & $\begin{array}{c}1 \\
\text { week }\end{array}$ & $\begin{array}{l}\text { Eq. } \\
\text { MC }\end{array}$ & $\begin{array}{c}1 \\
\text { week }\end{array}$ & $\begin{array}{l}\text { Eq. } \\
\text { MC }\end{array}$ & \\
\hline \multirow{12}{*}{1} & \multirow{6}{*}{ Sand } & 0.0 & 3648 & 6.55 & 7.15 & 6.49 & 35.8 & 110.0 & 25.6 & 78.7 & 24 \\
\hline & & 0.5 & 3780 & 6.85 & 7.25 & 6.56 & 43.0 & 110.0 & 32.2 & 82.3 & 18 \\
\hline & & 1.0 & 3515 & 6.65 & 7 & 6.58 & 45.2 & 111.3 & 34.1 & 84.0 & 14 \\
\hline & & 2.0 & 3582 & 6.53 & 7.10 & 6.46 & 50.6 & 111.8 & 37.7 & 81.8 & 12 \\
\hline & & 5.0 & 3984 & 6.3 & 7.05 & 6.46 & 56.0 & 108.4 & 42.0 & 81.2 & 8 \\
\hline & & 8.0 & 3701 & 5.82 & 6.57 & 6.46 & 62.6 & 106.6 & 46.7 & 79.5 & 8 \\
\hline & \multirow{6}{*}{ Clay } & 0.0 & 3846 & 6.9 & 7.50 & 6.44 & 33.1 & 83.1 & 23.6 & 59.5 & 26 \\
\hline & & 0.5 & 3664 & 6.63 & 6.93 & 6.47 & 36.3 & 90.3 & 27.2 & 67.5 & 22 \\
\hline & & 1.0 & 4006 & 6.93 & 7.42 & 6.46 & 39.1 & 95.1 & 29.5 & 71.7 & 16 \\
\hline & & 2.0 & 3312 & 6.4 & 6.72 & 6.49 & 42.2 & 96.6 & 31.5 & 72.0 & 16 \\
\hline & & 5.0 & 3595 & 5.92 & 6.43 & 6.47 & 43.3 & 95.9 & 32.4 & 71.9 & 16 \\
\hline & & 8.0 & 3426 & 5.58 & 6.08 & 6.46 & 44.6 & 96.6 & 33.3 & 72.0 & 8 \\
\hline \multirow{12}{*}{2} & \multirow{6}{*}{ Sand } & 0.0 & 4499 & 7.75 & 9.67 & 8.02 & 35.3 & 137.7 & 15.4 & 60.1 & 32 \\
\hline & & 0.5 & 4535 & 7.36 & 9.3 & 8.02 & 38.4 & 136.4 & 17.2 & 61.1 & 32 \\
\hline & & 1.0 & 5295 & 7.8 & 10.85 & 8.01 & 42.4 & 137.7 & 19.4 & 63.0 & 32 \\
\hline & & 2.0 & 4998 & 7.32 & 10.1 & 8.05 & 48.4 & 149.7 & 22.0 & 68.0 & 28 \\
\hline & & 5.0 & 4811 & 7.28 & 9.71 & 8.03 & 58.7 & 154.1 & 26.0 & 68.3 & 20 \\
\hline & & 8.0 & 4795 & 6.85 & 9.2 & 8.02 & 55.8 & 154.0 & 24.8 & 68.5 & 12 \\
\hline & \multirow{6}{*}{ Clay } & 0.0 & 4985 & 7.33 & 7.77 & 8.01 & 30.5 & 60.0 & 13.3 & 26.2 & 32 \\
\hline & & 0.5 & 4924 & 7.47 & 8.47 & 8.00 & 35.0 & 69.1 & 15.7 & 31.0 & 27 \\
\hline & & 1.0 & 4664 & 7.68 & 8.11 & 7.99 & 37.1 & 72.9 & 17.0 & 33.3 & 15 \\
\hline & & 2.0 & 5174 & 7.82 & 8.45 & 8.01 & 38.0 & 83.2 & 17.3 & 37.8 & 28 \\
\hline & & 5.0 & 4986 & 7.60 & 8.13 & 8.01 & 42.3 & 75.0 & 18.7 & 33.2 & 16 \\
\hline & & 8.0 & 4791 & 6.73 & 7.53 & 8.02 & 42.7 & 70.0 & 19.0 & 31.2 & 8 \\
\hline
\end{tabular}

* Results for $\mathrm{w}_{\text {ref }}$ are shown in Figure 3.7. 


\subsubsection{Moisture content profile in subsoil}

The initial and final profiles of gravimetric moisture content for sand (SP) and clay (CL) subsoils are demonstrated in Figure 3.4. The initial moisture content of the sand (SP) subsoil was approximately $12 \%$. As could be expected, the moisture content of the soil in contact with the GCL decreased due to the absorption of water by the GCL. In contrast, the moisture content increased at the bottom of the sand (SP) subsoil since the water moved downward due to gravimetric force. The moisture reduction (6.4-9.8\%) on top of the subsoil was more than the increase observed $(2.6-5.6 \%)$ at the bottom of the subsoil. This could be related to the absorption of moisture content by the GCL on top of the sand subsoil. The results reported for the clay (CL) subsoil also indicated a decrease of moisture content on top of the subsoil due to the absorption of moisture by the GCL. Nevertheless, the variation of final moisture content in the profile of the clay was less than that of the sand profile. This could be related to the grain size distribution and hence higher field capacity of the clay compared to sand. 


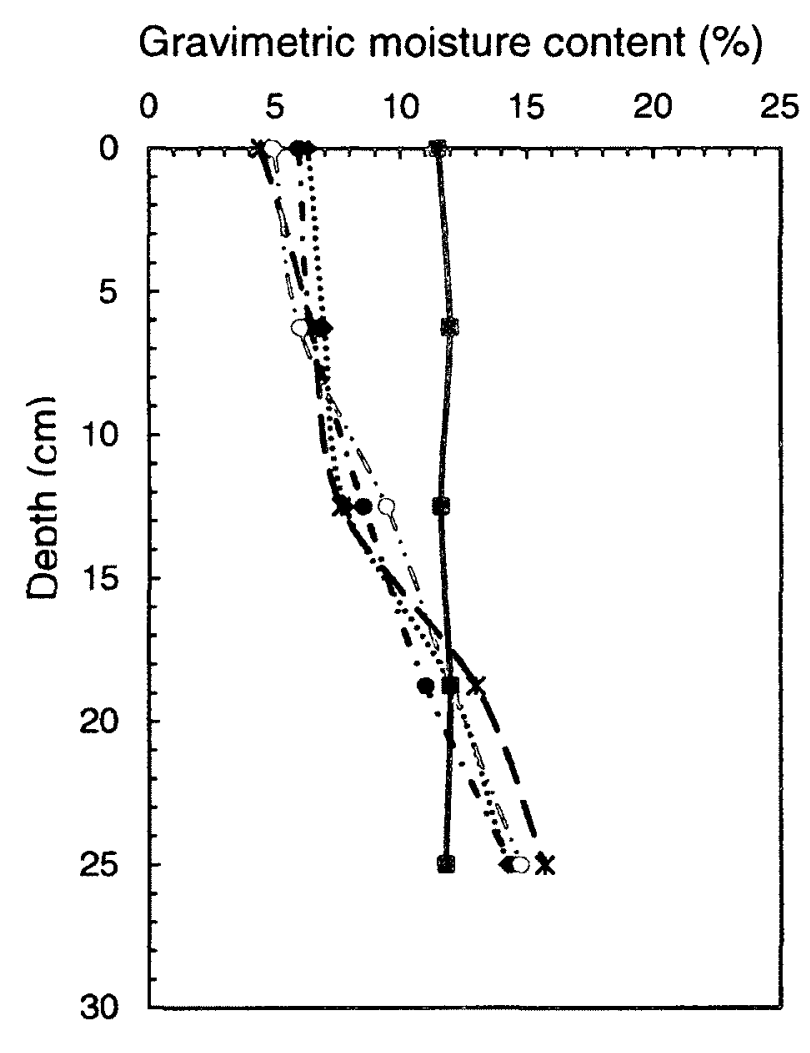

a) Sand (SP)
Gravimetric moisture content (\%)

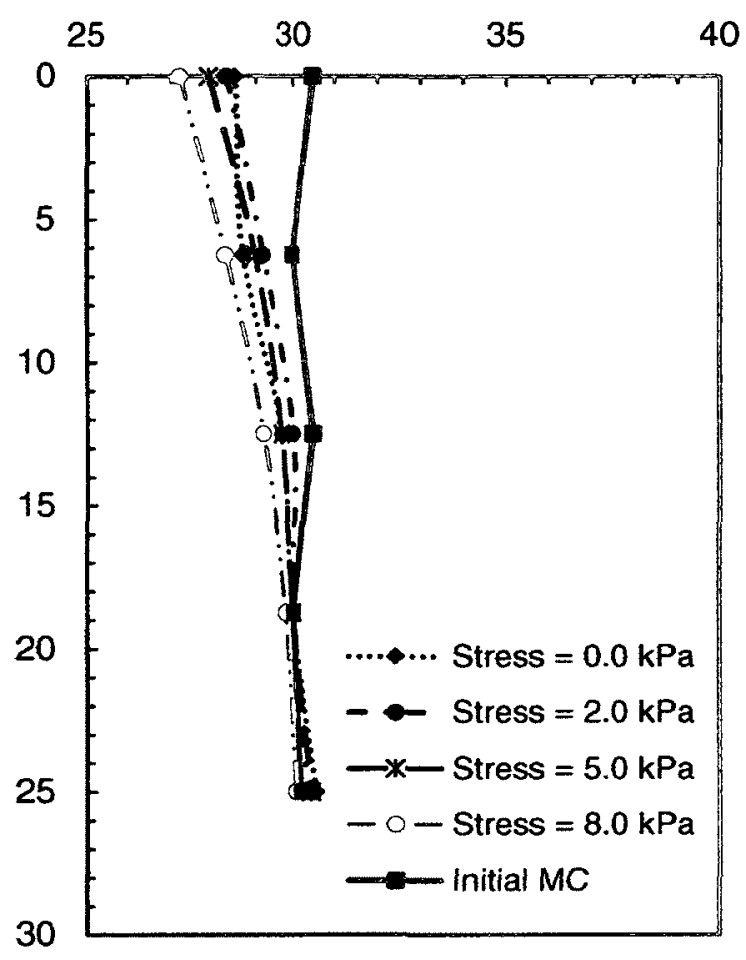

b) Clay (CL)

Figure 3.4 profile of the gravimetric moisture content in the subsoil before and after the test

\subsection{Analysis and discussion}

\subsubsection{Effect of normal stress on GCL hydration}

The hydraulic performance of a GCL in a barrier system depends on the degree of hydration of the bentonite in the GCL. The level of normal stress provided by the leachate collection system could affect the swelling characteristics and hence the degree of hydration of the GCL. Figure 3.5 shows the evolution of hydration for GCL1 from a sand subsoil at an initial moisture content of $12 \%$. The rate of moisture uptake increased significantly as the normal stress increased from 0 to $8 \mathrm{kPa}$. GCL1 achieved more than $62 \%$ gravimetric moisture content after one week when subjected to a normal stress of 8 $\mathrm{kPa}$ (Table 3.2). Under similar conditions but with no normal stress, this GCL reached 
only a $36 \%$ moisture content after one week of hydration. The time required to reach final equilibrium hydration, also, varied significantly for GCLs subjected to different normal stresses. Under no normal stress, the rate of moisture uptake from the subsoil was much slower and it took 24 weeks for GCL1 to reach its equilibrium moisture content. Under similar conditions but with a normal stress of $8 \mathrm{kPa}, \mathrm{GCL} 1$ approached its final equilibrium moisture content in 8 weeks. The normal stress enhanced the contact intimacy between the GCL and subsoil which induced a higher rate of moisture uptake. The magnitude of the final equilibrium moisture content of GCLs, however, was not significantly affected by the normal stress. There was no significant variation in the values of the equilibrium moisture contents for GCL1 subjected to the normal stresses of $0 \mathrm{kPa}$ to $2 \mathrm{kPa}$ (Figure 3.5). However, the equilibrium moisture content decreased from $111.8 \%$ to $106.6 \%$ as the normal stress increased from 2 to $8 \mathrm{kPa}$. Although higher normal stress generally reduces the potential for zones of poor contact between the GCL and the subsoil, there will be more of a restriction on the swelling of the bentonite as the normal stress increases. Therefore, a meager decrease of equilibrium moisture content was expected after a specific stress due to the much higher limitation for absorption of water. The results indicated that the normal stress which results in the optimum equilibrium moisture uptake for GCL1, while placed over a sand subsoil, was $2 \mathrm{kPa}$ (Figure 3.5). 


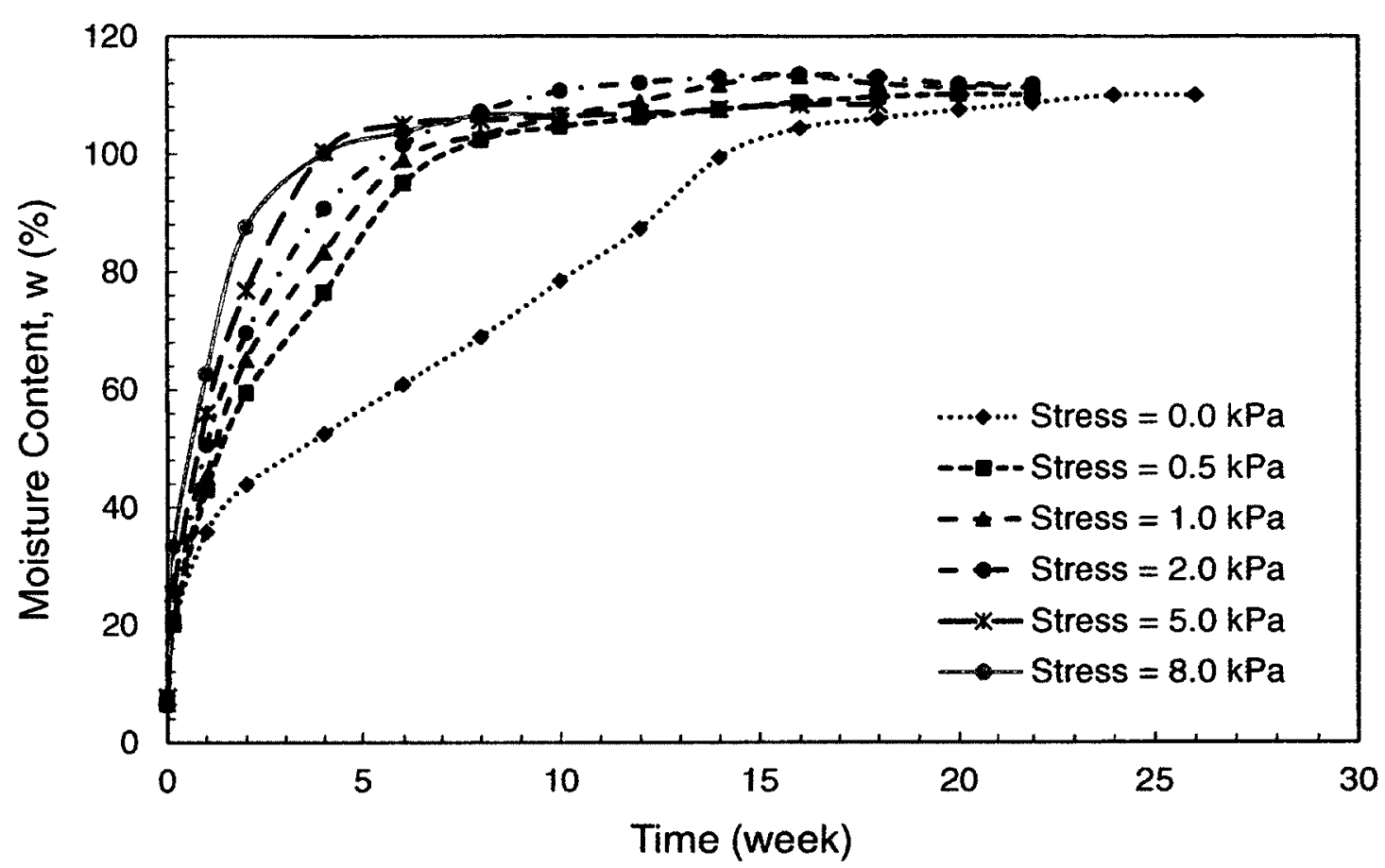

Figure 3.5 Hydration of GCL 1 from sand (SP) subsoil while subjected to different normal stresses

Figure 3.6 demonstrates the variation of equilibrium moisture content versus the normal stress for 4 different conditions, including either GCL1 or GCL2 placed over sand and clay subsoils. In general, the equilibrium moisture uptake slightly increased as the normal stress increased from 0 to $2 \mathrm{kPa}$. This small normal stress enhanced the contact between the GCL and the subsoil leading to faster and slightly higher moisture uptake. The normal stress of $2 \mathrm{kPa}$ led to the highest value of equilibrium moisture content for all conditions except for GCL2 placed over a sand subsoil. To elaborate, the equilibrium moisture content for GCL2 over sand increased from $149.7 \%$ to $154 \%$ as the normal stress increased from 2 to $5 \mathrm{kPa}$, which is not significant. Under the other conditions, a negligible reduction in moisture uptake was observed as the normal stress increased from 2 to $8 \mathrm{kPa}$. However, the results did not indicate a significant variation in the equilibrium moisture content as the stress increased from 2 to $8 \mathrm{kPa}$. This is mainly considered to be 
related to the fact that the swelling stress of the GCL controlled the normal stress applied to the GCLs. As a result, increasing the normal stress from 2 to $8 \mathrm{kPa}$ did not induce a significant decrease of the equilibrium moisture content.

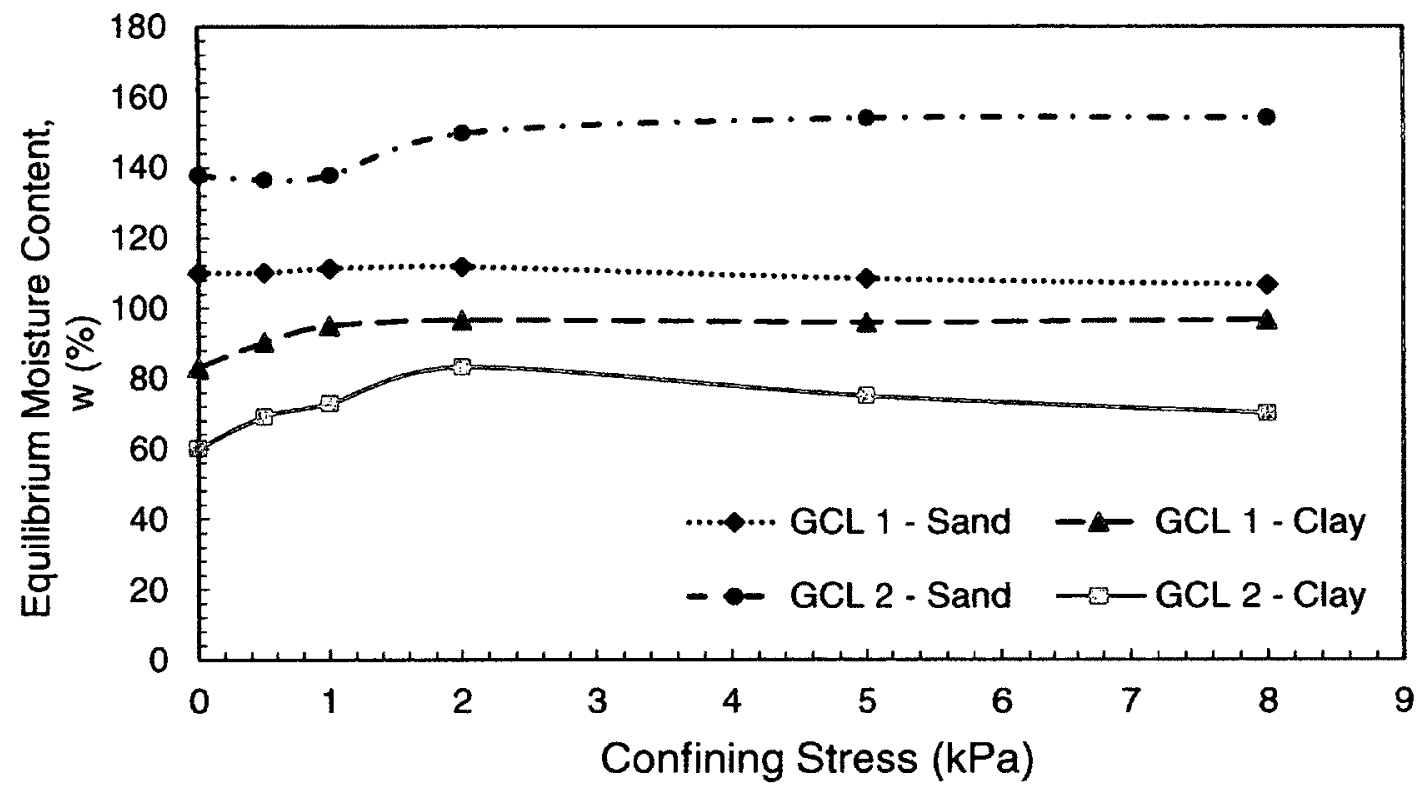

Figure 3.6 Effect of normal stress on the equilibrium moisture content of GCLs

These results could be also explained in terms of the maximum moisture content $\left(w_{\text {ref }}\right)$ attained by the GCL when immersed in water. As shown in Figure 3.7, there was no significant variation in the maximum moisture content of GCLs while subjected to normal stresses ranging from 0 to $8 \mathrm{kPa}$. The results for maximum moisture content $\left(\mathrm{w}_{\text {ref }}\right)$ substantiated that the swelling stress of GCLs controlled the normal stress applied to them. Immersion of GCLs in water represents the conditions under which there is no limitation on the amount of water available to the GCL for absorption. 


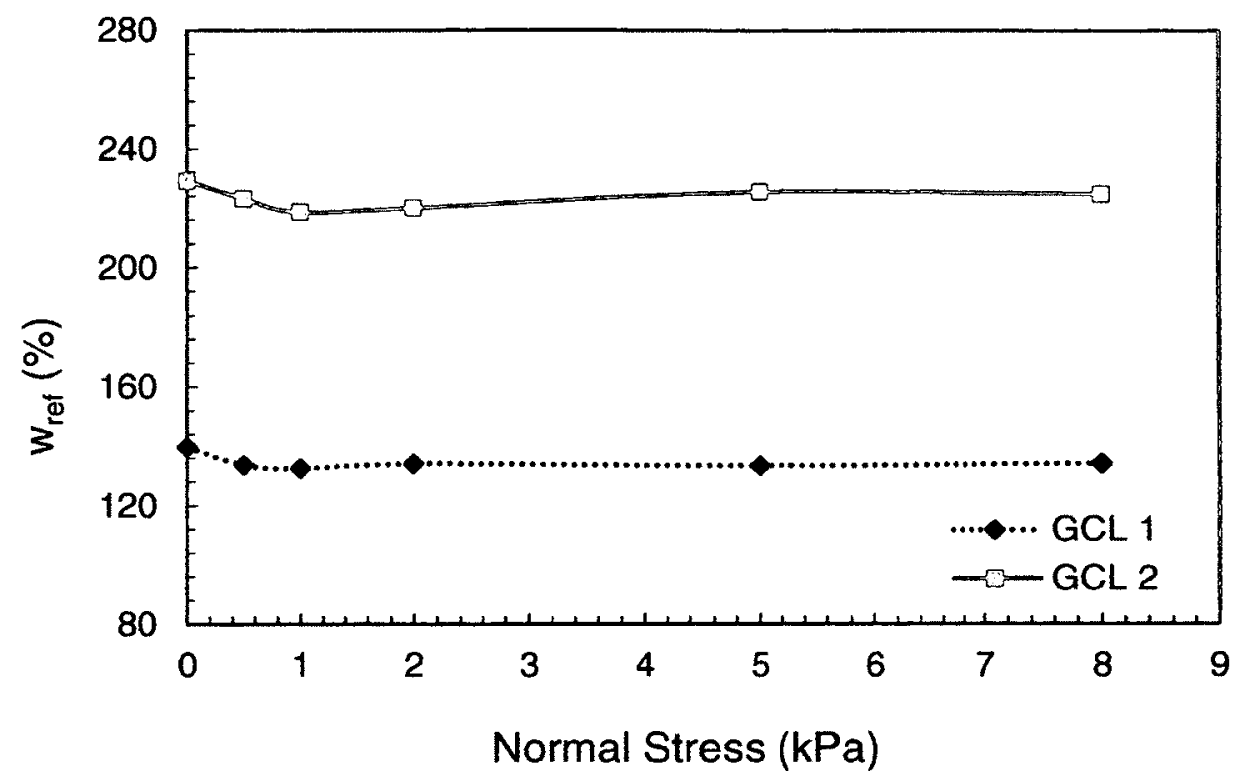

Figure 3.7 Effect of normal stress on maximum moisture content, immersed in water $\left(w_{\text {ref }}\right)$

\subsubsection{Effect of normal stress on GCL swelling (thickness)}

To evaluate the effect of normal stress on GCL swelling, the ratio of the final thickness of GCL specimens after hydration to their corresponding initial thickness were plotted (Figure 3.8). There was little variation observed for GCL1 placed over either sand (SP) or clay (CL) subsoil with the values ranging from $108 \%$ to $113 \%$ and $104.5 \%$ to $110.5 \%$, respectively. As shown in Figure 3.8, the ratio of swelling for GCL1 placed over sand (SP) subsoil was up to $5 \%$ more than that of the clay (CL) subsoil due to increased absorption of water by the GCL. In contrast, the results for GCL 2 indicated much more swelling for sand (SP) subsoil compared to clay (CL) subsoil. The former exhibited a swelling ratio of up to $135 \%$ while the latter swelled to $112 \%$ under the same normal stress of $8 \mathrm{kPa}$. There was a significant increase in the swelling ratio from 124 to $135 \%$ for GCL 2 on sand (SP) subsoil as the normal stress increased from 0 to $1 \mathrm{kPa}$ (Figure 3.8). It might be concluded that the increase of normal stress induced much better contact 
between the GCL and the sand subsoil, which resulted in higher moisture uptake and swelling. Nonetheless, the swelling ratio almost stabilized and there was little fluctuation observed for normal stresses ranging from 1 to $8 \mathrm{kPa}$. The meager variations pertaining to GCL1 could be attributed to the sufficient anchorage induced by the scrim-reinforced needle-punching and thermally treated layer connection of GCL1, which will be further discussed.

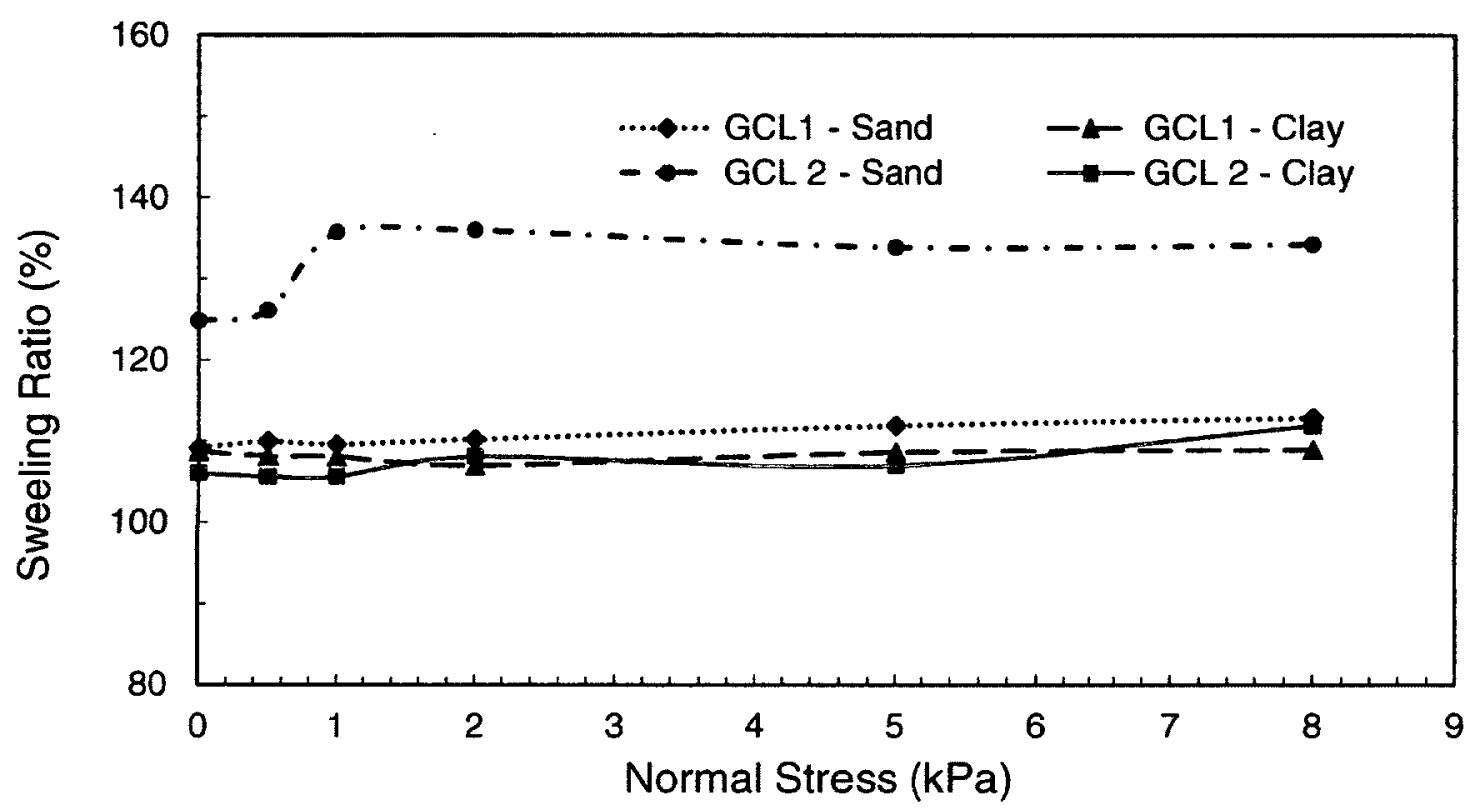

Figure 3.8 Effect of normal stress on the final thickness of GCLs

\subsubsection{Effect of GCL manufacturing techniques on hydration}

The hydration of the GCL is dependent on the method of GCL manufacture, and different GCL products exhibit different hydration and swelling behaviours. The maximum moisture uptake for GCLs immersed in water varied significantly for the two GCL products examined. Hence, the degree of hydration for GCL1 at a moisture content of e.g., $\mathrm{w}=100 \%\left(\mathrm{w} / \mathrm{w}_{\mathrm{ref}}=71 \%\right)$ would be different than that for GCL2 at the same gravimetric moisture content $\left(\mathrm{w} / \mathrm{w}_{\mathrm{ref}}=45 \%\right)$. Therefore both the absolute gravimetric 
moisture content $(\mathrm{w})$ and the moisture content normalized with respect to the maximum moisture uptake when immersed in water $\left(\mathrm{w} / \mathrm{w}_{\text {ref }}\right)$ are used to compare the performance of different GCLs subjected to various normal stresses (Table 3.2).

Figure 3.9 demonstrates the normalized moisture contents (w/wref) of GCL1 and GCL2 placed over a clay subsoil while subjected to a $2 \mathrm{kPa}$ stress. GCL1 demonstrated a much higher rate of hydration compared to GCL2. As shown in Table 3.2, the former GCL reached a plateau by the $16^{\text {th }}$ week with a normalized moisture content of $72 \%$, while the latter stabilized at the normalized moisture content of about $38 \%$ by the $28^{\text {th }}$ week. Figure 3.10 shows the normalized equilibrium moisture contents of both GCLs placed over a clay subsoil for normal stresses from 0 to $8 \mathrm{kPa}$. The normalized equilibrium moisture content of GCL1 was approximately twice that of GCL2 for all normal stresses. This could be related to the difference in interlocking of the GCLs examined. GCL1 has a scrim-reinforced non-woven carrier geotextile with a needle punched and thermally treated connection layer that provides a sufficient anchorage (Table 3.1) resulting in less swelling during the hydration process, in contrast to GCL2. This contributed to its higher normalized equilibrium moisture content. In addition, the results showed that a normal stress of $2 \mathrm{kPa}$ induced the maximum normalized equilibrium moisture content for both GCL 1 and GCL 2. For normal stresses greater than $2 \mathrm{kPa}$, there was no significant change observed in the normalized equilibrium moisture content for either GCLs. 


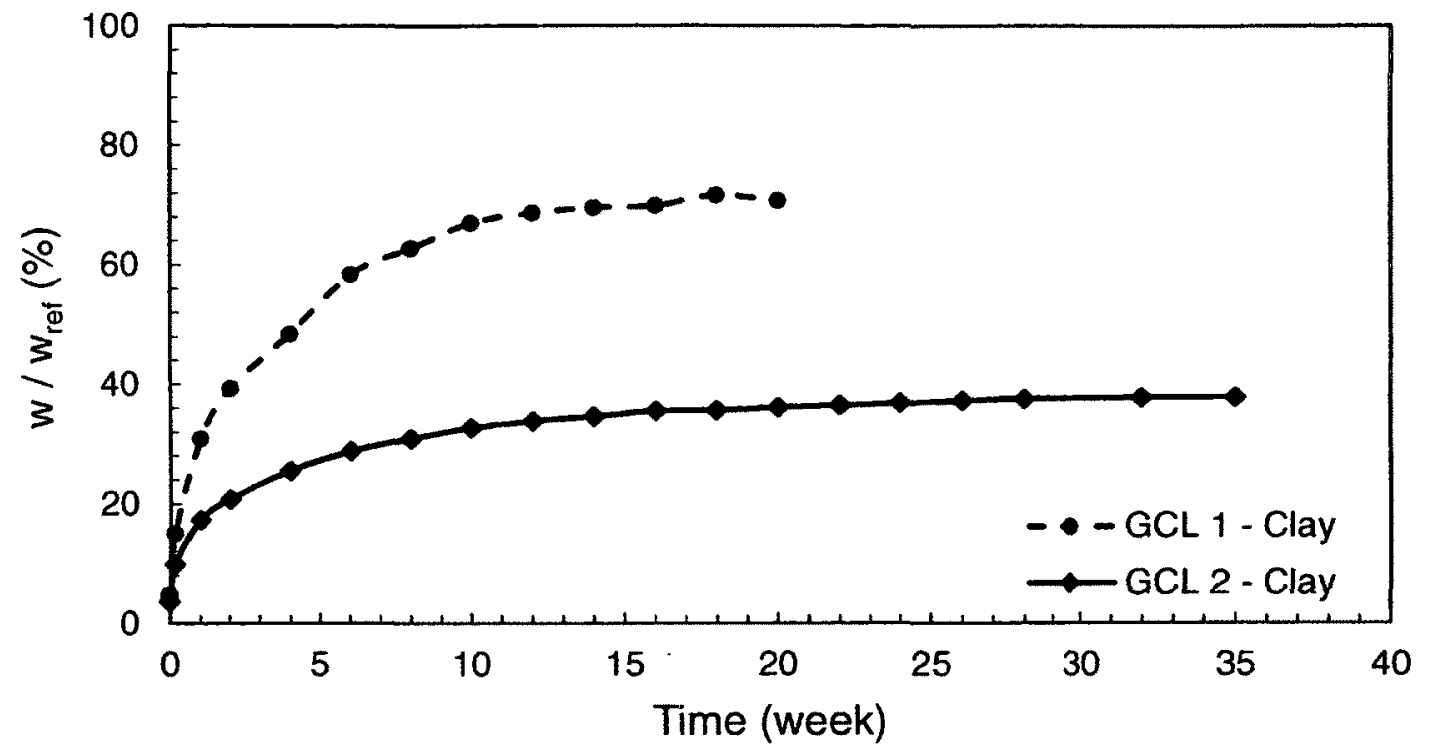

Figure 3.9 Effect of GCL type on rate of hydration from clay subsoil

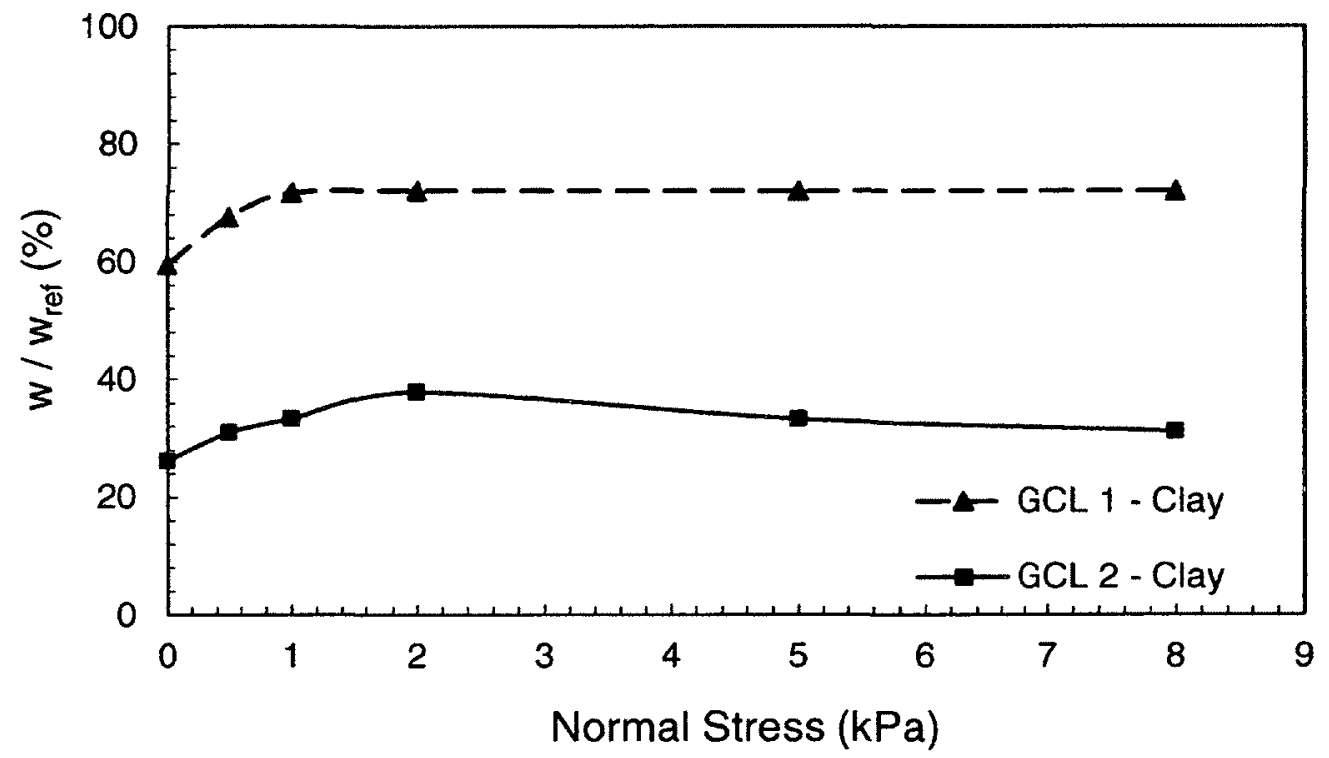

Figure 3.10 Effect of GCL type on the normalized equilibrium moisture content for different normal stresses

The results noted above are consistent with those reported in the literature in terms of GCL hydration behavior. Rowe et al. (2011b) indicated a lower daily variation in moisture content and furthermore less potential susceptibility to shrinkage for GCL1. 
Petrov et al. (1997), Lake and Rowe (2000), and Beddoe et al. (2011) reported that the limitation of swelling could be induced by much more sufficient anchorage of a GCL.

\subsubsection{Effect of subsoil grain size distribution on GCL hydration}

The effect of normal stress on GCL hydration was highly dependent on the grain size distribution and associated matric suction of the subsoil (Figure 3.2). For sand with an initial moisture content close to the optimum moisture content, there is a significant uptake of moisture by both the GCLs under all normal stresses (Table 3.2). Figure 3.11 compares the equilibrium moisture uptake of GCL2 from both sand and clay subsoils for all normal stresses. GCL2 reached $140-145 \%$ (depending on the normal stress) equilibrium moisture content when placed on the sand subsoil. Under similar conditions with clay subsoil, GCL2 achieved only $60-80 \%$ moisture content, approximately half that achieved on sand. Similarly, higher equilibrium moisture contents were observed for GCL1 with sand subsoil compared to clay subsoil (Table 3.2).

The rate of hydration was also different for the two subsoils examined. After 1 week of hydration, GCL2 achieved $48 \%$ moisture uptake from the sand subsoil, while it was about $38 \%$ from the clay subsoil under similar conditions (Figure 3.12). This observation shows the importance of the subsoil on GCL hydration. The difference in hydration behavior of GCL from different subsoils is related to the difference in suction levels of the soil and the GCL (Figure 3.2). The initial suction in the sand is much lower than that in the clay. This lower suction supplied by the sand subsoil results in a higher difference between the suction of the GCL and the subsoil, which leads to the higher moisture uptake by the GCL. 


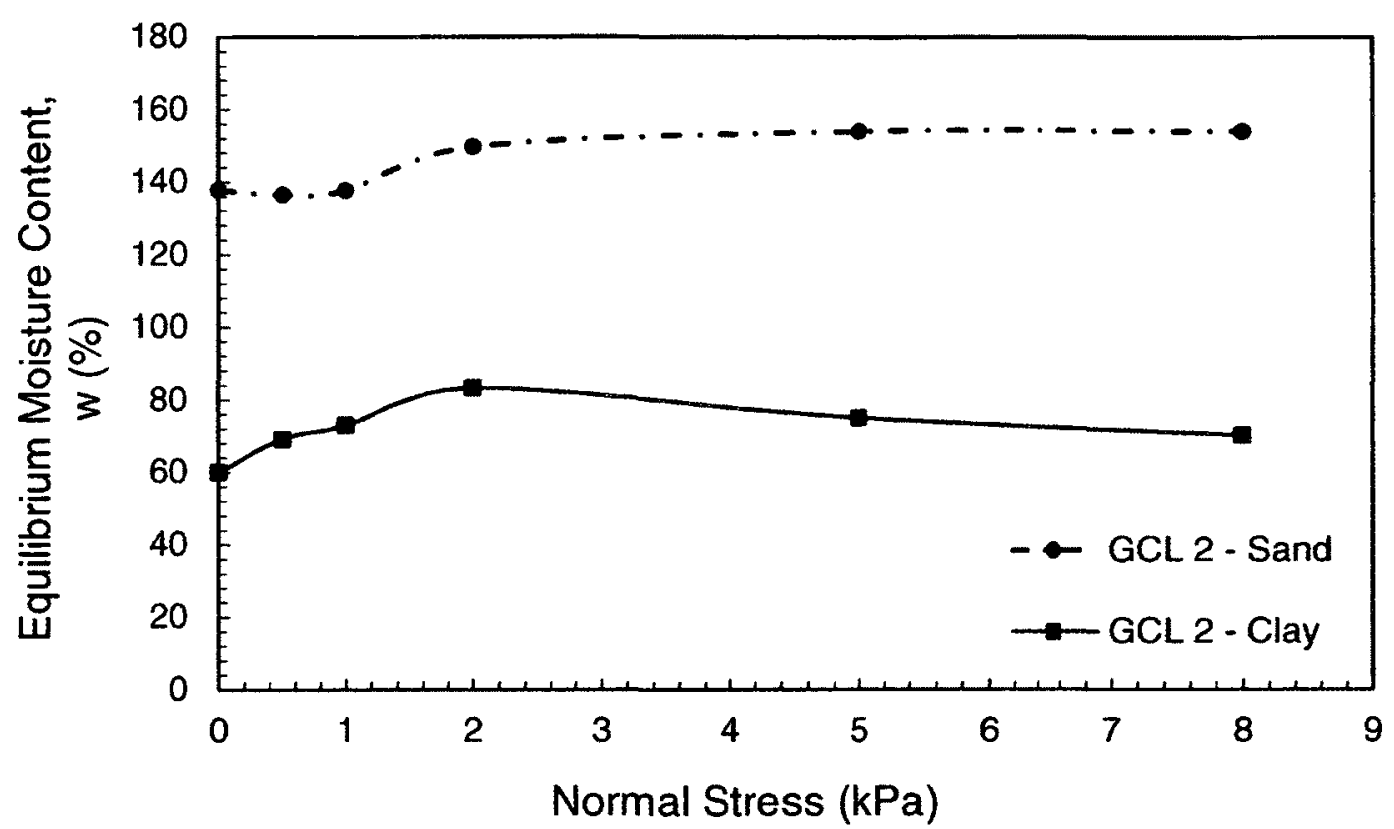

Figure 3.11 Effect of subsoil grain size distribution on the equilibrium moisture content of GCL2 for different normal stresses

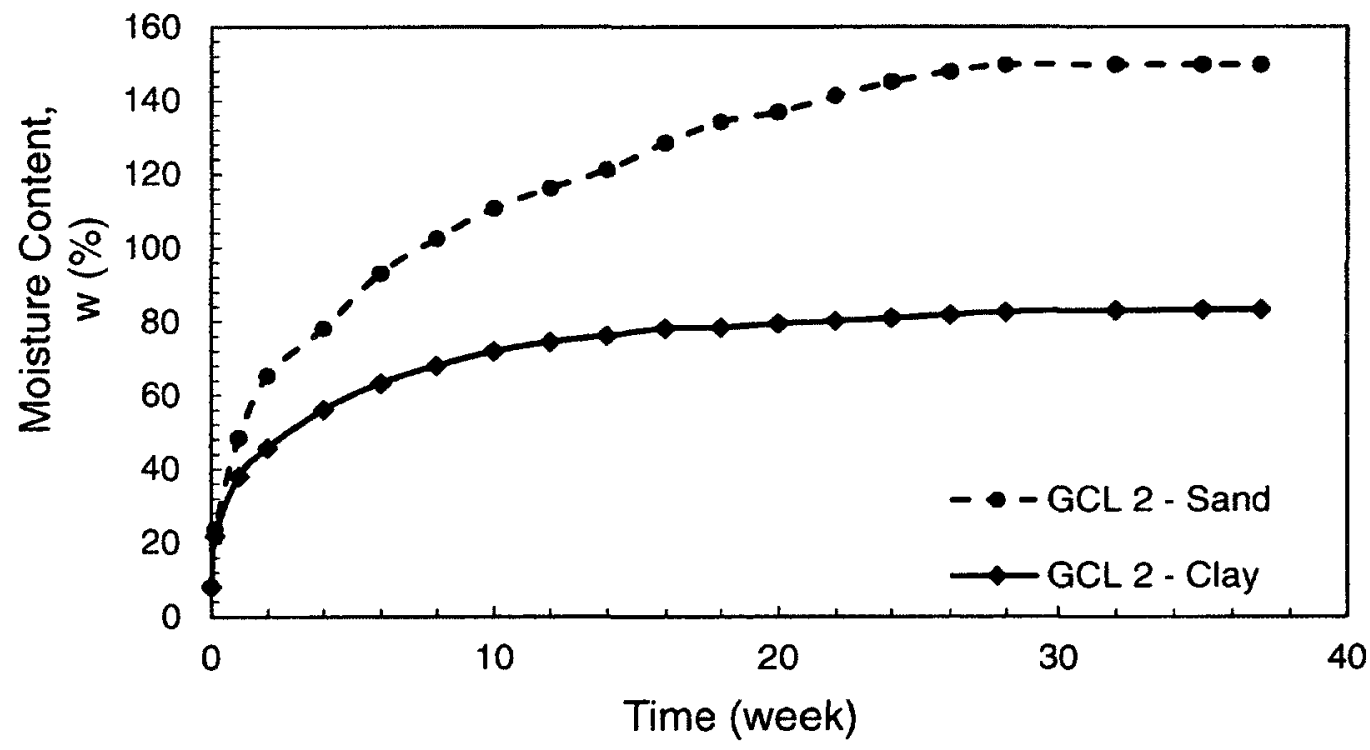

Figure 3.12 Effect of subsoil grain size distribution on GCL hydration

\subsubsection{Comparison with results of previous studies}

Chevrier et al., (2010) evaluated the rate of hydration of GCL specimens placed over sand subsoil with an initial moisture content of $12.5 \%$. The specimens were subjected to 
normal stresses of $7.0,9.9,14.1,21.2$ and $28.2 \mathrm{kPa}$ under isothermal conditions $\left(\mathrm{T}=20 \pm 2^{\circ} \mathrm{C}\right.$ ). Figure 3.13 compares the data derived in the present study with those of Chevrier et al., (2010). As previously noted, results from the present study complement those reported by Chevrier et al., (2010) indicating that there is little variation observed as the normal stress increases in the range of relatively high normal stresses. However, a meager decrease of equilibrium moisture content occurs due to the restriction on swelling of the GCL by the applied normal stress. Combining results from the two studies indicates that the equilibrium moisture content decreased by approximately $14 \%$ as the normal stress increased from 2 to $28.2 \mathrm{kPa}$. Rayhani et al. (2011) reported a higher rate of hydration for GCL specimens subjected to $2 \mathrm{kPa}$ normal stress compared to those hydrated under unconfined conditions. These studies substantiate the results of the present study indicating that increasing the normal stress results in much better contact between the GCL and the subsoil, and consequently higher rates of hydration.

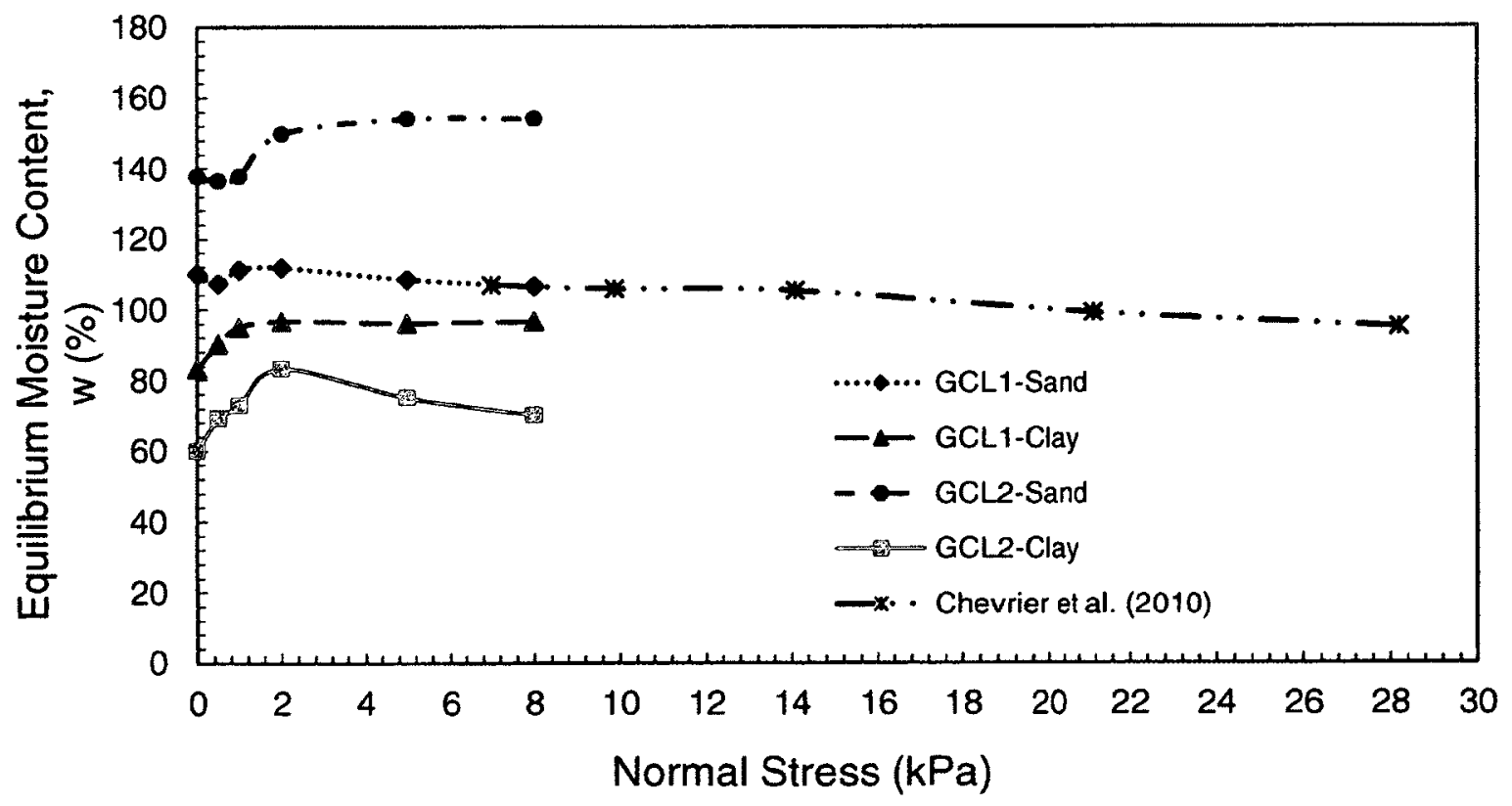

Figure 3.13 Comparison with results of previous studies 


\subsection{Summary}

The hydration of two different GCL products from subsoil pore water at room temperature (i.e. $22^{\circ} \mathrm{C}$ ) was examined under normal stresses ranging from 0 to $8 \mathrm{kPa}$. The results indicate a positive correlation between the rate of hydration and the normal stresses tested, which could be attributed to the better contact between the GCL and subsoil at the GCL-soil interface. GCL1 placed over sand subsoil while subjected to 8 $\mathrm{kPa}$ normal stress stabilized and attained equilibrium moisture content 16 weeks earlier compared to the condition without normal stress. The equilibrium moisture uptake was slightly increased for all experiments as the normal stress increased from 0 to $2 \mathrm{kPa}$. A meager decrease was observed as the normal stress increased from 2 to $8 \mathrm{kPa}$. For instance, the equilibrium moisture content for GCL1 in contact with sand subsoil decreased from about $112 \%$ to $106.5 \%$. This is attributed to the restriction imposed on the swelling of the GCL because of the normal stress. Nevertheless, the equilibrium moisture content of GCL 2 with sand subsoil had an insignificant increase from $149.7 \%$ to $154 \%$ ) as the normal stress increased from 2 to $5 \mathrm{kPa}$. Hence it might be concluded that the optimum normal stress would be between 2 to $5 \mathrm{kPa}$, resulting in the maximum equilibrium moisture content and an adequate rate of hydration. This level of stress can easily be provided by a typical Leachate Collection System (LCS) of solid waste landfills. Therefore, it is proposed that the LCS be constructed shortly after placement of the GCL to provide the sufficient normal stress for hydration. The LCS will also prevent the thermal exposure which could suppress the GCL hydration from the underlying subsoil. 
In order to validate the data, the results for the maximum water content $\left(w_{\text {ref }}\right)$ which GCLs could absorb while immersed in water were determined under similar normal stresses $(0-8 \mathrm{kPa})$. The normal stress applied to the GCLs is shown to have no significant influence on the maximum moisture which GCLs could absorb. This is mainly related to the fact that the swelling stress of GCLs controlled the normal stresses applied to them.

The GCL manufacturing techniques were also found to affect the rate of hydration. GCL1 and GCL2 attained normalized moisture contents of $72 \%$ and $38 \%$, respectively, while placed over clay subsoil $(\sigma=2 \mathrm{kPa})$. Hence, it might be concluded that the needle-punched and thermally treated connection layer and scrim-reinforced nonwoven carrier geotextile of GCL1 provided sufficient anchorage and much better hydration in comparison to GCL2.

The grain size distribution of the subsoil was also shown to affect both the rate of hydration and the equilibrium moisture content attained. Both GCLs placed over the sand subsoil achieved much higher equilibrium moisture uptakes and rate of hydration compared to the clay subsoil. This was attributed to the different levels of suction provided by the sand and the clay. Since sand has a lower suction compared to clay in unsaturated condition, there is a much higher difference between the suction of sand and the GCL at their interface. As a result, more water at a much higher rate is absorbed by the GCL placed over sand subsoil compared to the clay subsoil. 


\section{CHAPTER: 4 SHRINKAGE OF THE GCL UNDER SIMULATED}

\section{THERMAL CYCLES}

\subsection{Introduction}

The composite liners may be exposed to weather prior to deposition of the waste in the landfill. During this time, the temperature of the geomembrane may reach $70^{\circ} \mathrm{C}$ due to daily solar radiation (Pelte et al., 1994; Koerner and Koerner, 1995), which in turn can induce drying of the GCL panels. Drying isolated samples of GCL in the lab was shown to induce comparatively small maximum shrinkage of about $2 \%$ which is negligible compared to values observed in the field setting (3.3-30\%) (Thiel et al. 2006). Nevertheless, the subsequent drying and cooling cycles under field conditions could cause significant amounts of accumulated shrinkage, and separation of the GCL panels (Thiel et al. 2006).

The shrinkage data derived in previous studies demonstrate the expected effect of various factors on the shrinkage of GCLs subjected to severe thermal cycles (Rowe et al., 2011a). These experiments, however, did not represent field conditions since the GCL samples were not in close contact with subsoil and they were watered directly during the cooling cycle over a pan. Therefore, the objective of this chapter is to investigate the shrinkage of the GCL under simulated field conditions where the hydration of the GCL is influenced by hydraulic reaction of the subsoil and GCL, as well as the initial moisture content of the subsoil. The effects of initial moisture content and the aspect ratio of GCL specimens on the maximum shrinkage of GCLs are also discussed. 


\subsection{Material Properties}

\subsubsection{Geosynthetic Clay Liners}

Three types of GCLs with differences in index properties, including carrier geotextile, layer connection, and average peel strength were investigated in this study (Table 4.1). All GCLs consisted of a core of granular sodium bentonite clay with similar variations in smectite content ranging from 50 to $58 \%$. GCL1 and GCL3 had both fine grained bentonite with $D_{50}$ of $0.35 \mathrm{~mm}$ while GCL2 had coarse grained bentonite with $\mathrm{D}_{50}$ of nearly $1.0 \mathrm{~mm}$. Grain size distributions for the GCLs bentonite were reported by Rowe et al. (2011a). GCL1 and GCL 3 had similar swell and plasticity indices of $24 \mathrm{ml} / 2 \mathrm{~g} \mathrm{~min}$. and 216\% (ASTM D 4318), respectively. GCL2 had a swell index of $23 \mathrm{ml} / 2 \mathrm{~g} \mathrm{~min}$. and plasticity index of $262 \%$

Table 4.1 Properties of GCLs Examined

\begin{tabular}{|c|c|c|c|c|c|c|c|}
\hline \multirow[t]{2}{*}{ GCL } & \multirow{2}{*}{$\begin{array}{c}\text { Total dry } \\
\text { mass/area } \\
(\mathrm{g} / \mathrm{m} 2)\end{array}$} & \multicolumn{2}{|c|}{ Carrier GT } & \multicolumn{2}{|c|}{ Cover GT } & \multirow{2}{*}{$\begin{array}{c}\text { Connection } \\
\text { Layer }\end{array}$} & \multirow{2}{*}{$\begin{array}{c}\text { Average } \\
\text { peel } \\
\text { strength } \\
(\mathrm{N})^{*}\end{array}$} \\
\hline & & Type & $\begin{array}{c}\text { Mass } \\
(\mathrm{g} / \mathrm{m} 2)\end{array}$ & Type & $\begin{array}{c}\text { Mass } \\
(\mathrm{g} / \mathrm{m} 2)\end{array}$ & & \\
\hline 1 & $3312-4006$ & SRNW & $230-253$ & NW & $200-224$ & NPTT & $260 \pm 17$ \\
\hline 2 & $4499-5295$ & $\mathrm{~W}$ & $120-130$ & NW & $260-280$ & NP & $204 \pm 35$ \\
\hline 3 & $4555-4988$ & $\mathrm{~W}$ & $120-130$ & NW & $210-250$ & NPTT & $94 \pm 16$ \\
\hline
\end{tabular}

W = Woven, $\mathbf{N W}=$ Nonwoven, SRNW $=$ Scrim reinforced nonwoven, $\mathrm{NP}=$ Needle punched, $\mathrm{NPTT}=$ Needle punched \& thermally treated; *Tests performed by M. Hosney, Queen's University

\subsubsection{Soil Properties}

Ordinary construction sand (SP in USCS classification system, ASTM D2487), and Ontario Leda clay (CL) from the Navan landfill near Ottawa, Ontario, Canada were 
utilised as the subsoil to conduct shrinkage analysis. The maximum dry density was found to be 1.68 and $1.43 \mathrm{Mg} / \mathrm{m}^{3}$ at the optimum gravimetric moisture contents of $10 \%$ and $28.3 \%$ for the sand (SP) and Clay (CL), respectively, in accordance with the Standard Proctor test (ASTM D698). The sand (SP) was non-plastic, and contained approximately 5\% fines passing through the $0.075 \mathrm{~mm}$ sieve. The clay (CL) had a plasticity index of 21.6\% (ASTM D4318). The particle size distributions and the Water Retention Curves (WRCs) for both subsoils are demonstrated in Figure 4.1 (ASTM D 422) and Figure 4.2 (Geostudio, 2007 and Taha, 2010), respectively.

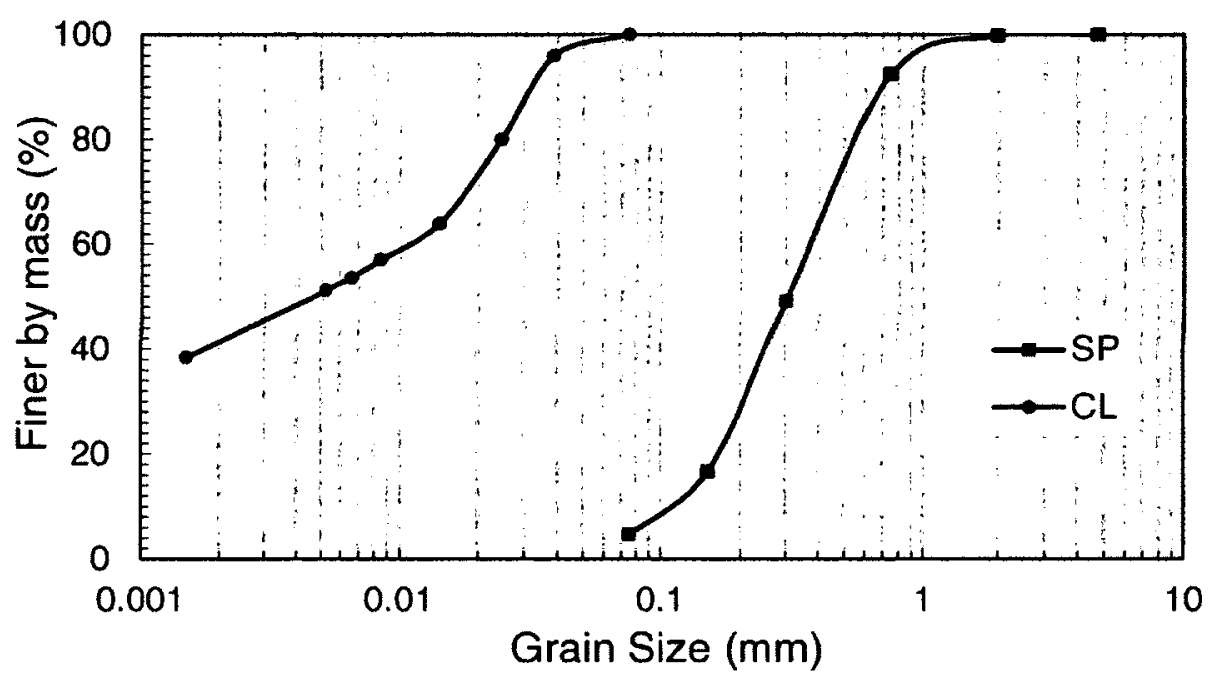

Figure 4.1 Grain size distributions for the subsoils examined 


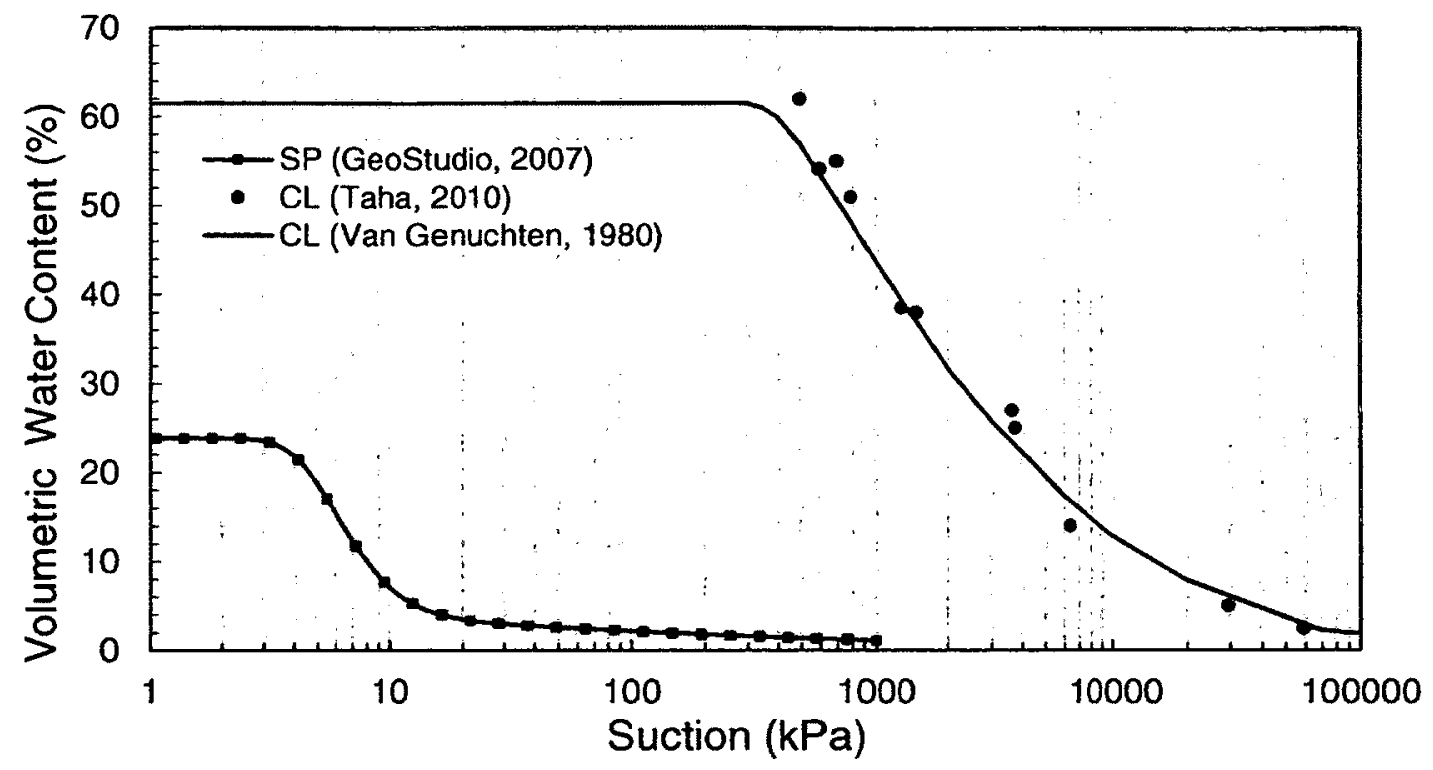

Figure 4.2 Water Retention Curves (WRCs) for the subsoils examined

\subsection{Experimental method}

\subsubsection{Model preparation}

Rectangular wooden containers with internal dimensions of $650 \times 300 \times 300 \mathrm{~mm}$ and $1520 \times 300 \times 300 \mathrm{~mm}$ were utilized to investigate the shrinkage of GCL specimens under simulated daily thermal cycles. The former was utilized for experiments with the Aspect Ratio (AR) of 2.3 while the latter was used for those with an AR of 5. The aspect ratio was defined as the ratio of the length (L) to the width (W) of the GCL specimen, i.e. $\mathrm{AR}=\mathrm{L} / \mathrm{W}$. The model containers were insulated with fibreglass in order to simulate the vertical 1-D heat transfer in landfill conditions which occurs due to solar radiation. In order to prevent the escape of water outside the container, rubber membrane was stretched inside the soil containers.

Tap water with a calcium concentration of $40 \mathrm{mg} / \mathrm{l}$ was used to moisten the dried sand (SP) and clay (CL). The moisture content of the subsoil was set at $2 \%$ more than the 
optimum gravimetric moisture content, i.e. $\mathrm{w}_{\mathrm{opt}}+2 \%$. This water content was used to simulate the moisture content utilized in the construction of barrier systems of typical solid waste landfills. Hence the initial moisture content of the sand and clay subsoils was $12 \%$ and $30 \%$, respectively. The sand was compacted into the container in five layers with a final height of $250 \mathrm{~mm}$, and a dry density of $1.51 \mathrm{Mg} / \mathrm{m}^{3}$, i.e. a dry density equivalent to $90 \%$ of the maximum dry density $(\rho d(\max ))$. Similarly, the clay was compacted into the container to a dry density of $1.29 \mathrm{Mg} / \mathrm{m}^{3}$. Afterwards, the containers were closed, sealed, and left for 24 hours in order that the soil cures and attains moisture equilibrium.

GCL specimens with dimensions of $710 \times 300 \mathrm{~mm}$ and $1600 \times 300 \mathrm{~mm}$ were cut from the roll for the experiments with $A R=2.3$ and $A R=5$, respectively. $A$ border was drawn around all sides of the specimens to outline an area of interest of $600 \times 270 \mathrm{~mm}$ and $1350 \times 270 \mathrm{~mm}$ for the specimens with $A R=2.3$ and $A R=5$, respectively. The length of the area of interest for the specimens with the aspect ratio of 2.3 was divided by vertical lines at $100 \mathrm{~mm}$ intervals which were numbered from 1 to 7 (Figure 4.3a). Similarly, the specimens with the aspect ratio of 5 were divided by 10 vertical lines with $150 \mathrm{~mm}$ spacing (Figure 4.3b). This was done in order to measure the value of shrinkage of the specimens along the transverse direction while subjected to daily thermal cycles. The initial length of the vertical lines was approximately $270 \mathrm{~mm}$. 


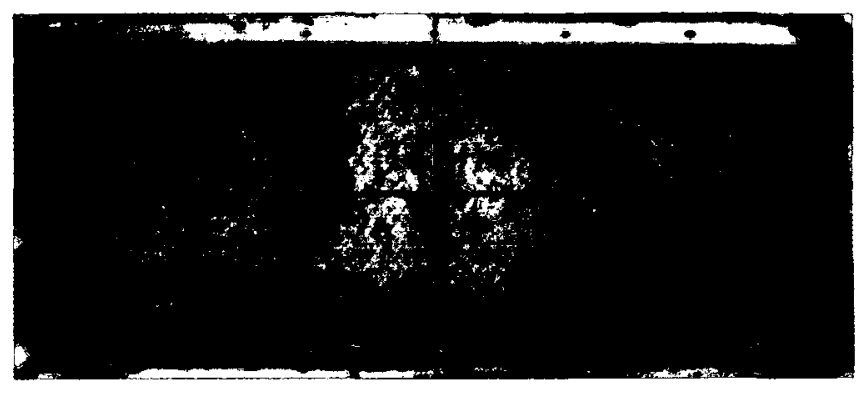

a)

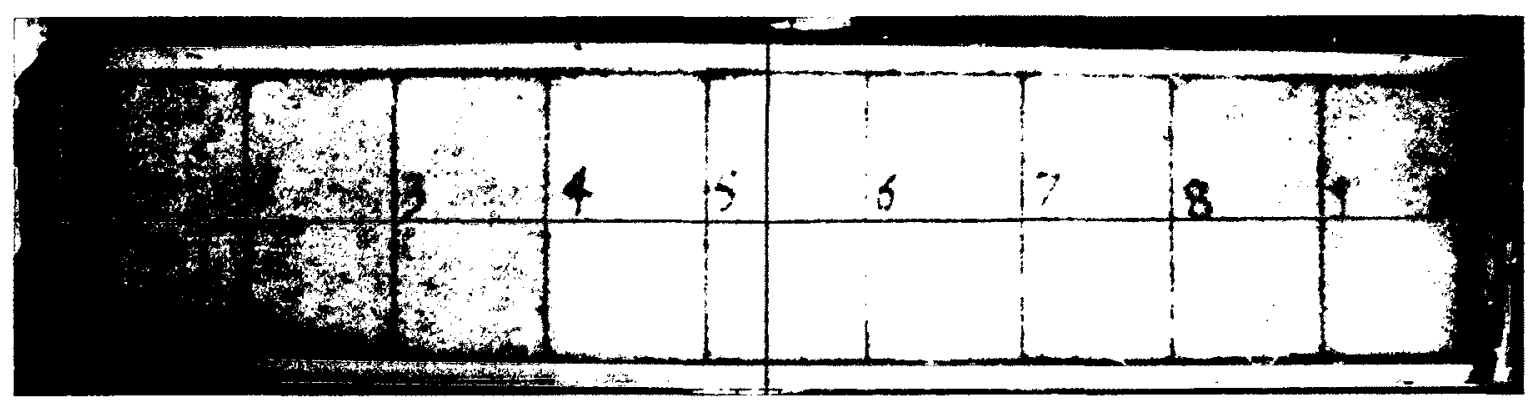

b)

Figure 4.3 Geometry of the experimental model utilized for the evaluation of GCL shrinkage; a: $A R=2.3, b: A R=5$.

In order to hydrate the GCL specimens, sufficient water was sprayed uniformly over the GCL specimens using a commercial garden sprayer so that the specimens would reach the required initial normalized moisture content $\left(\mathrm{w} / \mathrm{w}_{\mathrm{ref}}\right)$. The $\mathrm{GCL}$ specimens were then wrapped in a plastic bag, and left for 24 hours to attain moisture equilibrium. The boxes were opened after 24 hours in order to place the GCL samples over the subsoils. All samples were restrained at both ends along the vertical direction to simulate field conditions where panels of GCLs are anchored at either end. Details of the initial normalized moisture content $\left(w / w_{\text {ref }}\right)$ and the aspect ratio of the GCL specimens along with the type of subsoils and their initial moisture content are given in Table 4.3. 


\subsubsection{Monitoring}

5TM sensors were used to measure the moisture content and temperature profile of the subsoil during the heat-cool cycles. Capacitance/frequency domain technology is used by the 5TM sensor to measure the dielectric constant and, hence, the moisture content of the soil. The errors associated with soil salinity are minimized by signal filtering (Decagon Devices, Inc.). The sensors were embedded within the soil at different depths, and connected to the computer via a data logger (Table 4.2). In order to verify the temperature data derived from the 5TM sensors, thermocouples were also utilized to measure the temperature at the same depths at which the 5TM sensors were placed. Also, the temperature of the headspace on top of the GCL was measured by an additional thermocouple to control the heat transferred to the $\mathrm{GCL}(\mathrm{Z}=0 \mathrm{~mm})$. The container was finally closed and sealed with a transparent Plexiglas (with a thickness of $10 \mathrm{~mm}$ ) in order to conduct the test in a closed system. This was intended to represent a GCL underlain by a geomembrane which is subjected to thermal cycles in solid waste landfills. The geometry of the containers is demonstrated in Figure 4.4. 
Table 4.2 Location of the TM probes embedded within the subsoil

\begin{tabular}{|c|c|c|c|}
\hline $\begin{array}{c}\text { TM } \\
\text { Probe }\end{array}$ & $\begin{array}{c}\mathbf{X}(\mathbf{m m}) \\
(\mathbf{A R = 2 . 3 / A R = 5 )}\end{array}$ & $\begin{array}{c}\mathbf{Y}(\mathbf{m m}) \\
(\mathbf{A R = 2 . 3} \\
\mathbf{\&} \mathbf{A R = 5})\end{array}$ & $\begin{array}{c}\mathbf{Z} \\
(\mathbf{m m})\end{array}$ \\
\hline 1 & $325 / 760$ & 150 & 10 \\
\hline 2 & $325 / 760$ & 150 & 30 \\
\hline 3 & $325 / 760$ & 150 & 60 \\
\hline 4 & $325 / 760$ & 150 & 125 \\
\hline 5 & $325 / 760$ & 150 & 240 \\
\hline
\end{tabular}

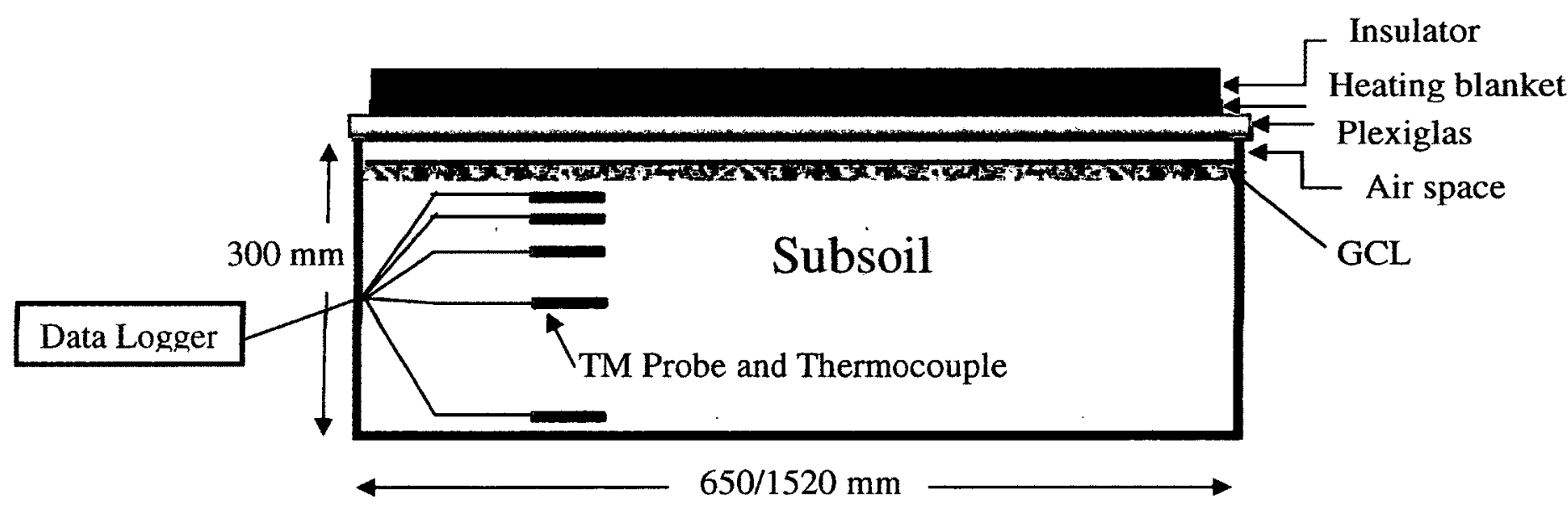

Figure 4.4 Schematic of the containers used for evaluation of shrinkage under simulated daily thermal cycles

\subsubsection{Experimental procedure}

To simulate daily thermal cycles, a heating blanket was placed over the Plexiglas. The heating blanket was set at a temperature of $60^{\circ} \mathrm{C}$. Heat was applied to the surface of the Plexiglas for 8 hours, which increased the temperature of the air trapped on top of the GCL. Sufficient thermal gradient was provided since heat was only applied from the top of the model, and the container was placed on the floor (approximately, there was a 
constant temperature of $20^{\circ} \mathrm{C}$ at the bottom of the container). The heating blanket was then removed, and the whole system was left at room temperature $\left(22^{\circ} \mathrm{C}\right)$ for 16 hours to simulate a typical overnight cooling cycle under field conditions. Hence, a total cycle lasted 24 hours. The heating temperature of $60^{\circ} \mathrm{C}$ represents the typical temperature which could be generated in a black geomembrane due to exposure to solar radiation (Thiel et al., 2006).

\subsubsection{Shrinkage analysis}

In order to measure the shrinkage of the GCL specimens along the transverse direction, measurements were carried out along the numbered vertical grids. No shrinkage was expected nor observed along the length of the specimens due to the anchorage at both ends. The GCL specimens were only visible through the Plexiglas after the drying portion of the heat-cool cycle. Condensed water beneath the Plexiglas after the cooling portion obscured the GCL specimens. Hence, digital images were taken at specified times using a 10 megapixel digital SLR camera at the end of the drying portion of each daily thermal cycle. The camera was fixed to a stand above the containers. Photogrammetry technique was applied for shrinkage analysis. The length of the vertical grids was measured via digitizing the images using a commercial program (Grapher). The shrinkage of the GCL specimens was then calculated along the vertical lines by comparison with their initial lengths. 


\subsection{Results}

\subsubsection{Subsoil temperature profile}

5TM probes along with thermocouples were utilized to obtain the subsoil temperature profile, and also the temperature of the air trapped above the GCL specimen $(\mathrm{Z}=0 \mathrm{~mm})$. Figure 4.5 demonstrates the temperature profile of the sand (SP) subsoil for both the heating and cooling portions of the daily thermal cycles. The temperature of the subsoil after the heating portion was significantly higher compared to the cooling portion of the daily thermal cycles. In particular, the results indicated much higher temperature variation within the top $60 \mathrm{~mm}$ which ranged between 34 and $53.4^{\circ} \mathrm{C}$. A meagre temperature increase of $6^{\circ} \mathrm{C}$ was observed at a depth of $240 \mathrm{~mm}$ (the approximate bottom of the model container) due to accumulation of heat (Figure 4.6).

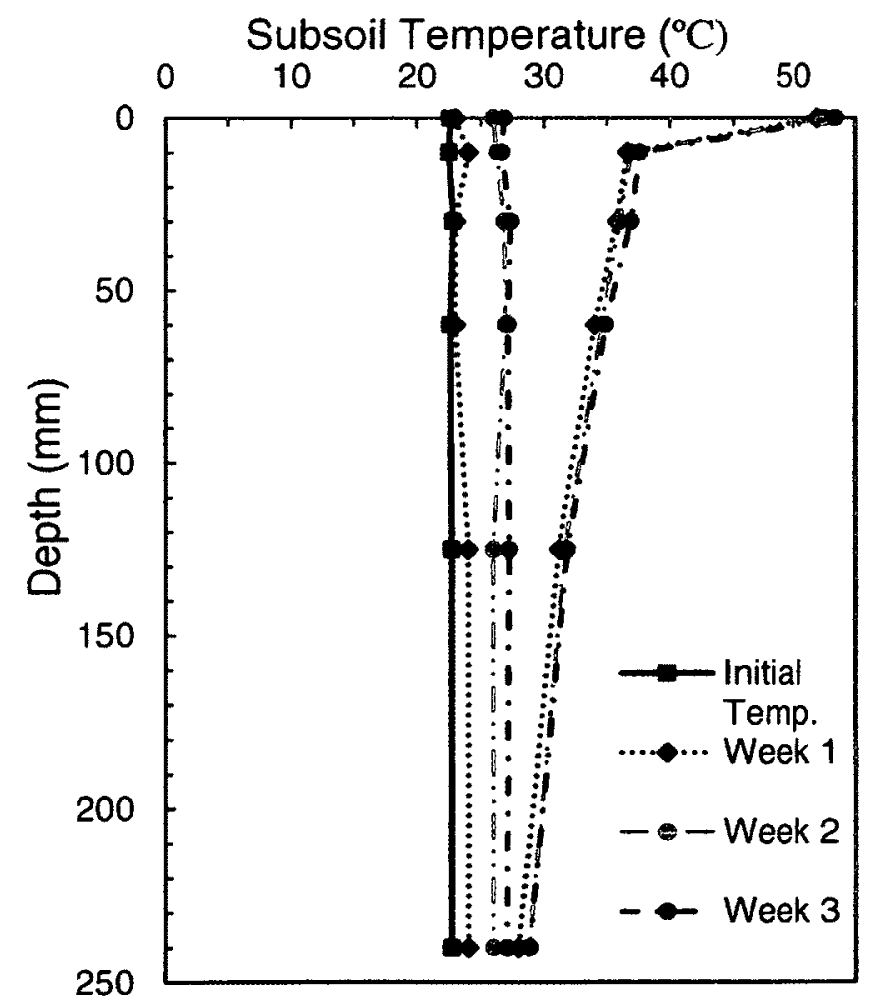

Figure 4.5 Profile of the temperature in sand (SP) subsoil $\left({ }^{\circ} \mathrm{C}\right)$ 


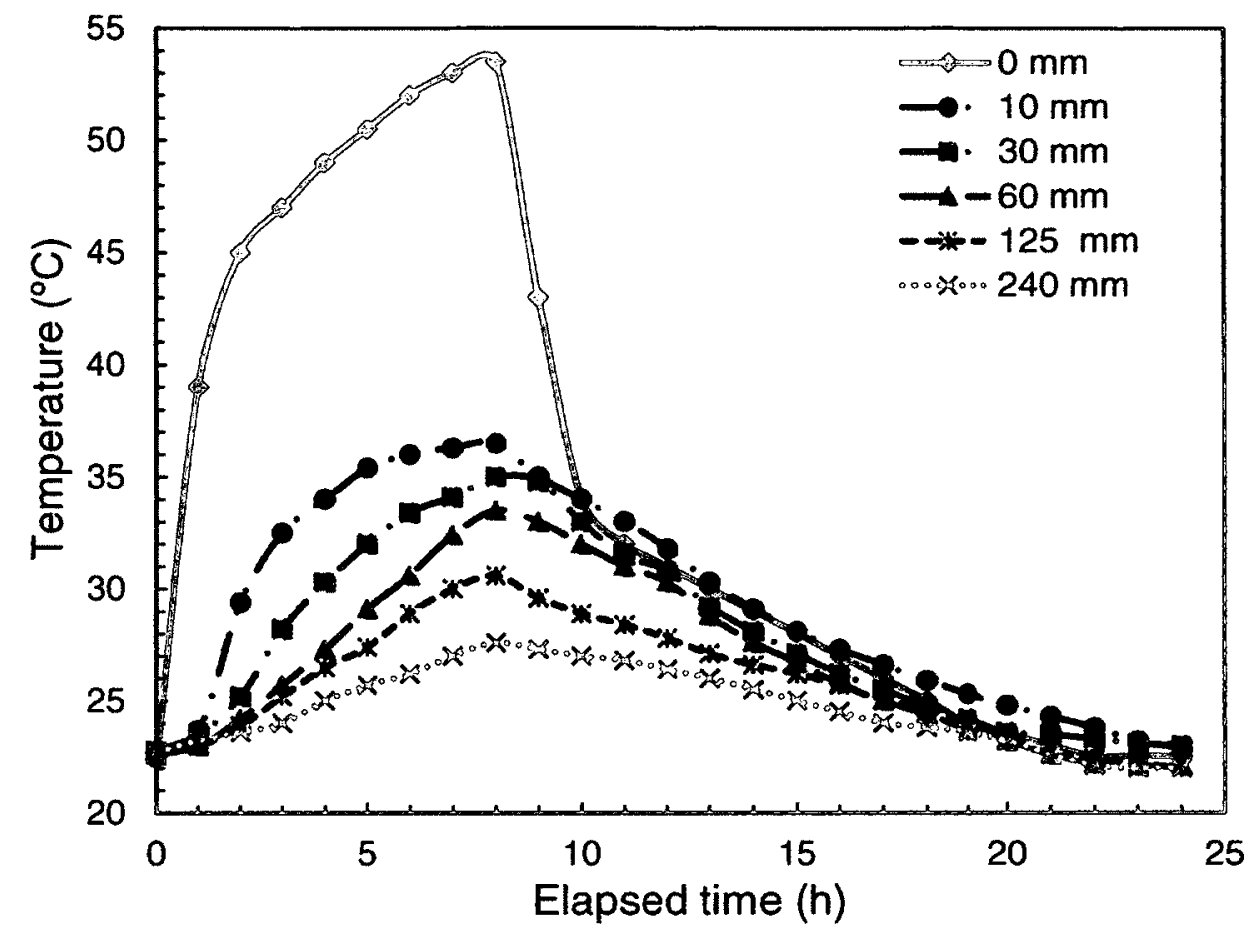

Figure 4.6 Applied temperature and temperature profile in sand (SP) subsoil during a thermal cycle

\subsubsection{Subsoil gravimetric moisture content profile}

5TM probes were also utilized to obtain the initial and final gravimetric moisture content profiles for the sand (SP) and clay (CL) subsoils. The final gravimetric moisture content profiles were derived when the daily thermal cycles were terminated. As shown in Figure 4.7, the gravimetric moisture content of the sand subsoil at depths below $60 \mathrm{~mm}$ decreased noticeably to an average of $6 \%$. This could be attributed to the grain size distribution and lower field capacity of the sand (SP) which in turn resulted in the downward movement of water within the subsoil. Thus, as could be expected, the gravimetric moisture content at the bottom of the container increased to approximately $18 \%$ for the sand (SP) subsoil. More notable is the fact that no significant variation was observed between the initial and final gravimetric moisture content of the clay (CL) 
subsoil. This could be related to the high field capacity of the clay (CL). Figure 4.8 demonstrates the profile of the gravimetric moisture content during a thermal cycle. As can be seen, the moisture content of the clay subsoil during the heating portion of the thermal cycle (0-8 hour) slightly increased due to downward transfer of the vapor moisture from the GCL to the subsoil.

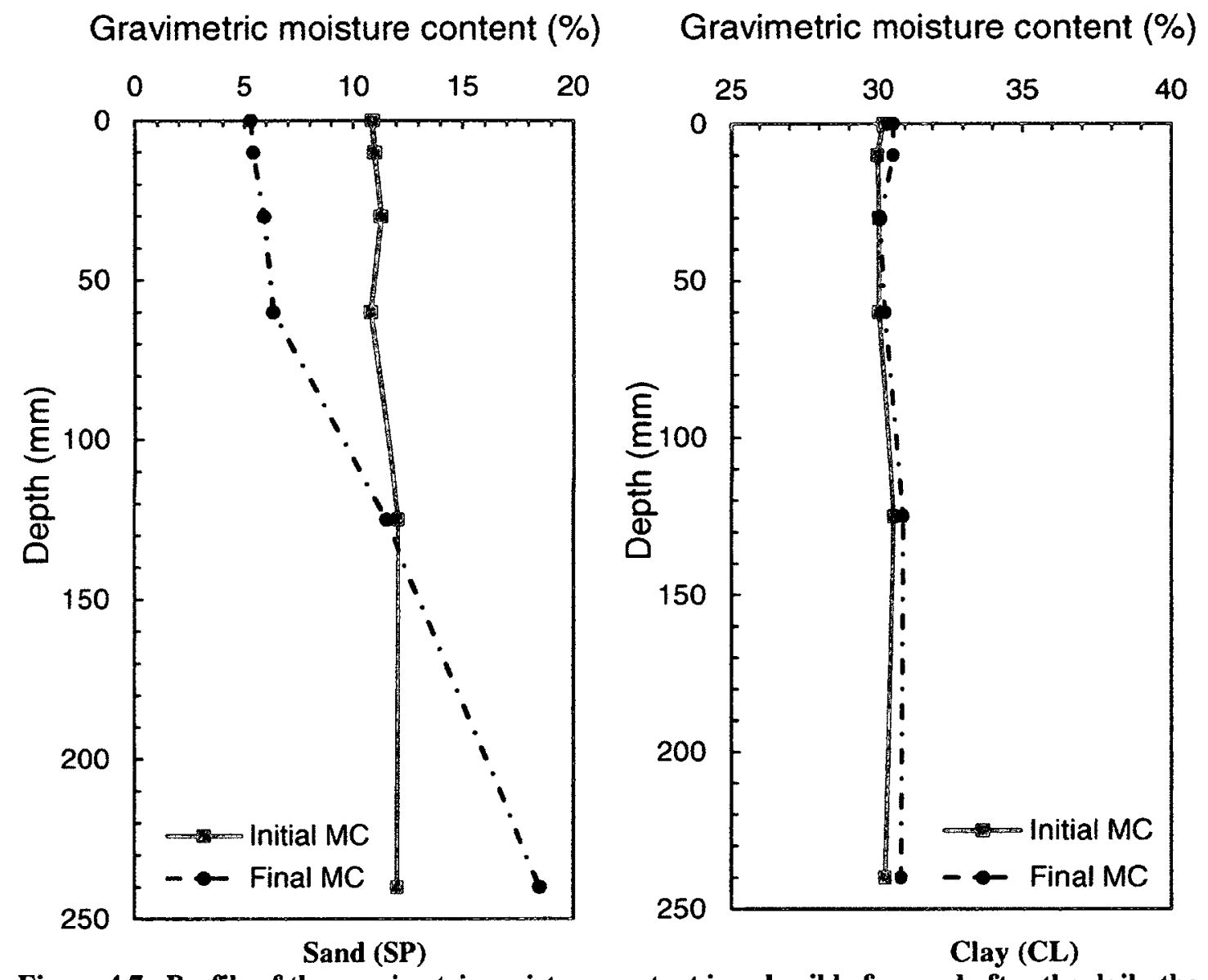

Figure 4.7 Profile of the gravimetric moisture content in subsoil before and after the daily thermal cycle 


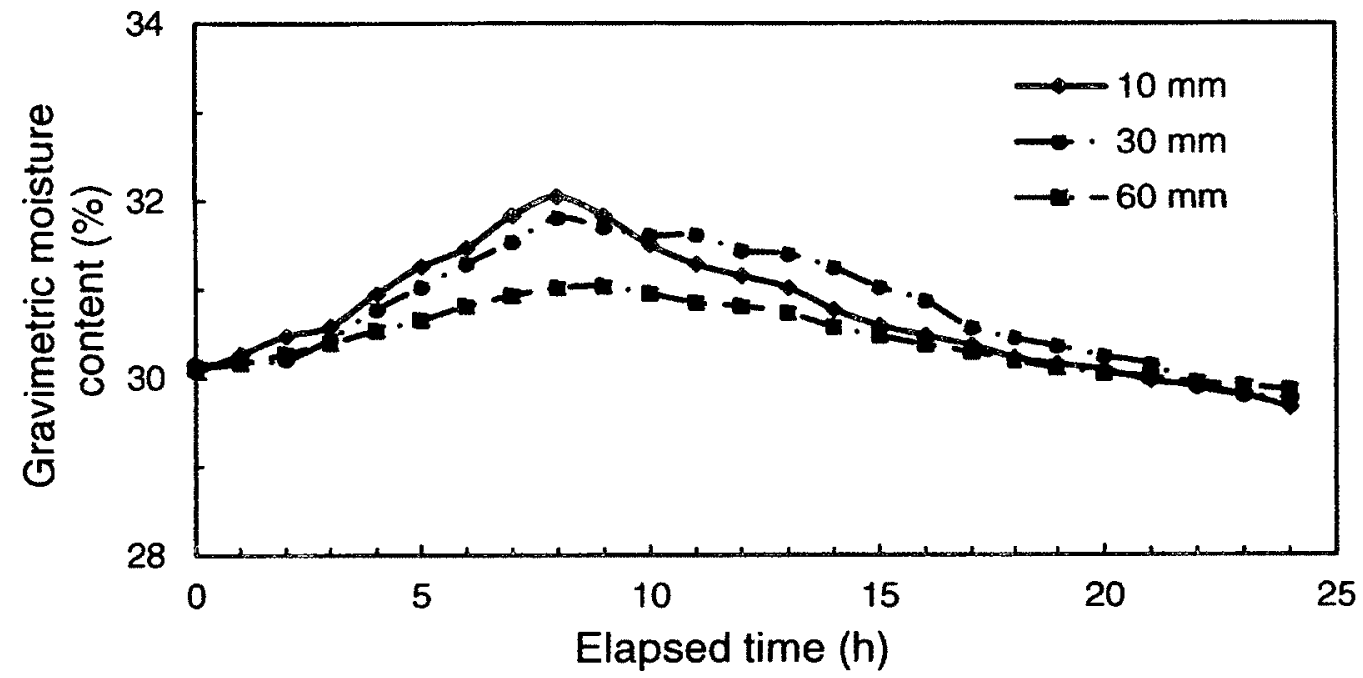

Figure 4.8 Profile of the gravimetric moisture content in clay (CL) subsoil during a thermal cycle

\subsubsection{Shrinkage of the GCL}

GCL specimens were subjected to daily thermal cycles until they attained equilibrium, i.e. their shrinkage leveled out. Figure 4.9 shows the shrinkage of GCL1 $\left(w / w_{\text {ref }}=25 \%\right.$, $\mathrm{AR}=5$ ) while placed over sand subsoil with an initial gravimetric moisture content of $12 \%$. Only the results for half of the specimen (grids $1,2,3,4$, and 5) were plotted due to symmetry of the shrinkage mirrored in the other half of the specimen. The shrinkage along the grids increased as the number of thermal cycles applied to the GCL specimens increased. In general, the maximum shrinkage was observed at the midpoint of the GCLs. The restraint induced by the clamps at either end prevented shrinkage along the grids adjacent to the clamps. As shown in Figure 4.9, no shrinkage was observed along grid 1 while grid 5 underwent the maximum equilibrium shrinkage of $5 \%$ for this experiment. 
This could be attributed to the minimum effect of the clamps on the shrinkage at the midpoint of the GCL specimens.

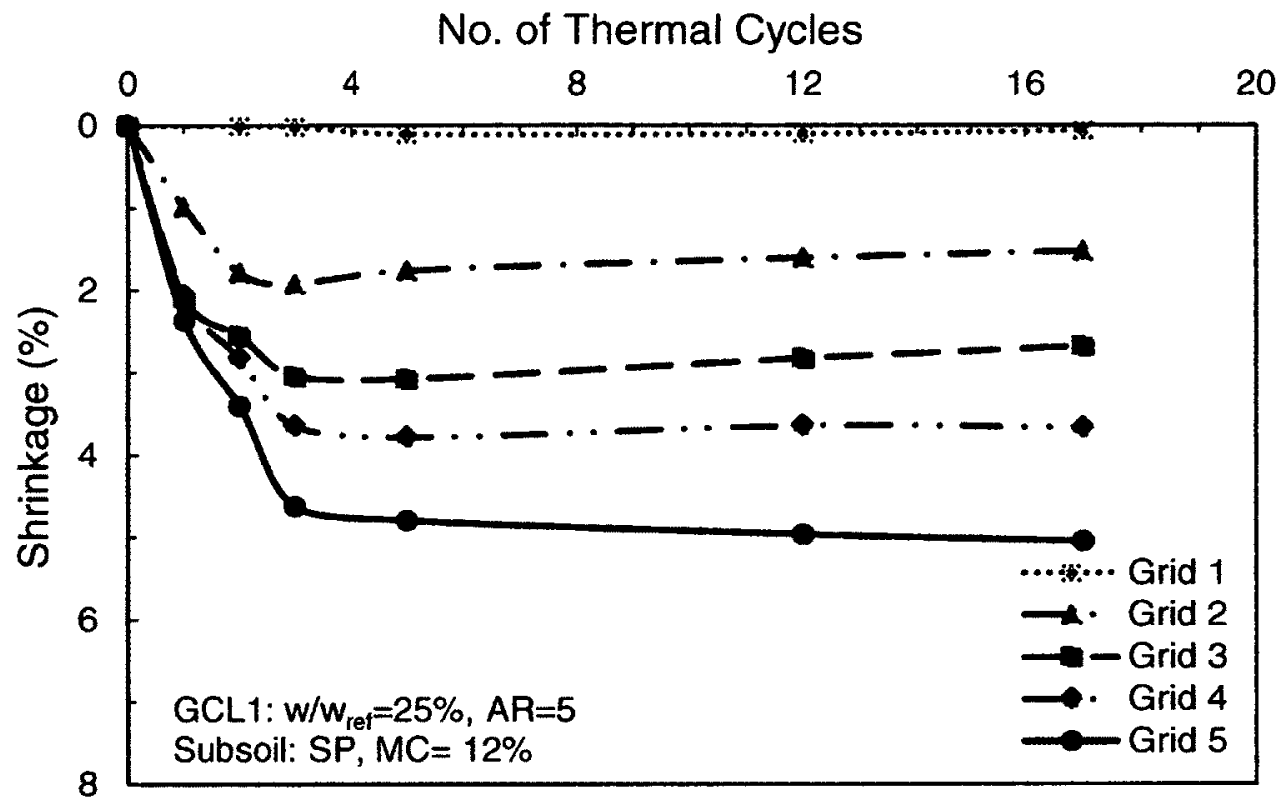

Figure 4.9 Shrinkage of GCL1 $\left(w / w_{\text {ref }}=25 \%, A R=5\right)$ under simulated thermal cycles, Subsoil: SP, $\mathrm{MC}=12 \%$

The experiments were conducted for GCLs with different initial properties while placed over different subsoils. The shrinkage values of GCL specimens after 3 days and 1 week of simulated daily thermal cycles, as well as the maximum shrinkage and number of thermal cycles to reach maximum shrinkage are reported in Table 4.3. All GCL specimens were hydrated to the initial normalized moisture content $\left(\mathrm{w} / \mathrm{w}_{\mathrm{ref}}\right)$ of $85 \%$ except for the specimen which had an initial normalized moisture content of $25 \%$. GCL specimens were measured for their final moisture contents after the termination of the daily thermal cycles. In the remainder of this chapter, the factors influencing the shrinkage of GCLs under the daily thermal cycles, including the GCL manufacturing techniques, their initial moisture content, aspect ratio, and grain size distribution of the 
subsoil along with its initial moisture content are evaluated and discussed. Also, the derived data are compared with those of previous studies.

Table 4.3 Details of experiments conducted for shrinkage analysis of GCLs under simulated daily thermal cycles.

\begin{tabular}{|c|c|c|c|c|c|c|c|c|c|c|}
\hline \multirow[b]{2}{*}{ Type } & \multicolumn{3}{|c|}{ GCL } & \multicolumn{2}{|c|}{ Subsoil } & \multicolumn{3}{|c|}{ Shrinkage (\%) } & \multirow{2}{*}{$\begin{array}{c}\text { No. of } \\
\text { Thermal } \\
\text { Cycles }\end{array}$} & \multirow{2}{*}{$\begin{array}{r}\text { Final } \\
\text { MC\% }\end{array}$} \\
\hline & $\begin{array}{c}\text { Initial } \\
*_{\mathbf{w}} / \mathbf{w}_{\text {ref }} \\
(\%)\end{array}$ & $\begin{array}{c}\text { Initial } \\
\text { MC } \\
(\%)\end{array}$ & AR & Type & $\mathbf{M C}$ & $\begin{array}{c}3 \\
\text { days }\end{array}$ & $\begin{array}{c}1 \\
\text { week }\end{array}$ & $\begin{array}{c}\text { Max. } \\
\text { Shrinkage }\end{array}$ & & \\
\hline 1 & 85 & 100 & 5 & Sand & 12 & 4.6 & 10.7 & 11.3 & 10 & 18.5 \\
\hline 1 & 85 & 100 & 5 & Sand & 3 & 5.9 & 11 & 11.2 & 9 & 20.2 \\
\hline 1 & 25 & 100 & 5 & Sand & 12 & 4.6 & 4.9 & 5.0 & 3 & 16.9 \\
\hline 1 & 85 & 100 & 2.3 & Sand & 12 & 2.1 & 6 & 8.1 & 10 & 17 \\
\hline 1 & 85 & 100 & 2.3 & Clay & 30 & 1.7 & 4.4 & 5.5 & 10 & 18 \\
\hline 2 & 85 & 187 & 2.3 & Sand & 12 & 9.1 & 14.9 & 14.6 & 7 & 23 \\
\hline 2 & 85 & 187 & 2.3 & Clay & 30 & 3.5 & 8.1 & 8.6 & 8 & 19.3 \\
\hline 3 & 85 & 127 & 2.3 & Sand & 12 & 10.6 & 14.8 & 14.7 & 6 & 20.3 \\
\hline
\end{tabular}

$* w / w_{\text {ref }}(\%)=$ normalized moisture content

\subsection{Analysis and Discussion}

\subsubsection{GCL manufacturing techniques}

It is well known that shrinkage and occurrence of gaps between GCL panels induced by daily thermal cycles clearly deteriorate the effectiveness of composite barrier systems. Rowe et al. (2011b) noted that the shrinkage of GCLs depends on the range of variation in their moisture content which occurs due to absorption of moisture from the subsoil along with loss of moisture during daily thermal cycles. Different methods utilized to manufacture GCLs have been shown to affect the degree of hydration and also the rate of absorption of moisture by the GCL from the underlying subsoil (Anderson et al., 2012; 
Rayhani et al., 2011; and Rowe et al., 2011b). Thus, this could also affect the shrinkage of GCLs subjected to daily thermal cycles. Particularly, manufacturing techniques of the GCLs have been shown to affect the Water Retention Curves (WRCs) of GCLs which define their hydration and shrinkage behavior (Beddoe et al., 2010 and 2011).

In order to investigate the role of manufacturing techniques on the shrinkage, GCLs 1, 2, and 3 were subjected to simulated daily thermal cycles. All GCL specimens had the aspect ratio of 2.3 , and were hydrated to $85 \%$ normalized moisture content $\left(w / w_{\text {ref }}\right)$. This was chosen since GCLs should be sufficiently hydrated in order to have the required hydraulic conductivity. The GCLs were placed over sand (SP) subsoil with an initial gravimetric moisture content of $12 \%$. Figure 4.10 demonstrates the evolution of shrinkage for the GCL specimens along the grid which had the maximum shrinkage compared to other grids. GCLl was found to undergo a maximum shrinkage of $8.1 \%$ which was approximately half that of the other specimens. Also, the rate of shrinkage for GCL1 was significantly less than that of the other specimens. As shown in Table 4.3, the shrinkage of GCL2 and 3 reached a plateau within 1 week of daily thermal cycles while it took 10 thermal cycles for GCL1 to stabilize. The shrinkage behavior of GCLs could be attributed to the different technique utilized in interlocking the carrier and cover geotextiles. Although all GCLs were initially hydrated to $85 \%$ normalized moisture content, GCL1 had the lowest initial gravimetric moisture content compared to the other GCL specimens. The final moisture content for all GCLs after the termination of daily thermal cycles was found to be approximately $20 \%$ (Table 4.3 ). Hence, it could be concluded that GCL1 experienced the smallest variation in moisture content during each thermal cycle which in turn resulted in the least shrinkage compared to the other GCL 
types. This is due to the fact that the better anchorage provided in GCL1 induced less swelling and as a result less moisture uptake during the cooling portion of the daily thermal cycles. GCLs 2 and 3 experienced similar amounts of shrinkage (14.6 and 14.7\%, respectively). The main difference in their manufacturing techniques was that the former used fine granular bentonite with a thermally treated connection layer while the latter had coarse granular bentonite with needle-punched connection layer. Hence, it might be inferred that thermal treatment of the connection layer alone may not guarantee less shrinkage in comparison to simply needle-punched GCLs.

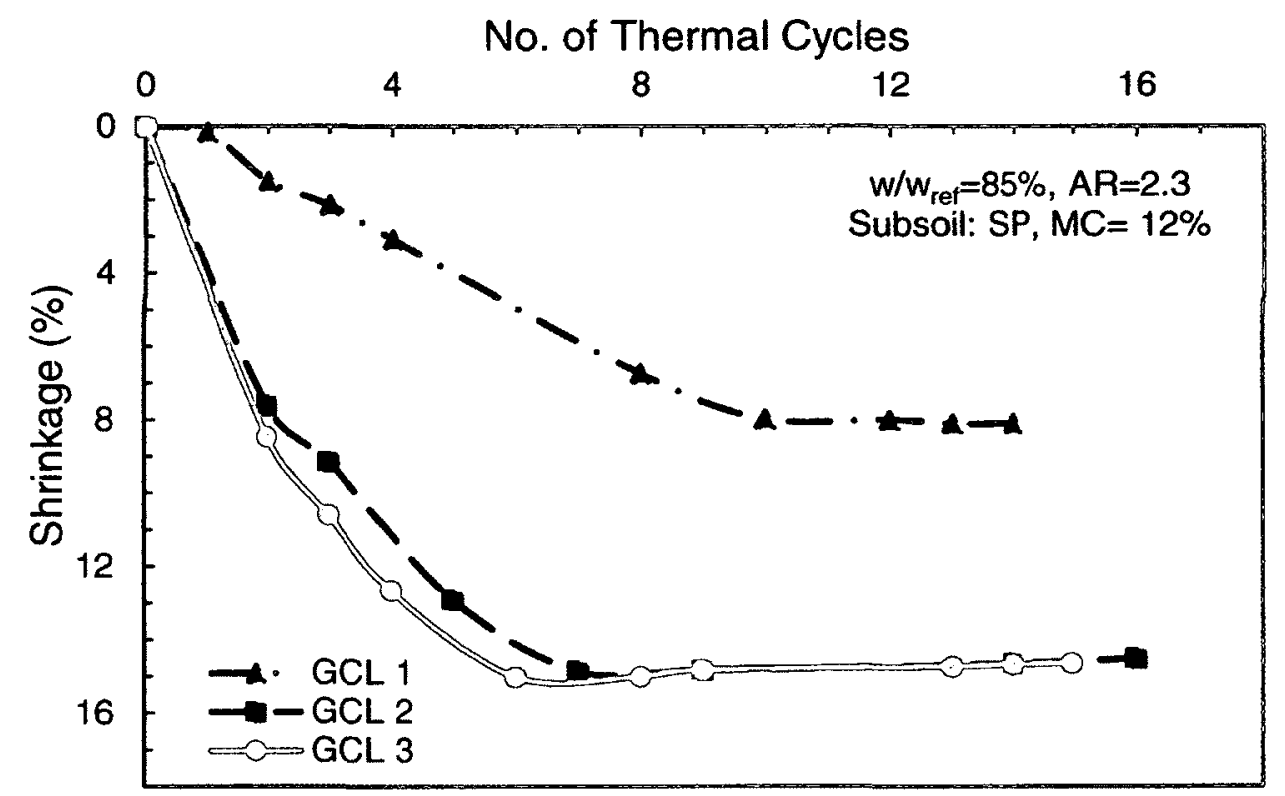

Figure 4.10 Effect of the manufacturing techniques of GCLs on maximum shrinkage

The better performance of GCL1 is consistent with the results reported by Rowe et al. (2011a) and Thiel et al. (2006), indicating that the thermally treated, needle-punched, and scrim-reinforced nonwoven GCL underwent less shrinkage compared to the needlepunched GCL with a simple nonwoven carrier geotextile. The maximum shrinkage 
measured in the current study $(8.1 \%)$ for GCL1 was found to be less than the values reported by Rowe et al. (2011a) (10.8\%) and Thiel et al. 2006 (12.8\%). This could be attributed to the difference in the GCL foundation conditions, which was placed over subsoil in this research but simply placed over a pan in the previous studies (Rowe et al., 2011a; and Thiel et al., 2006). The temperature of the subsoil was clearly lower than that of the pans placed in the oven. The frictional force induced by the subsoil could also hinder the movement and shrinkage of the GCL.

\subsubsection{GCL initial moisture content}

GCL rolls typically have different initial moisture contents when they are placed over subsoil. In some field conditions, they may also be watered and hydrated to the required initial moisture content. In order to investigate the effect of the initial moisture content on the potential shrinkage behavior of GCLs subjected to thermal cycles, the results derived for the GCL specimens hydrated to initial normalized moisture contents of $25 \%$ and $85 \%$ were juxtaposed for comparison. Specimens of GCL1 with aspect ratios of 5 were placed over sand subsoil with an initial gravimetric moisture content of $12 \%$. As shown in Figure 4.11 , increasing the initial normalized moisture contentfrom $25 \%$ to $85 \%$ resulted in much more accumulated shrinkage at the end of the daily thermal cycles. The former stabilized at a maximum shrinkage of $5 \%$ after 3 daily thermal cycles, while the latter underwent a maximum shrinkage of $11.3 \%$ after 10 cycles. This could be attributed to the fact that increasing the initial moisture content of the GCL specimens induced a much higher variation in moisture content during each daily thermal cycle which in turn caused much more shrinkage. The system was closed and sealed which augmented the effect of 
the initial moisture content on the maximum shrinkage of the GCLs. Similar results were also reported by Rowe et al. (2011a) in which an increase in the initial moisture content led to higher values of shrinkage after 5 thermal cycles.

The results could also be clarified by the WRCs of the GCLs. Beddoe et al. (2011) reported that the wetting path WRC and the drying path (which closely follows the wetting curve) will be a good combination to study the shrinkage behavior of GCLs. Interestingly, their results also showed that the aforementioned curves followed the same path, i.e. either of them could be utilized to analyze the wetting and dying portions of the thermal cycles. Considering the wetting path WRC for GCL1 derived by Beddoe et al. (2011), the corresponding initial suction in GCL1 for $85 \%$ and $25 \%$ initial normalized moisture content will be approximately 5 and $3000 \mathrm{kPa}$, respectively. Hence it could be concluded that the higher initial moisture content resulted in more variation of suction during each thermal cycle which in turn resulted in significantly more accumulated shrinkage.

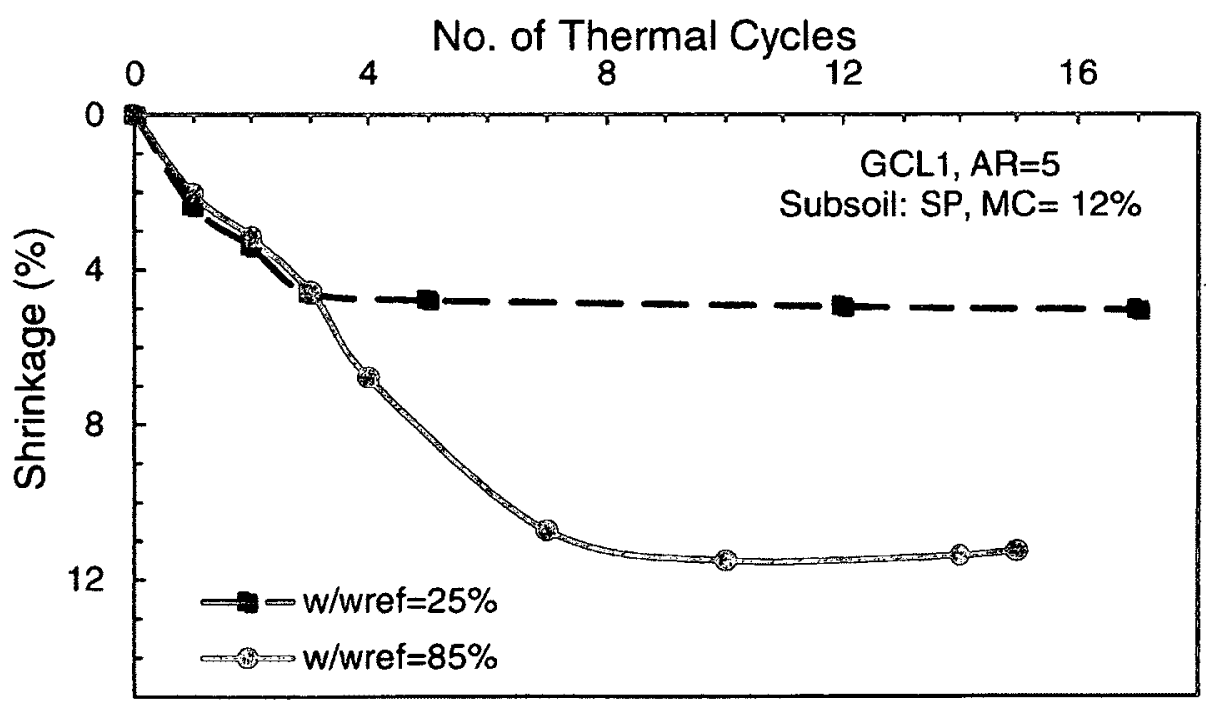

Figure 4.11 Effect of the initial normalized moisture content $\left(w / w_{r e f}\right)$ of GCLs on maximum shrinkage 
GCLs should be sufficiently hydrated before they are exposed to the waste to prevent the escape of contaminants. The final gravimetric moisture content for all GCL specimens was found to approximately $20 \%$ after the termination of the daily thermal cycles. Hence, it could be concluded that solar radiation could also significantly decrease the equilibrium moisture content of GCLs which in turn induces higher hydraulic conductivity of GCLs. Anderson et al. (2012) and Rowe et al. (2011b) investigated the effect of daily thermal cycles on the hydration of GCLs, indicating that the daily thermal cycles could significantly decrease the rate of hydration as well as the equilibrium moisture content of GCLs.

\subsubsection{GCL aspect ratio}

In general, the GCL panels normally utilized in solid waste landfills have an aspect ratio of 7 to 10 (Thiel et al. 2006). Bostwick et al. $(2010,2007)$ conducted a series of GCL shrinkage tests in ovens to evaluate the effect of aspect ratio on the maximum shrinkage of a coarse granular GCL which had nonwoven carrier and cover geotextiles needlepunched together. They reported that the maximum shrinkage of the GCL specimen with an aspect ratio of 10 was nearly $25 \%$ more than that of the specimen with an aspect ratio of 1.6, and that no significant difference was observed between the specimens with aspect ratios of 5 and 10 . This was attributed to the lessening of the effect of the restraint at the ends of specimens on hindering the movement and shrinkage at the midpoint for panels with higher value aspect ratios. Nonetheless, no data has been documented in the literature regarding the effect of aspect ratio on shrinkage of GCLs under thermal cycles when placed on subsoil in a closed system simulating field conditions. Thus, the results 
derived for two specimens of GCL1 with aspect ratios of 2.3 and 5 were compared in order to evaluate the potential effect of the aspect ratio on the maximum shrinkage of GCLs. Both GCL specimens were hydrated to an initial normalized moisture content of $85 \%$, and were placed over sand subsoil with an initial gravimetric moisture content of 12\%. As shown in Figure 4.12, there was a noteworthy increase in the maximum shrinkage from 8.1 to $11.3 \%$ as the aspect ratio increased from 2.3 to 5 . In other words, the required overlap to prevent panel separation for typical $4.5 \mathrm{~m}$ wide GCL panels with an aspect ratio of 2.3 and 5 would be approximately $360 \mathrm{~mm}$ and $500 \mathrm{~mm}$, respectively.

The maximum shrinkages of $8.1 \%(\mathrm{AR}=2.3)$ and $11.3 \%(\mathrm{AR}=5)$ in the current study are less than those reported by Bostwick et al. (2010) of 10.5\% (AR=1.6) and $13.4 \%(\mathrm{AR}=5)$. This could be attributed to the difference between the pan tests and the system utilized in the current study. Also, the fact that the type of the GCL in the present study is different from that of Bostwick et al. (2010) might be another plausible reason.

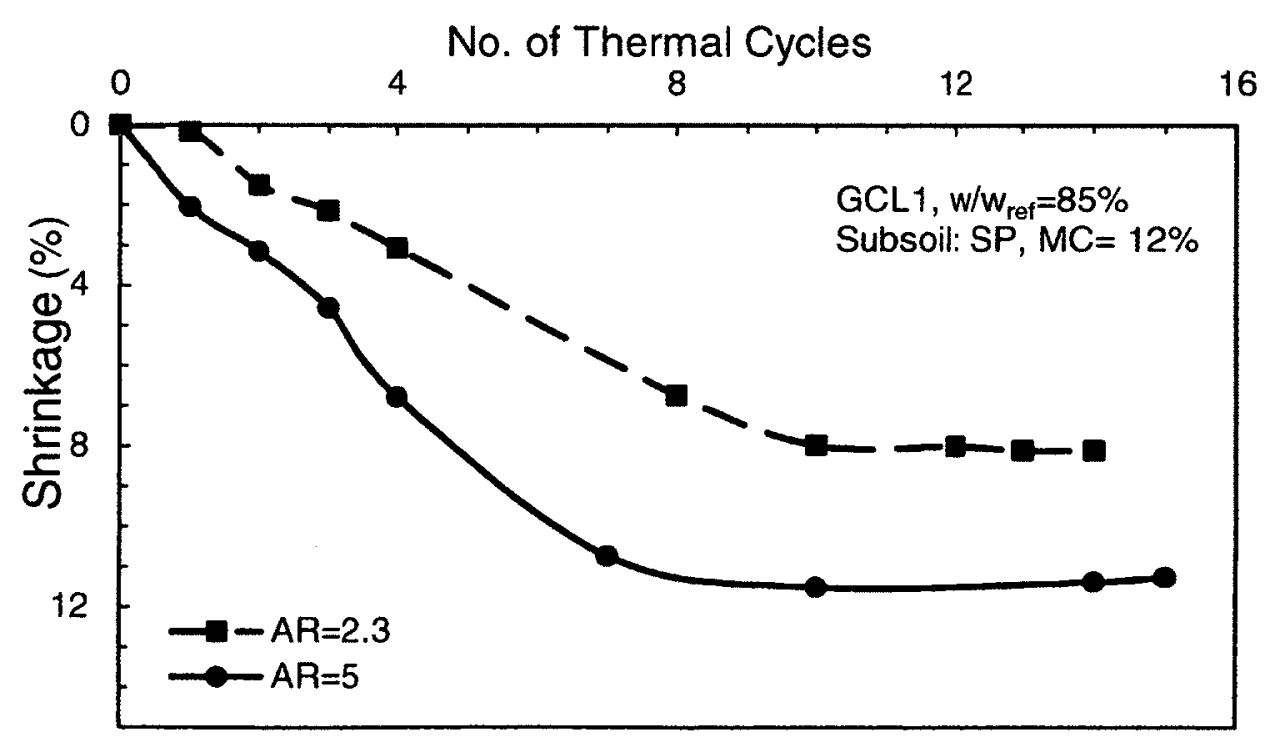

Figure 4.12 Effect of the aspect ratio of GCLs on maximum shrinkage 


\subsubsection{Subsoil grain size distribution}

The grain size distribution of the subsoil has been shown to affect the rate of hydration as well as the equilibrium moisture content of GCLs (Anderson et al., 2012; Chevrier et al., 2012; Rayhani et al., 2011; and Rowe et al., 2011). However, there is a paucity of data reported in the literature concerning the effect of the grain size distribution of subsoil on the shrinkage of GCLs. Figure 4.13 demonstrates the evolution of maximum shrinkage observed at the end of each thermal cycle for GCL1 ( $A R=2.3$, and $w / w_{\text {ref }}=85 \%$ ) placed over sand (SP) and clay (CL) subsoils with initial moisture contents of $12 \%$ and $30 \%$, respectively. The results indicated that the GCL specimen placed over sand subsoil experienced more shrinkage compared to the specimen placed over clay subsoil. The former was found to stabilize at the maximum shrinkage of $8.1 \%$ while the latter had the maximum shrinkage of $5.5 \%$ at the end of the daily thermal cycles. This could be explained by analysis of the hydration behavior of GCLs from the sand subsoil. The initial suction of sand is relatively lower than that of the clay during the hydration which occurs in the cooling portion of each daily thermal cycle (Figure 4.2). Hence the difference in suction between the GCL and sand subsoil is more than that of the GCLclay interface which causes much more moisture uptake during the cooling cycle. This would induce higher moisture variation during daily thermal cycles, which in turn causes much more accumulated shrinkage for the GCL placed over sand subsoil.

It should be noted that the results of pan tests conducted by Thiel et al. (2006) could also corroborate more shrinkage for a GCL placed over sand subsoil. Thiel et al. (2006) reported that a decrease in the volume of water added to GCL1 during each cycle from 
$500 \mathrm{ml}$ to $300 \mathrm{ml}$ (i.e. approximate reduction of normalized moisture content ( $\mathrm{w} / \mathrm{w}_{\mathrm{ref}}$ ) from $55 \%$ to $33 \%$ ) induced a decrease in the maximum shrinkage from $19.2 \%$ to $14.4 \%$ after 40 wet-dry cycles. However, Rowe et al. (2011a) demonstrated that increasing the moisture content of GCL1 at the beginning of each thermal cycle from $65 \%$ to $100 \%$ (i.e. approximate increase of normalized moisture content ( $\left.\mathrm{w} / \mathrm{w}_{\text {ref }}\right)$ from $55 \%$ to $85 \%$ ) did not significantly affect the maximum shrinkage. This could be elucidated by the wetting WRC given by Beddoe et al. (2011). That said, due to the logarithmic feature of the WRC and a lower slope in the high suction region, decreasing the moisture content of the GCL in higher suction values (i.e. lower moisture contents) caused significantly smaller suction cycles and lower shrinkage. Hence, it could be concluded that the GCL with sand subsoil is expected to undergo more shrinkage than that with clay subsoil provided that the sand subsoil has the sufficient moisture for hydration of the GCL in cooling portion of thermal cycles.

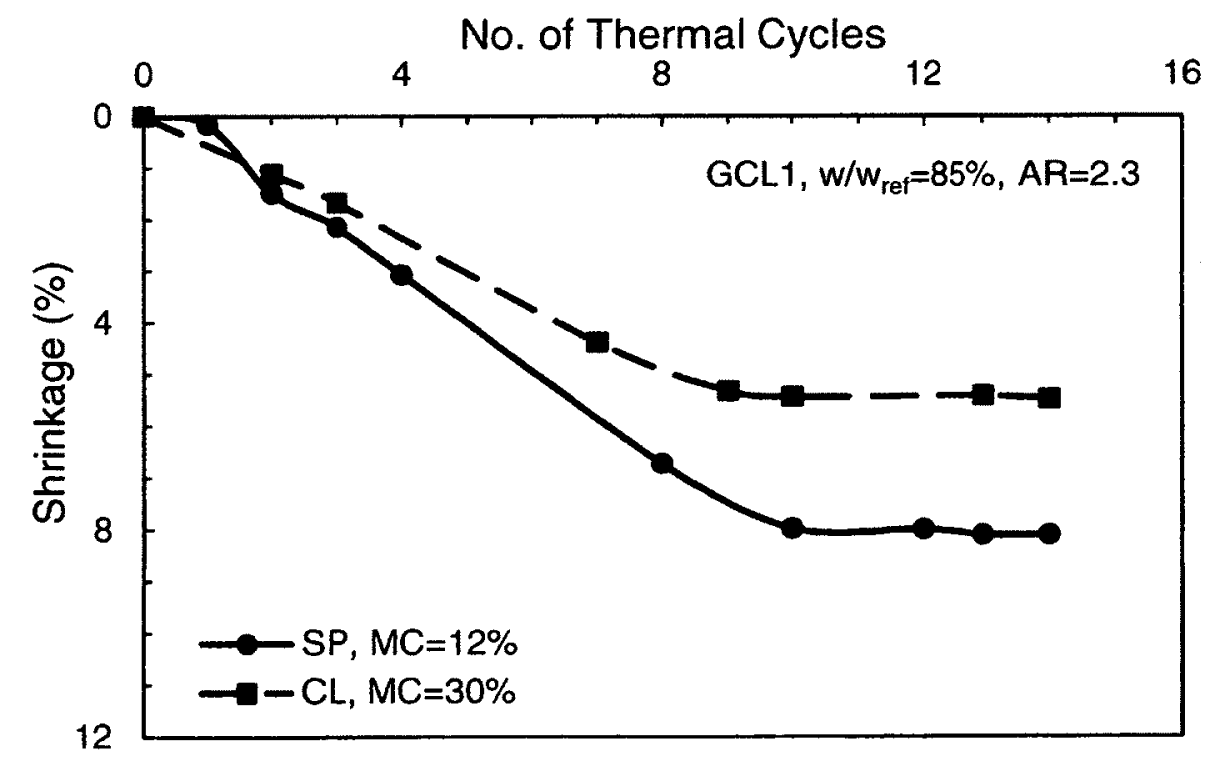

Figure 4.13 Effect of the grain size distribution of subsoil on maximum shrinkage 


\subsubsection{Subsoil initial moisture content}

The initial moisture content of the subsoil may vary based on the field conditions, i.e. the groundwater level, the type of subsoil, the weather conditions, etc. Hence the maximum shrinkage results obtained on sand subsoil with initial gravimetric moisture contents of $3 \%$ and $12 \%$ were compared to investigate the potential effects of the initial moisture content of the subsoil on the shrinkage of GCLs. Both GCL specimens (GCL1) were hydrated to an initial normalized moisture content of $85 \%$, and had an aspect ratio of 5 . As shown in Figure 4.14, no significant difference between the shrinkage of the GCL specimens was observed, and they both leveled out at the maximum shrinkage of approximately $11 \%$ (Table 4.3 ). This could be due to the low field capacity water content of the sand. The sand subsoil with a higher initial moisture content of $12 \%$ ended up at a final moisture content of approximately $5 \%$ near the soil surface. This moisture content is close to the initial moisture content used in the other experiment (3\%), leading to a small difference between the moisture contents of both subsoils. This shows that there was no significant difference in either experiment in terms of providing water for the GCL specimen during the cooling cycles which in turn induced no considerable change in the values of the shrinkage. 


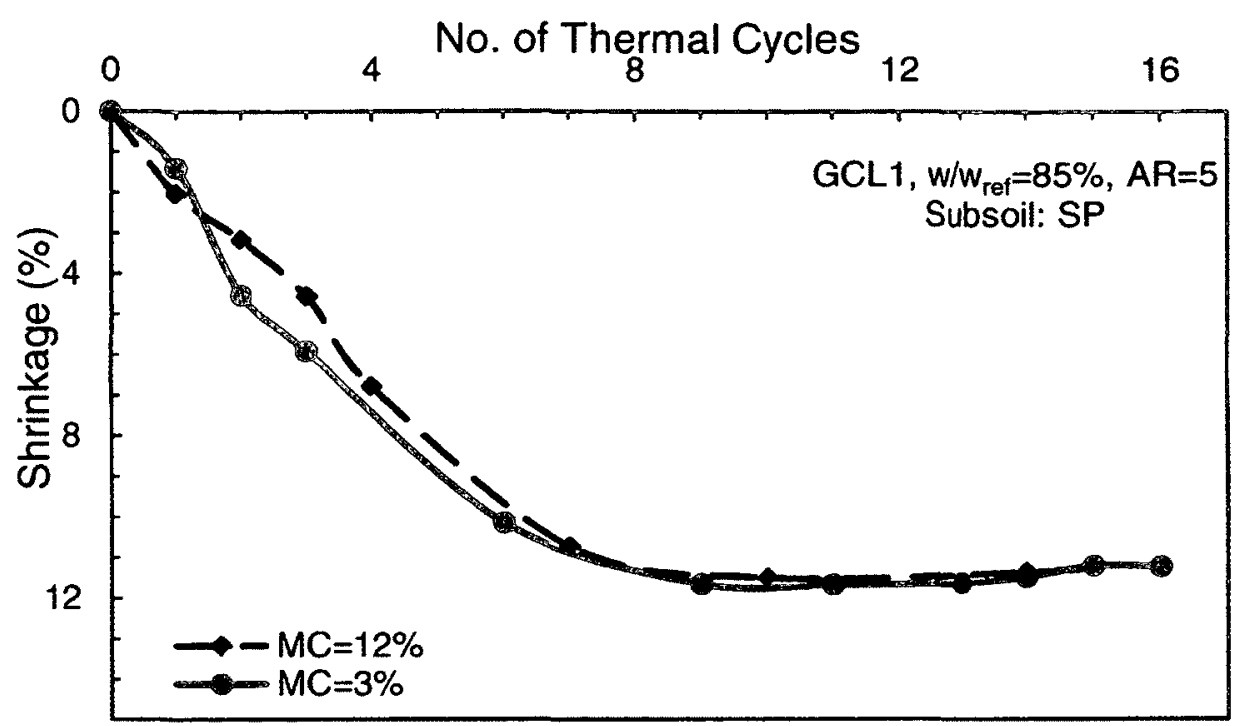

Figure 4.14 Effect of the initial moisture content of the subsoil on maximum shrinkage

\subsection{Summary}

A series of experimental models were utilized to evaluate the effect of daily thermal cycles on the shrinkage of three different GCL products placed in contact with different subsoils. The GCL specimens were subjected to the elevated temperature of $60^{\circ} \mathrm{C}$ for 8 hrs and subsequent cooling at room temperature for $16 \mathrm{hrs}$. This simulated the typical field conditions where the geomembrane placed over the GCL roll is exposed to solar radiation. The following conclusions were drawn from these experiments:

- The needle-punched and thermally treated GCL with scrim-reinforced nonwoven carrier geotextile (GCL1) experienced a maximum shrinkage of $8.1 \%$ which was significantly less (about $6.5 \%$ ) than that of the other two products (14.6-14.7\%). This could be attributed to the better of anchorage of GCL1 which limited the range of moisture variation in the GCL during the thermal cycles and, hence, limited the shrinkage of the GCL. 
- The initial moisture contentof the GCL significantly affected the maximum shrinkage under daily thermal cycles. The maximum shrinkage increased from $5 \%$ to $11.3 \%$ as the initial normalized moisture contentof GCL increased from $25 \%$ to $85 \%$. Higher variation of the moisture content associated with the specimens with higher initial moisture contentscould be considered as the reason for more shrinkage of the GCLs.

- Increasing the ratio of the GCL panel length to width (aspect ratio) could cause augmentation of the shrinkage. This could be due to the less effect of the clamps at either end in hindering the movement and shrinkage at the midpoint of the GCL panel.

- The grain size distribution of the subsoil could affect the maximum shrinkage due to the difference in moisture content variation during each daily thermal cycle. GCL1 with sand subsoil (SP) underwent more shrinkage (8.1\%) compared to the same GCL with Clay subsoil (CL) (5.5\%).

- The initial moisture content of the sand subsoil was found to have no significant influence on the maximum shrinkage of GCL with an initial normalized moisture content $\left(\mathrm{w} / \mathrm{w}_{\mathrm{ref}}\right)$ of $85 \%$. This could be attributed to the low field capacity moisture content of the sand. Increasing the initial moisture content of the subsoil from $3 \%$ to $12 \%$ did not seem to make any significant difference in the amount of the moisture available to the GCL and, consequently, the maximum shrinkage.

- The final gravimetric moisture content of all GCL specimens at the end of daily thermal cycles was found to be approximately $20 \%$ regardless of their initial moisture content. This shows the severe effect of thermal cycles on impeding the 
moisture uptake by the GCL which in turn reduces the hydraulic performance of the GCL. Thus, the liner should be covered by the cover soil or Leachate Collection System (LCS) shortly after its installation. This would prevent the loss of moisture as well as significant shrinkage of the GCL panels induced by solar radiation.

The values of shrinkage given in the current study indicate the potential effect of thermal cycles on the shrinkage of GCLs which is influenced by the GCL and subsoil properties. It should be noted that the results reported could only be considered for the careful design in composite landfill liners. This is due to the fact that there are many other factors which could affect the maximum shrinkage of GCLs, including the bentonite mass distribution (Bostwick et al. 2010) and the severity of field conditions. 


\section{CHAPTER: 5 CONCLUSIONS AND RECOMMENDATIONS}

\subsection{Summary and conclusions}

Geosynthetic Clay Liners are typically underlain by the geomembrane as part of a composite liner to prevent the escape of the contaminants from the solid waste landfills. The GCL should have a sufficient rate of hydration (moisture uptake) from the underlying subsoil in order to become adequately saturated prior to exposure to the leachate of the waste. This is attributed to the fact that higher moisture content of the GCL results in lower bulk void ratio and, hence, lower hydraulic conductivity. There are many factors which have been shown in the literature to affect the hydration of the GCL, including the GCL manufacturing techniques, grain size distribution of the subsoil, initial moisture content of the subsoil, etc. After the installation of the GCL, the liner is either covered by the cover soil or leachate collection system shortly after its installation or it may be exposed to weather for several months prior to being covered due to practical or economic issues. The normal stress provided by the overlying LCS and/or waste could affect the hydration behavior of the GCL. However, only a few studies have been conducted to evaluate this phenomenon. In this study, the hydration of two types of GCLs in contact with Sand (SP) or Clay (CL) subsoils while subjected to different normal stresses $(0-8 \mathrm{kPa})$ was investigated. The following conclusions were extracted from this study: 
- The rate of moisture uptake from the subsoil increased as the normal stress applied to the GCL increased from 0 to $8 \mathrm{kPa}$ due to improvement of contact intimacy at the GCL-subsoil interface. GCL1 with sand subsoil (SP, MC=12\%) under $8 \mathrm{kPa}$ normal stress was found to attain $62 \%$ gravimetric moisture content within one week of hydration while the unconfined specimen of the same GCL attained the moisture content of $36 \%$ within the same period. Furthermore, the optimum normal stress which could induce the maximum equilibrium moisture content as well as adequately high rate of hydration would be between 2 and $5 \mathrm{kPa}$.

- Scrim-reinforcement of the carrier geotextile along with the thermal treatment of the connection layer induced sufficient anchorage, and in turn better hydration. GCL1 underwent significantly higher rate of hydration in comparison to GCL2 which had simply-needle punched connection layer. Also, the normalized equilibrium moisture content $\left(w / w_{\text {ref }}\right)$ for GCL1 with clay $(C L)$ subsoil was found to be approximately twice that of the GCL2 under similar conditions for all levels of normal stress.

- The grain size distribution of the subsoil also affected the hydration behavior of the GCL. The GCL specimen with sand (SP) subsoil underwent considerably higher rate of hydration compared to those with clay (CL) subsoil. This is associated with the higher difference of suction at the GCL-sand interface than that of the GCL-Clay interface. 
On the other hand, the liner may be exposed to solar radiation and, therefore, thermal cycles for several months prior to being covered. Both laboratory investigations and case histories have demonstrated the shrinkage and separation of GCL panels under thermal cycles. However, there were considerable uncertainties pertaining to the factors affecting the shrinkage of GCLs while they are in close contact with subsoil. Therefore, a series of experimental models was initiated to evaluate the shrinkage of different types of GCLs placed over sand (SP) and clay (CL) subsoil. The following conclusions could be drawn after the evaluation of the results:

- The thermally treated, scrim-reinforced GCL with sand subsoil underwent the lowest value of maximum shrinkage (8.1\%) compared to the other types of GCLs due to better anchorage of the connection layer and, hence, lower variation of moisture content in each thermal cycle.

- Increasing the initial moisture content of the GCL specimen could significantly increase the maximum shrinkage. Also, the grain size distribution of the subsoil affects the shrinkage potential of the GCL. The maximum value of shrinkage for GCL with sand (SP) subsoil was found to be more than that of clay (CL) subsoil. Higher variation of moisture content in each thermal cycle is considered to be the main reason for these phenomena.

- Increasing the aspect ratio which is defined as the ratio of the length to the width of the GCL panel could increase the possibility of panel separation due to the less effect of the restraints at either end on hindering the shrinkage. 
It should be also noted that the daily thermal cycles significantly decreased the moisture content of the GCLs (less than 20\%). Hence, it is recommended that the geomembrane is covered by the cover soil or the leachate connection system shortly after the installation of the liner. This will in turn provide the sufficient normal stress $(2-5 \mathrm{kPa})$ for the better hydration of the GCL, and also impede significant moisture loss and shrinkage of the GCL panels due to prevention of the liner exposure to the weather.

\subsection{Recommendation for Future Studies}

The results of this research provide an understanding regarding the mechanisms involved in hydration and shrinkage of the GCLs. Generally, the previous studies along with the current research evaluated the effect of some variables (e.g. the level of normal stress, temperature, the type of subsoil, GCL manufacturing technique, grain size distribution of the subsoil, etc.) on the hydration or shrinkage of the GCL. However, the hydration of the GCL after waste placement is dependent on the conjunction of the aforementioned factors. For instance, the liner is expected to be influenced simultaneously by the high levels of normal stress and temperature as well as being exposed to the leachate. Hence, it could be beneficial to investigate this phenomenon in future studies in order to establish a better understanding of the hydration potential, the hydraulic conductivity, and consequently the service life of the GCLs under field exposure conditions. Also, the data obtained could be utilized for numerical analysis of the hydration and shrinkage of the GCLs which could be a key to a new era for the analysis and design of the composite liners. 


\section{APPENDICES}

\section{Appendix A}

Hydration of the GCL from the subsoil under different levels of normal stress

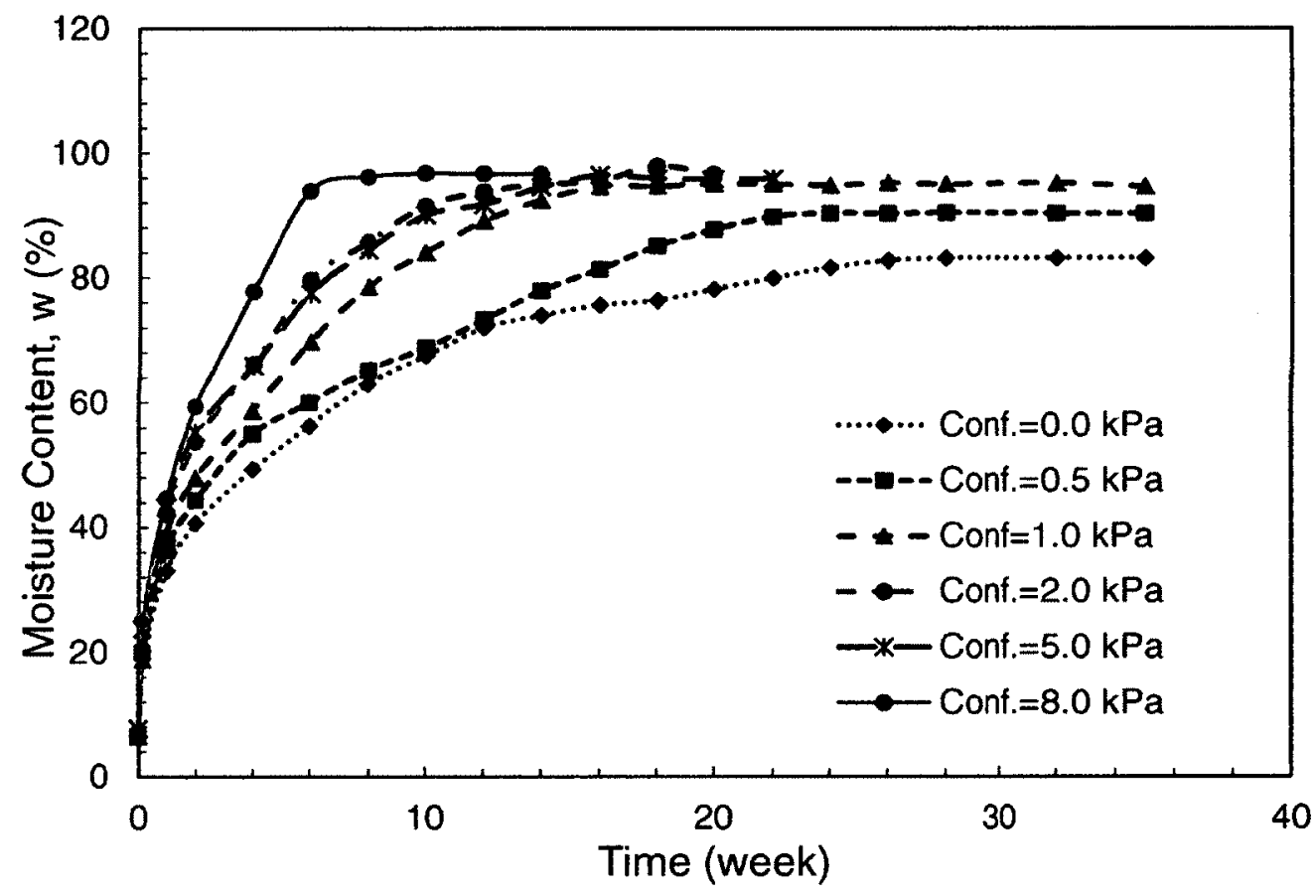

Hydration of GCL 1 from clay (CL) subsoil while subjected to different normal stresses 


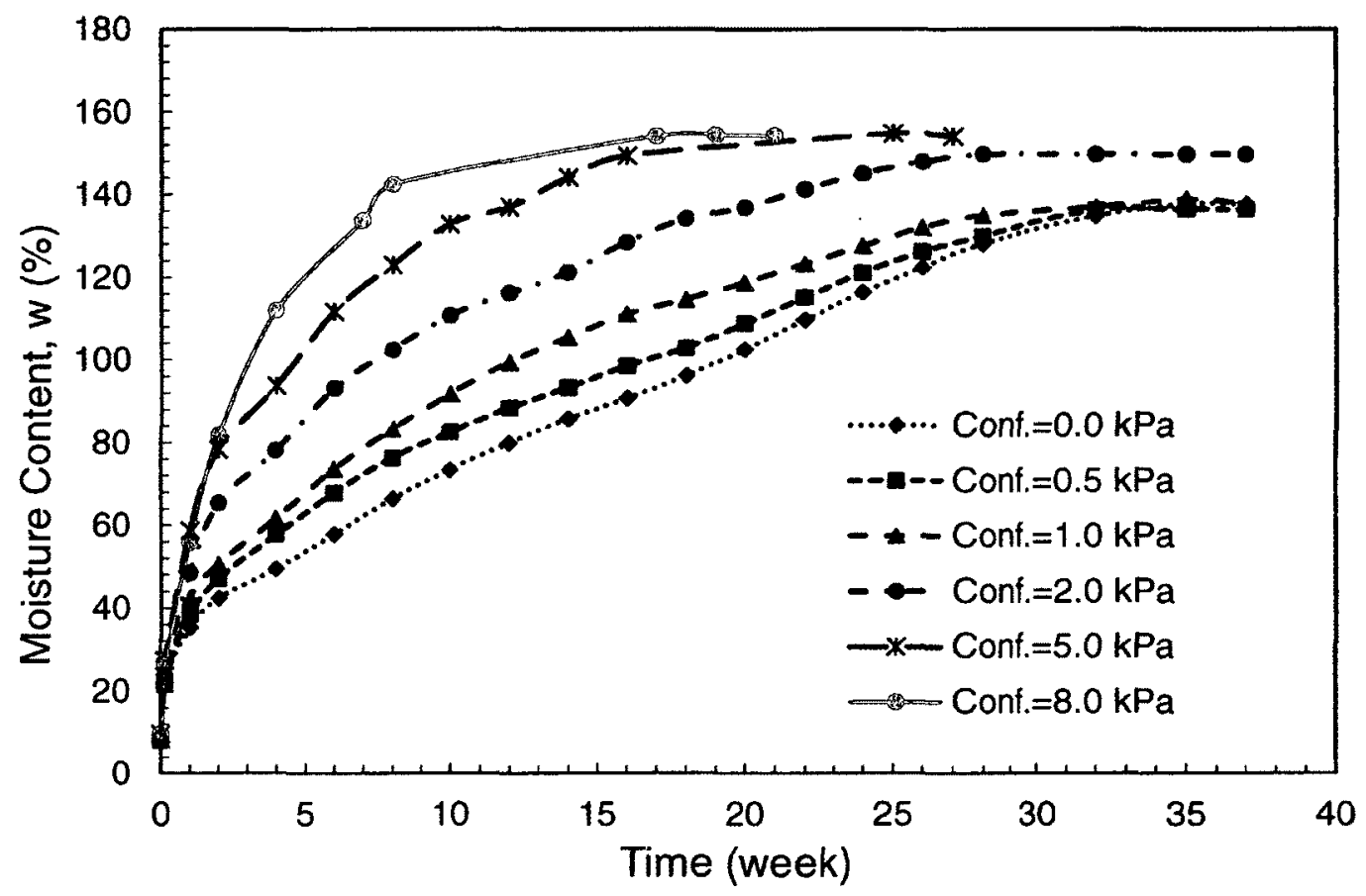

Hydration of GCL 2 from sand (SP) subsoil while subjected to different normal stresses 


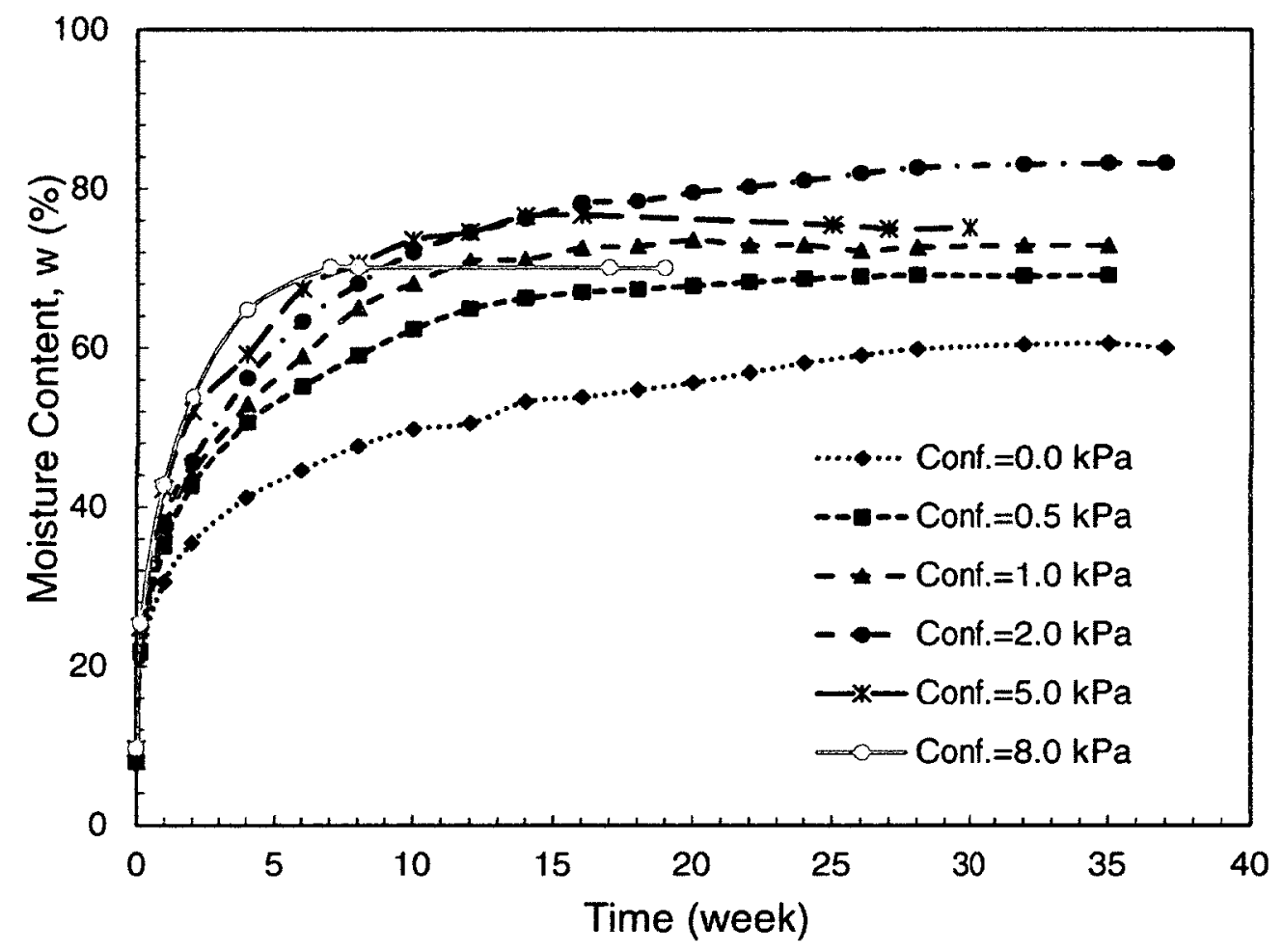

Hydration of GCL 2 from clay (CL) subsoil while subjected to different normal stresses 


\section{Appendix B}

Shrinkage of the GCL under the simulated daily thermal cycles

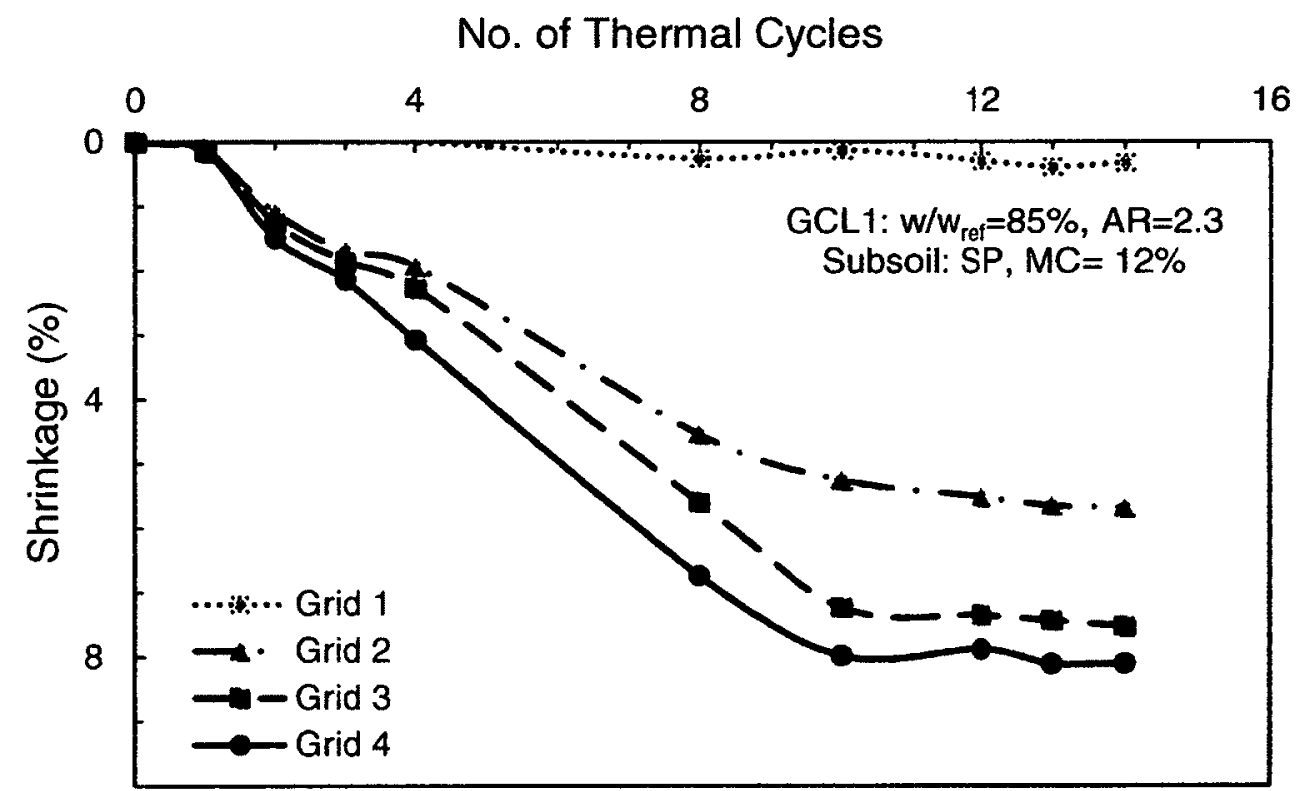

Shrinkage (\%) of GCL1 ( $w / w_{\text {ref }}=85 \%, A R=2.3$ ) under simulated thermal cycles, Subsoil: $S P$, $\mathrm{MC}=12 \%$ 


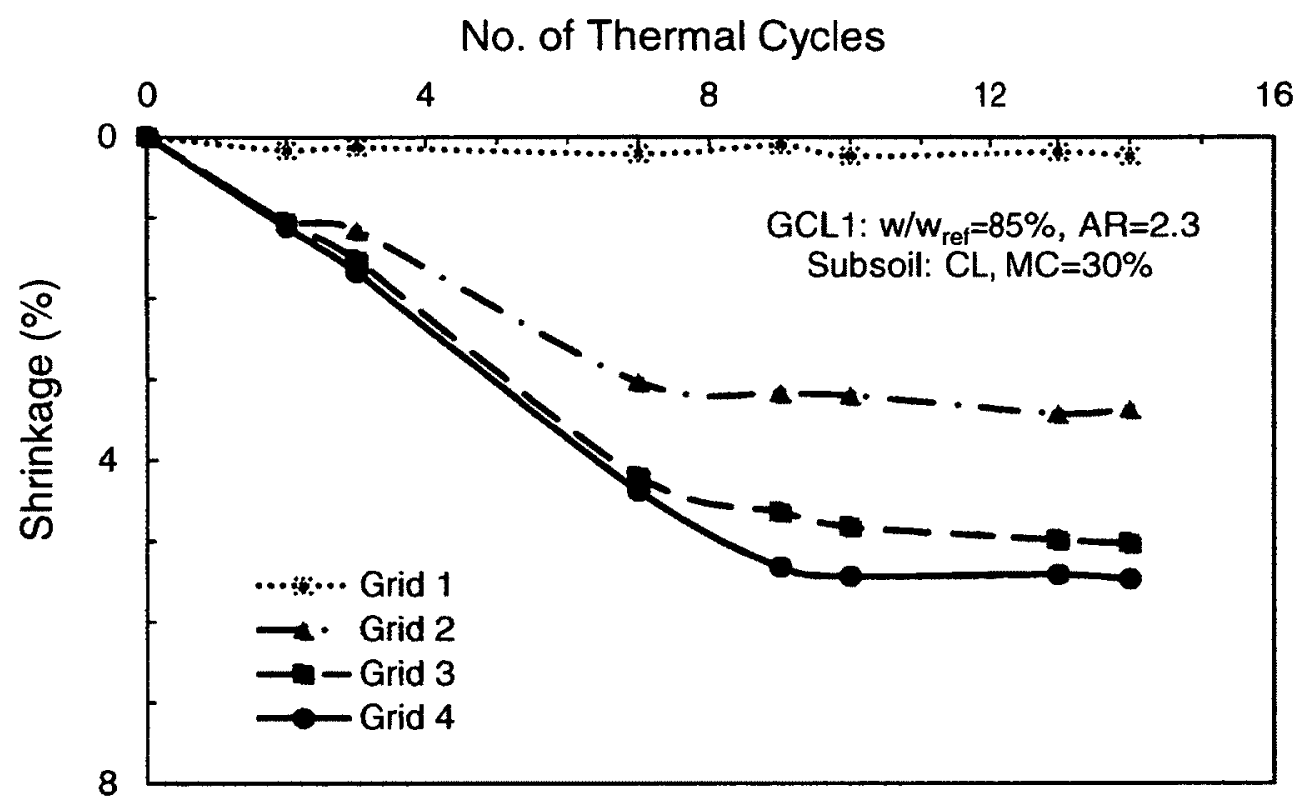

Shrinkage $(\%)$ of $\mathrm{GCL1}\left(\mathrm{w} / \mathrm{w}_{\mathrm{ref}}=\mathbf{8 5 \%}, \mathrm{AR}=2.3\right)$ under simulated thermal cycles, Subsoil: $\mathrm{CL}$, $\mathrm{MC}=\mathbf{3 0 \%}$

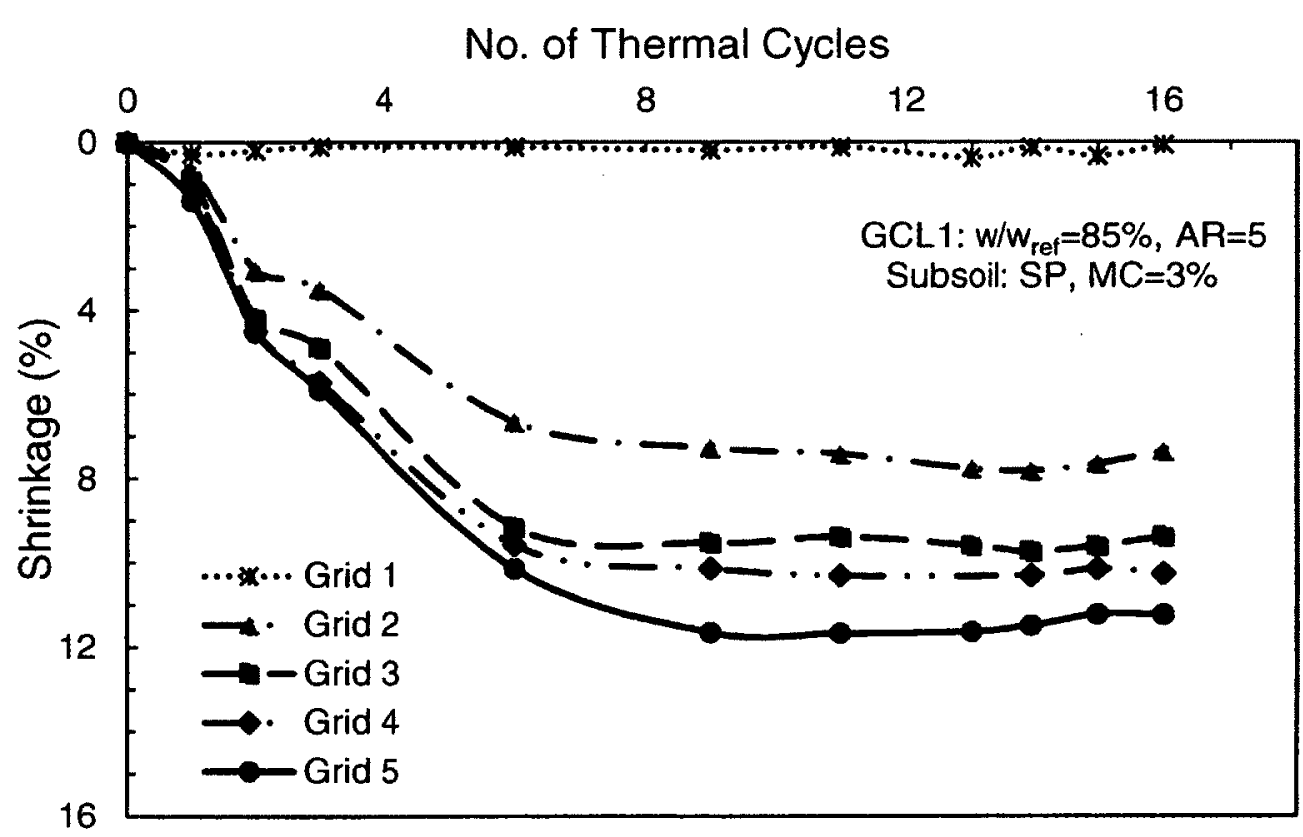

Shrinkage $(\%)$ of $\mathbf{G C L 1}\left(w / w_{\text {ref }}=85 \%, A R=5\right)$ under simulated thermal cycles Subsoil: $S P, M C=3 \%$ 


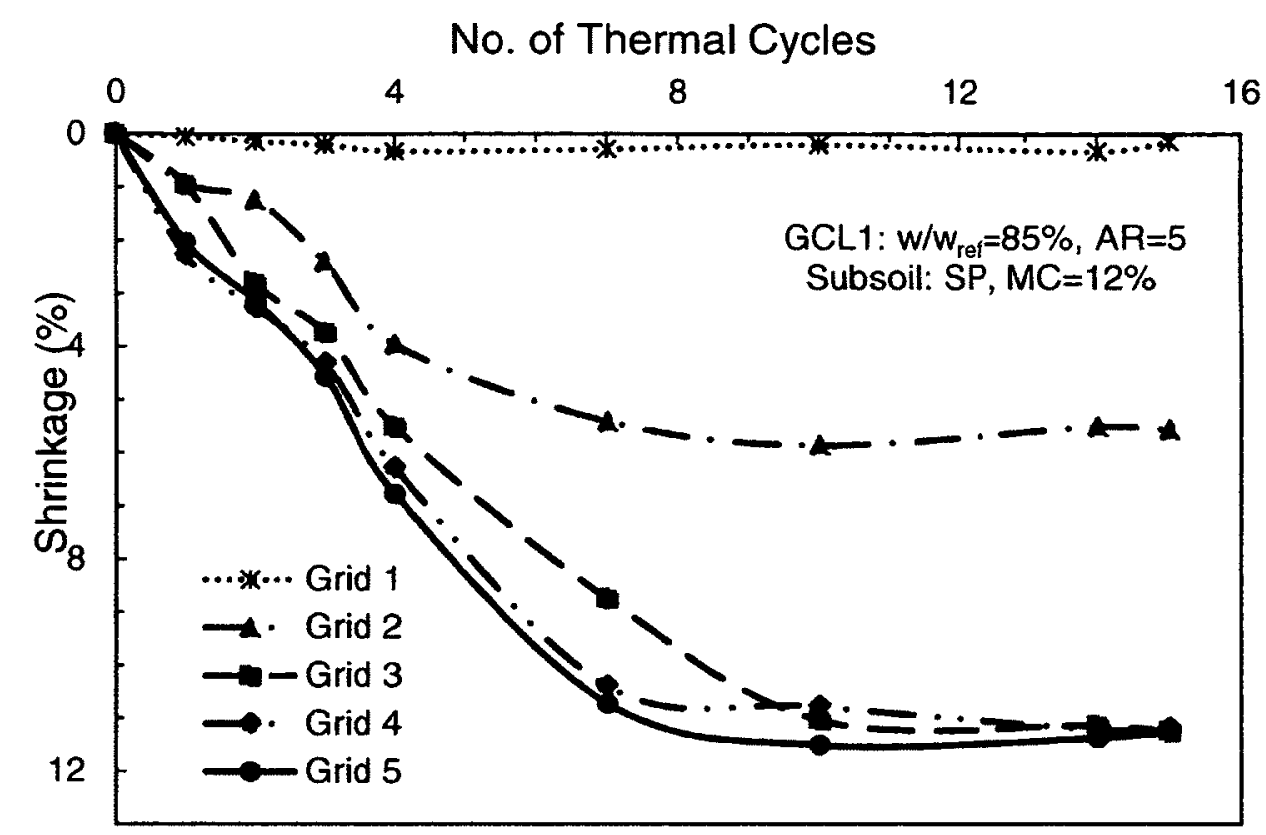

Shrinkage (\%) of GCL1 $\left(w / w_{r e f}=85 \%, A R=5\right)$ under simulated thermal cycles, Subsoil: SP, $M C=12 \%$

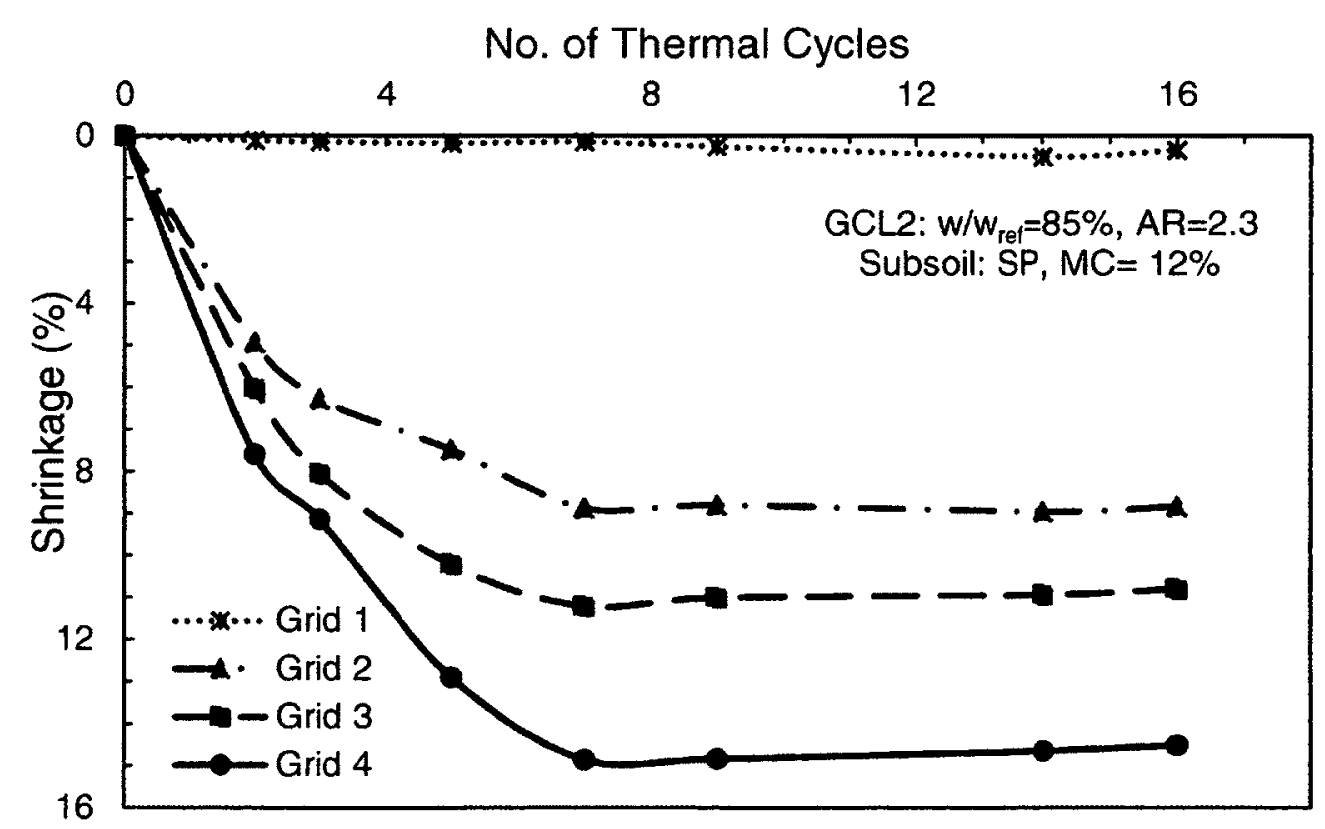

Shrinkage (\%) of GCL2 (w/w $\left.w_{\text {ref }}=85 \%, A R=2.3\right)$ under simulated thermal cycles, Subsoil: $S P$, $\mathrm{MC}=12 \%$ 


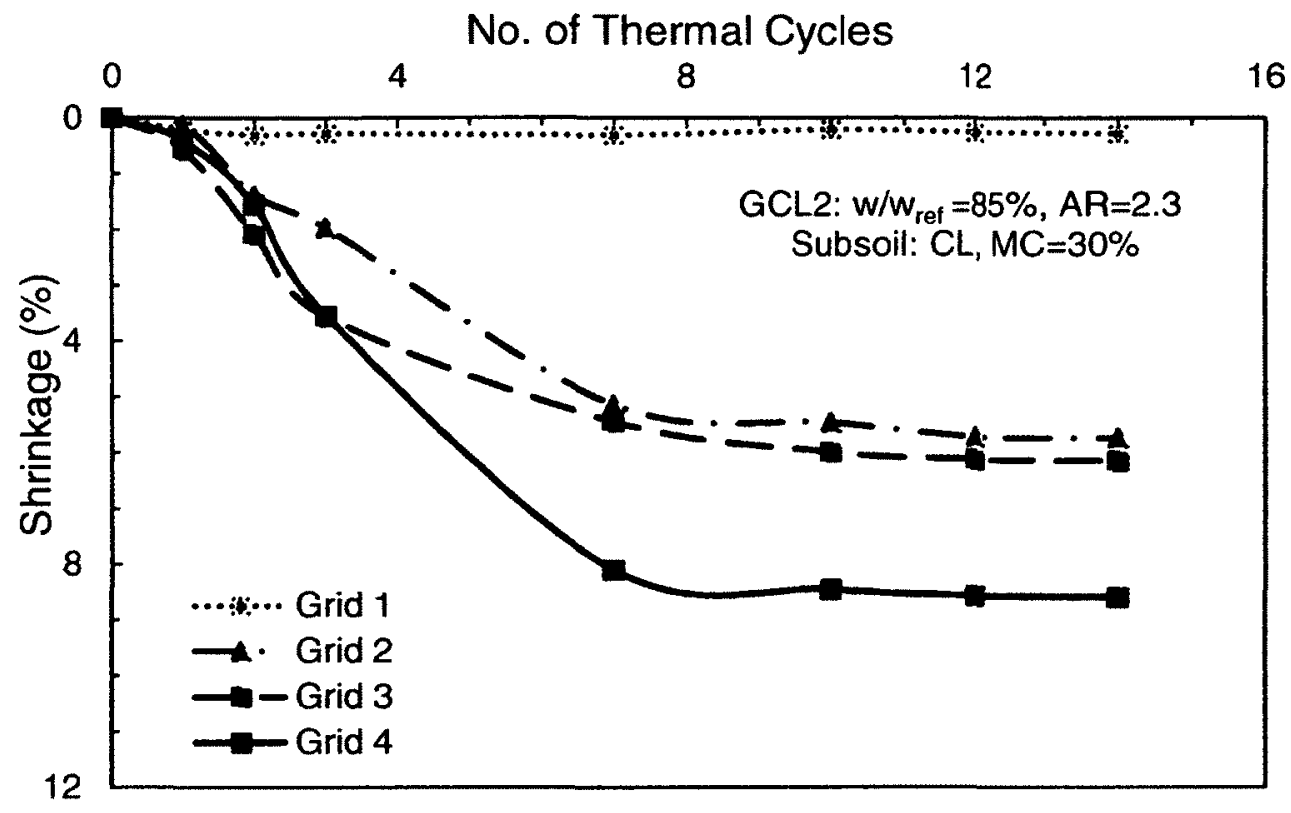

Shrinkage (\%) of GCL2 ( $\left.w / w_{\text {ref }}=85 \%, A R=2.3\right)$ under simulated thermal cycles, Subsoil: $C L$, $\mathrm{MC}=\mathbf{3 0 \%}$

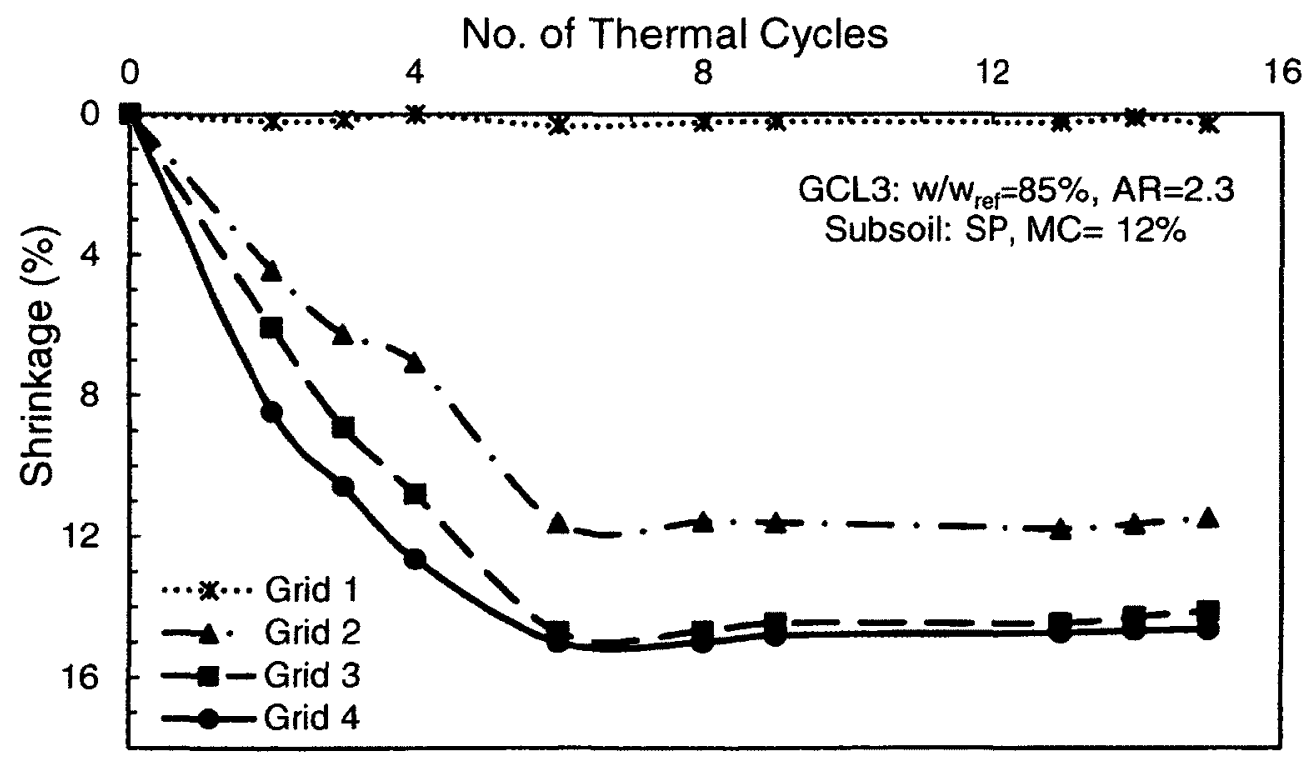

Shrinkage (\%) of GCL3 ( $w / w_{\text {ref }}=85 \%, A R=2.3$ ) under simulated thermal cycles, Subsoil: $S P$, $\mathrm{MC}=12 \%$ 


\section{REFERENCES}

- Anderson, R., Rayhani, M.T., and Rowe, K., 2012. Laboratory investigation of GCL hydration from clayey sand, Journal of Geotextiles and Geomembrane, Vol. 31, pp 31-38.

- ASTM D 2487. 2005. Standard Practice for Classification of Soils for Engineering Purposes (Unified Soil Classification System), ASTM Standard 04.08, ASTM, West Conshohocken, PA, USA: 249-260.

- ASTM D 422. 2005. Standard test method for particle size analysis of soils, ASTM Standard 04.08, ASTM, West Conshohocken, PA, USA: 10-17.

- ASTM D 698. 2005. Standard test methods for laboratory compaction characteristics on soil using standard effort, ASTM Standard 04.08, ASTM, West Conshohocken, PA, USA: 80-90.

- ASTM D 4318. 2005. Standard Test Method for Liquid Limit, Plastic Limit, and Plasticity Index of Soils, ASTM Standard 04.08, ASTM, West Conshohocken, PA, USA: $1-13$.

- ASTM D4595 Standard Test Method for Tensile Properties of Geotextiles by the Wide-Width Strip Method. American Society for Testing and Materials, West Conshohocken, Pennsylvania, USA.

- Azad, F. M., Rowe, R. K., El-Zein, A., Airey, D. W., 2011. Laboratory investigation of thermally induced desiccation of GCLs in double composite liner systems. Geotextiles and Geomembranes, Vol. 29, No. 6, pp 534-543. 
- Barclay, A., Rayhani, M.T., 2012. Effect of Temperature on Hydration of Geosynthetic Clay Liners in Landfills., Journal of Waste Management Research, (in press).

- Beddoe, R. A., Take, W. A., and Rowe, R. K. 2010. Development of suction measurement techniques to quantify the water retention behaviour of GCLs. Geosynthetics International, Vol.17, No. 5, pp 301-312.

- Beddoe, R.A., Take, W.A. and Rowe, R.K., 2011. Water retention behaviour of geosynthetic clay liners. ASCE Journal of Geotechnical and Geoenvironmental Engineering, Vol. 137, No. 11, pp 1028-1038.

- Bostwick, L., Rowe, R. K., Take, W. A., and Brachman, R.W.I. 2010. Anisotropy and Directional Shrinkage of Geosynthetic Clay Liners, Geosynthetics International, Vol. 17, No. 3, pp 157-170.

- Bostwick, L. E. 2009. Laboratory study of geosynthetic clay liner shrinkage when subjected to wet/dry cycles. M.Sc. thesis, Queen's Univ., Kingston, ON, Canada.

- Bostwick, L. E., Rowe, R. K., Take, W. A., and Brachman, R.W.I. 2007. The effect of sample size on shrinkage of a non-scrim reinforced geosynthetic clay liner in laboratory tests, OttawaGeo2007/OttawaGéo2007, pp 2123-2128.

- Bouazza, A., Zornberg, J. G., McCartney, J. S. \& Nahlawi, H. 2006. Significance of unsaturated behaviour of geotextiles in earthen structures. Australian Geomechanics, Vol. 41, No. 3, pp 133-142.

- CETCO, 2006. TR-339 GCL Panel Shrinkage Lab and Field Trials.

- Chevrier, B., Guyonnet, D., Gamet, M., Cazaux, D., Didier, G. 2010. GCLs in landfill applications: influence of subgrade, temperature and normal pressure on 
bentonite hydration. Proc. of $3^{\text {rd }}$ International Symposium on Geosynthetic Clay Liners, GBR-C 2k10, Würzburg, Germany, pp 63-70.

- Chevrier, B., Cazaux, D., Didier, G., Gamet, M., Guyonnet, D., 2012. Influence of subgrade, temperature and confining pressure on GCL hydration. Geotextiles and Geomembrane, Vol. 33, pp 1-6.

- Collins, H.J., 1993. Impact of the temperature inside the landfill on the behaviour of barrier systems. In: Proc. 4th International Landfill Symposium, S. Margherita di Pula, Cagliari, Italy, pp. 417-432.

- Decagon Devices, Inc., 2012. www.decagon.com

- Egloffstein, T., 1995. Properties and test methods to assess bentonite used in geosynthetic clay liners. Geosynthetic clay liners, proceedings of an international symposium held in Nurnberg, Germany, pp 51-72.

- Gassner Fred, 2009. Field observation of GCL shrinkage at a site in Melbourne Australia. Geotextiles and Geomembranes, Vol. 27, No. 5, pp 406-408.

- Gates,W. P., Hornsey, W. P., Buckley, J., L., 2009. Geosynthetic Clay Liners-Is the key component being overlooked?, GIGSA GeoAfrica 2009 Conference.

- GeoStudio 2007. Version 7.16, Build 4840, Geo-Slope International Ltd. pp 1-10.

- Grapher-Version 8.8.957, Golden Software, Inc.

- Japanese Nuclear Cycle Development Institute (JNC). 2000. H12: Project to establish the scientific and technical basis for HLW disposal in Japan. Supporting Rep. 2: Repository design and engineering technology, JNC TN1410, lbaraki, Japan, 2000-2001. 
- Koerner, G.R. \& Koerner, R.M. 1995. Temperature Behavior of Field Deployed HDPE Geomembranes, Proceedings of Geosynthetics '95, Nashville, TN, IFAI, Vol. 3, pp 921-937.

- Koerner, R.M. \& Koerner, G.R. 2005a. GRI White Paper \#5 - In-Situ Separation of GCL Panels Beneath Exposed Geomembranes, Geosynthetic Institute, Folsom, PA, 21 p.

- Koerner, R.M. and Koerner, G.R. 2005b. In-situ separation of GCL panels beneath exposed geomembranes, Geotechnical Fabrics Report, pp 34-39.

- Lake, C.B. and Rowe, R.K. 2000. Swelling characteristics of needle punched, thermally treated GCLs. Geotextiles and Geomembranes, Vol. 18, No. 2, pp 77102.

- Marcial, D., Delage, P., and Cui, Y. J. 2002. On the high stress compression of bentonites. Canadian Geotechnical Journal, Vol. 39, No. 4, pp 812-820.

- Pelte, T., Pierson, P., \& Gourc, J.P. 1994. Thermal analysis of geomembranes under the effect of solar radiation, Geosynthetics International, Vol. 1, No. 1, pp 21-44.

- Petrov, R.J., Rowe, R.K., and Quigley, R.M. 1997. Selected factors influencing GCL hydraulic conductivity. Journal of Geotechnical and Geoenvironmental Engineering, Vol. 123, No.8, pp 683-695.

- Rankka, K., Andersson- Skold, Y., Hultén C., Larsson, R., Leroux, V., and Dahlin, T. 2004. Quick clay in Sweden. Swedish geotechnical institute, Report 65, Linköping. 
- Rayhani, M.T., Rowe, R.K., Brachman, R.W.I., Take, W.A., and Siemens, G. 2011. Factors affecting GCL hydration under isothermal conditions. Geotextiles and Geomembranes, Vol. 29, No. 6, pp 525-533.

- Rowe, R. K., Quigley, R. M., Brachman, R. W. I. \& Booker, J. R. 2004. Barrier Systems for Waste Disposal Facilities. Taylor \& Francis Books Ltd (E \& FN Spon), London, UK.

- Rowe, R. K. 2005. Long-term performance of contaminant barrier systems. Géotechnique 55, No. 9, pp 631-678.

- Rowe, R. K., Pollard, A., Chong, A., Chisholm, E., Toda, R. \& Tomson, C. (2007). Sustainable landfills: a technique for extracting heat to prolong servicelife of geomembrane liners. Proceedings of the $60^{\text {th }}$ Canadian Geotechnical Conference, Ottawa, pp. 1310-1315.

- Rowe, R.K., Bostwick, L., Thiel, R. 2010. Shrinkage characteristics of heattacked GCL seams, Geotextiles and Geomembranes, Vol. 28, pp 352-359.

- Rowe, R. K., Bostwick, L. E., and Take, W. A. 2011a. Effect of GCL properties on shrinkage when subjected to wet-dry cycles, ASCE journal of geotechnical and geoenvironmental engineering, Vol. 137, No. 11, pp 1019-1027.

- Rowe, R.K, Rayhani M.T., Take A., Siemens G., and Brachman R.W.I., 2011 b. GCL hydration under simulated daily thermal cycles. Geosynthetics International, Vol. 18, No. 4, pp 196-205.

- Rowe, R. K. 2011, Systems engineering: the design and operation of municipal solid waste landfills to minimize contamination of groundwater, Geosynthetics International, Vol. 18, No. 6, pp 391-404. 
- Rowe, R. K. 2012, Short and long-term leakage through composite liners. The 7th Arthur Casagrande Lecture, Canadian Geotechnical Journal, Vol. 49, No 2, 141169.

- Sarabian, T., Rayhani, M. T., 2012. Hydration of geosynthetic clay liners from clay subsoil under simulated field conditions, Waste Management, http://dx.doi.org/10.1016/j.wasman.2012.08.010.

- Southen, J.M., Rowe, R.K., 2005. Laboratory investigation of geosynthetic clay liner desiccation in a composite liner subjected to thermal gradients. Journal of Geotechnical and Geoenvironmental Engineering 131, No. 7, pp 925-935.

- Southen, J. M., and Rowe, R. K. 2007. Evaluation of the water retention curve for geosynthetic clay liners. Geotextiles and Geomembranes, Vol. 25, No. 1, pp 2-9.

- Taha, M., A. Interface shear behavior of sensitive marine clays-leda clay. M.Sc. thesis, University of Ottawa, Ottawa, ON, Canada.

- Thiel, R. and Richardson, G. N. 2005. Concern for GCL shrinkage when installed on slopes, JGRI-18 at GeoFrontiers, GII Publications, Folsom, PA, USA, paper 2.31 .

- Thiel, R., Giroud, J.P., Erickson, R., Criley, K. and Bryk, J. 2006. Laboratory measurements of GCL shrinkage under cyclic changes in temperature and hydration conditions, Geosynthetics. Proceedings of 8th International Conference on Geosynthetics (8ICG), Millpress Science Publishers,Yokohama, Japan, Vol. 14, pp 157-162.

- Thiel, R., and Rowe, R. K., 2010. Technical developments related to the problem of GCL panel shrinkage when placed below an exposed geomembrane. $3^{\text {rd }}$ 
International Symposium on Geosynthetic Clay Liners, GBR-C 2k10, Zanzinger, Koerner and Touze-Foltz Eds., Würzburg, Germany, pp 93-102.

- Thiel, R. and Thiel, C., 2009. GCL Shrinkage - A Possible Solution, GFR, V27N1, Feb-Mar 2009, 10-21.

- Vanapalli, S. K., Salinas, L. M., Avila, D., Karube, D., 2002. Suction and Storage characteristics of unsaturated soils, Proceedings of the 3rd International Conference on Unsaturated Soils, Unsat 2002, Recife, Brazil, pp 1045-1070.

- Van Genuchten, M. Th., 1980. A closed-form equation for predicting the hydraulic conductivity of unsaturated soils. Soil Science Society of America Journal, Vol. 44, No. 5, pp 892-898.

- Villar,M. V., and Lloret, A. 2004. Influence of temperature on the hydro mechanical behaviour of a compacted bentonite. Appl. Clay Sci., Vol. 26, pp 337-350. 